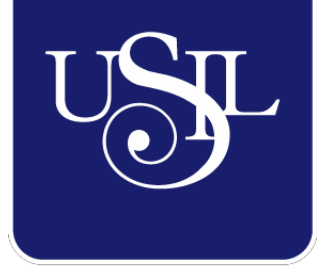

UNIVERSIDAD

SAN IGNACIO

DE LOYOLA

ESCUELA DE POSTGRADO

\title{
PLAN DE NEGOCIOS PARA LA CREACIÓN DE UN SALÓN DE BELLEZA MÓVIL
}

Trabajo de Investigación para optar el grado de:

DHERLY CERVANTES RODRÍGUEZ

Maestro en Ciencias Empresariales con Mención en Gestión de Proyectos

MARÍA JULIA CHÁVEZ RODRÍGUEZ

Maestro en Ciencias Empresariales con Mención en Gestión de Proyectos

CESAR RONNIE DELGADO VÁSQUEZ

Maestro en Ciencias Empresariales con Mención en Gestión de Proyectos

\section{JUAN MANUEL LOAYZA ROJAS}

Maestro en Ciencias Empresariales con Mención en Gestión de Proyectos

Asesor:

Carlos Ossio Sal y Rosas

Lima - Perú

2020 


\section{Resumen Ejecutivo}

El plan de negocio se ejecutó para determinar la viabilidad a nivel Financiero, Comercial, Logístico y de Recursos Humanos de la creación de un Salón de belleza móvil que se instale por un período de tiempo en las empresas para de atender a sus trabajadores.

La investigación realizada determinó que en el mercado no existían modelos de negocio similares, demostrando una oportunidad de negocio para establecer un salón de belleza móvil y brindar los servicios sin que el cliente se desplace fuera de su centro laboral.

El Salón de belleza móvil atenderá a los trabajadores de dos sedes correspondientes a dos entidades financieras de Lima Metropolitana, con espacio en sus instalaciones o estacionamiento para ubicar la móvil, la cual contará con la infraestructura, herramientas, materia prima, mano de obra especializada y todo lo requerido para brindar, con calidad, los servicios de manicura, planchado y cepillado de cabello.

El modelo de negocio impactará positivamente en los indicadores de clima laboral, retención y atracción de talento humano de las empresas, al ofrecer un servicio oportuno, ágil y de calidad a sus trabajadores evitándoles tiempo adicional por traslado al salón.

El Salón de belleza móvil se constituirá legalmente según la regulación actual para obtener los permisos de funcionamiento y circulación.

La implementación según el estudio financiero arroja una inversión inicial de S/358,128, la cual estará compuesto por $50 \%$ de capital propio que asciende a S/ 182,345 y la diferencia se obtendrá mediante crédito. El valor total de la inversión se recuperará al segundo año con doce meses, con tasa interna de retorno de $46.6 \%$ y un Valor Actual Neto (VAN) de S/ 2’220,405. El estudio demuestra que el plan de negocio es viable debido a los indicadores positivos del proyecto y al mercado objetivo en crecimiento. 


\section{Tabla de contenidos}

Capítulo I: Generalidades

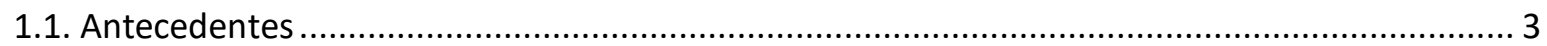

1.2. Determinación del Problema u Oportunidad ............................................................. 4

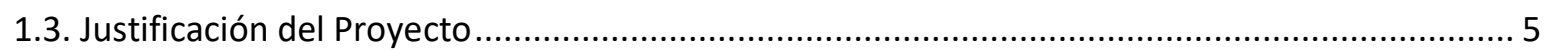

1.4. Objetivos Generales y Específicos ......................................................................... 5

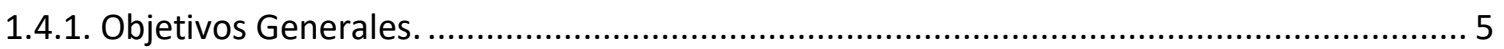

1.4.2. Objetivos Específicos................................................................................. 6

1.5. Alcances y Limitaciones de la Investigación ............................................................ 6

Capítulo II: Estructura Económica del Sector ................................................................ 7

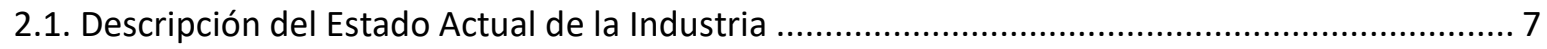

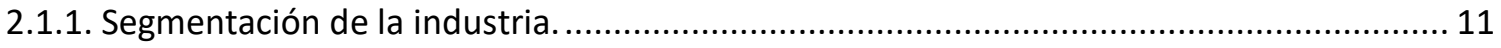

2.1.2. Empresas que la conforman........................................................................... 12

2.2. Tendencias de la industria (crecimiento, inversiones) .............................................. 14

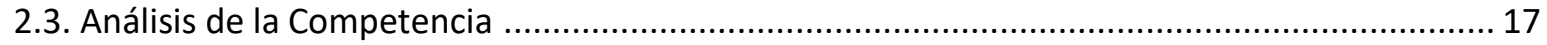

2.3.1. Empresas que ofrecen el mismo servicio. .......................................................... 17

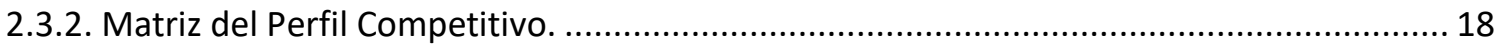

2.4. Análisis del Contexto Actual y Esperado. ........................................................... 21

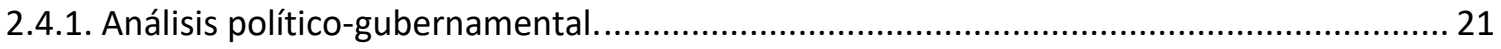

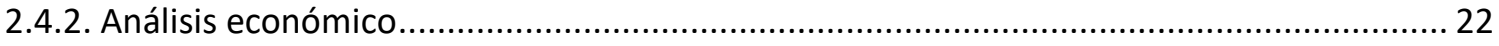

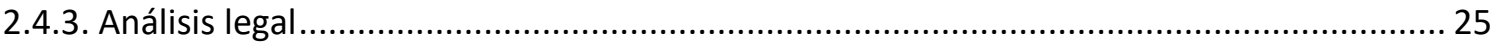

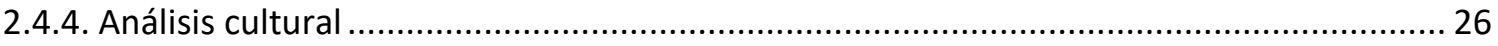

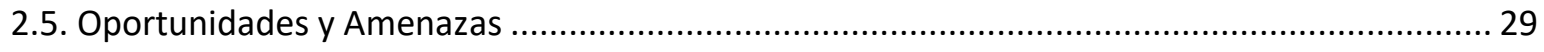

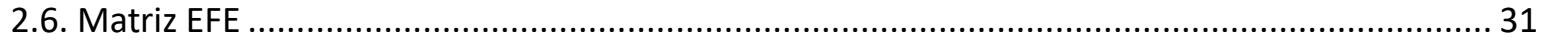

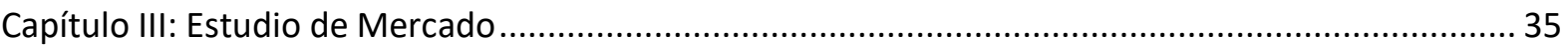

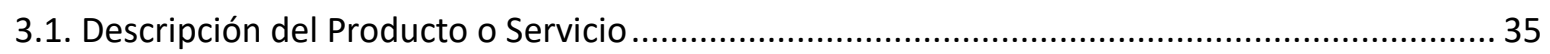

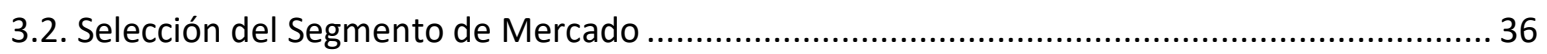

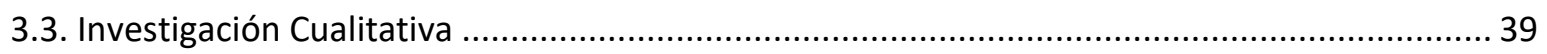

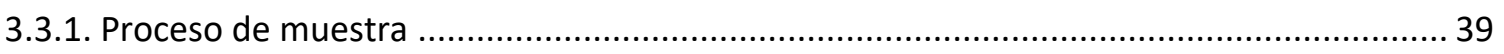

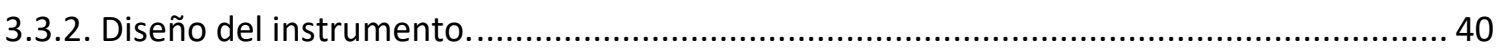

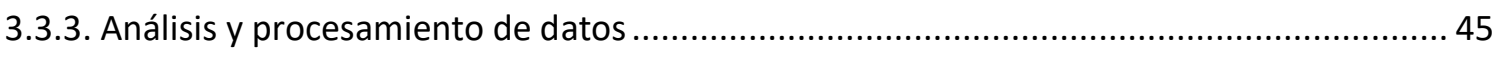

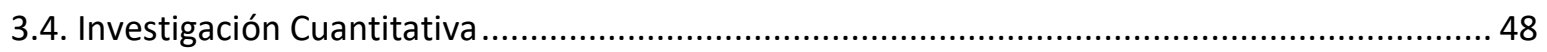

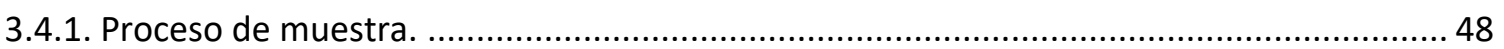

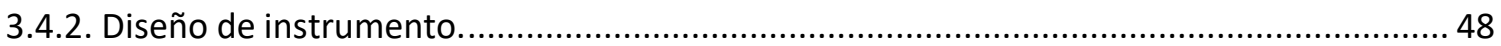




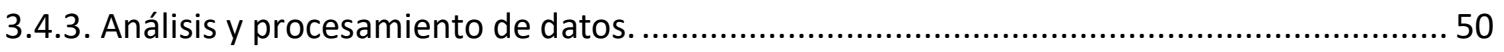

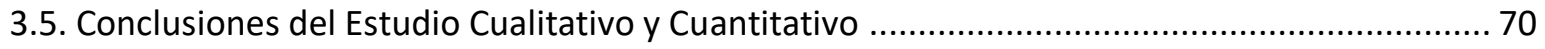

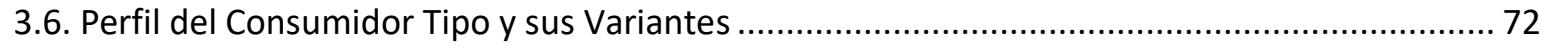

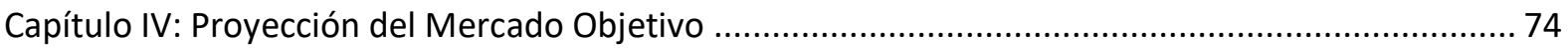

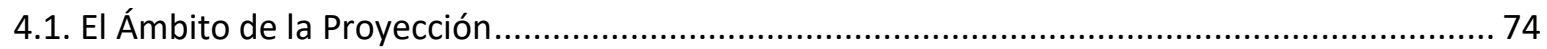

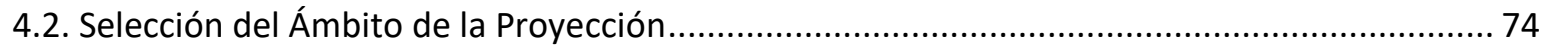

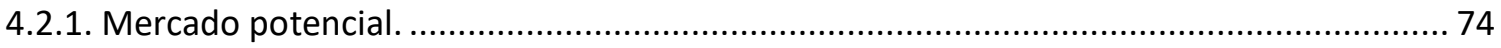

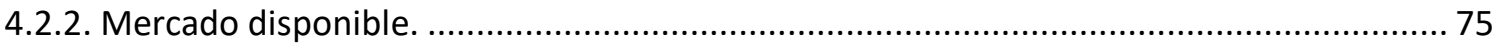

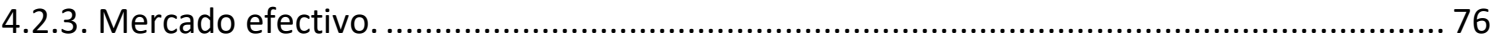

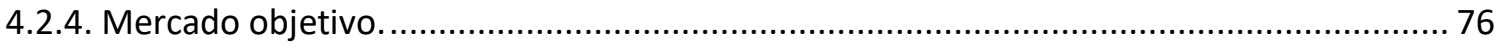

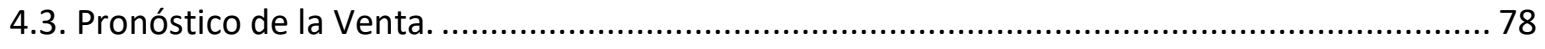

4.4. Aspectos Críticos que Impactan en el Pronóstico de las Ventas ............................................. 78

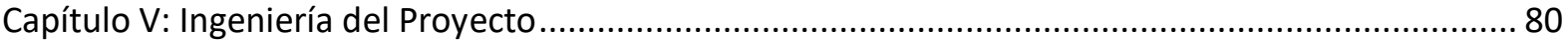

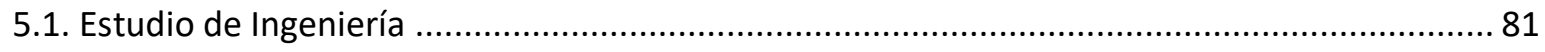

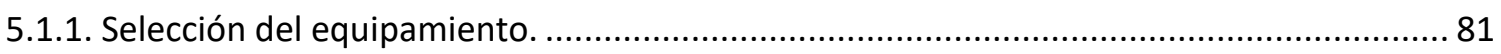

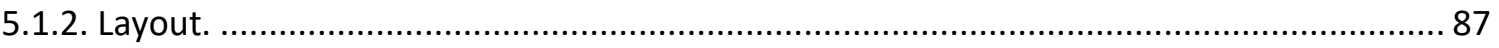

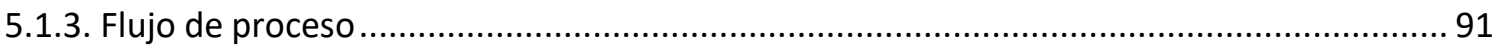

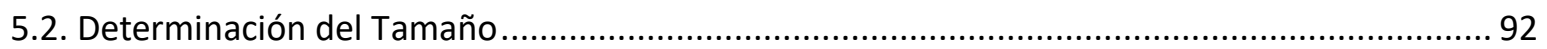

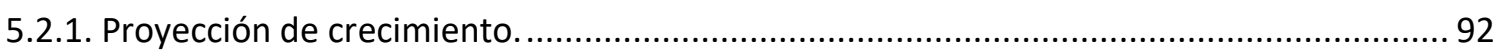

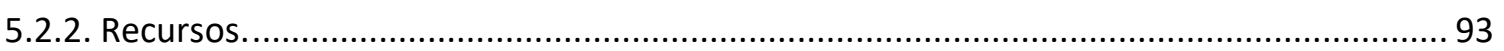

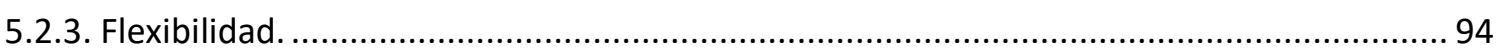

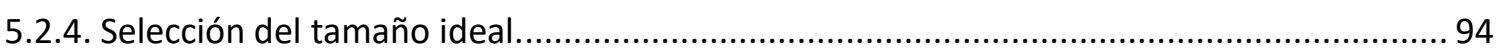

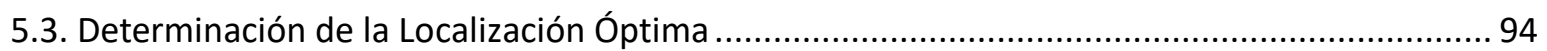

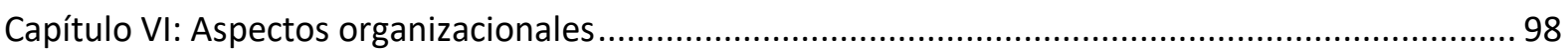

6.1. Caracterización de la Cultura Organizacional Deseada ........................................................... 98

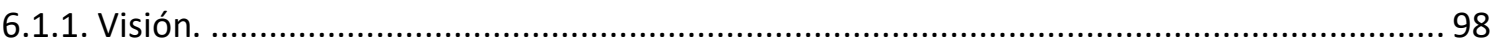

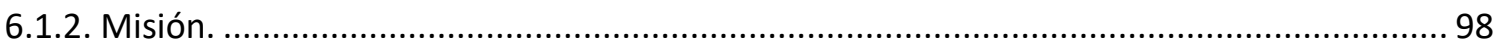

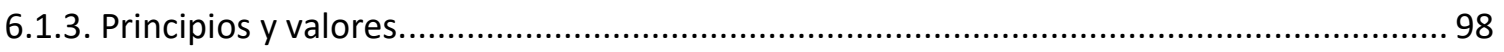

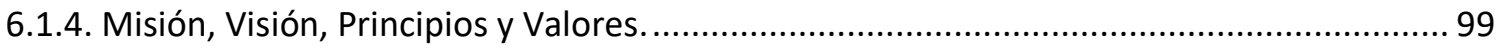

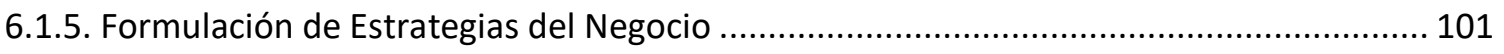

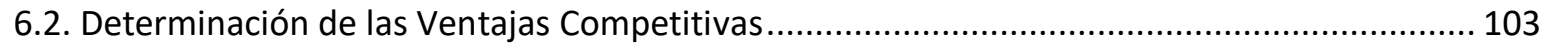

6.3. Diseño de la Estructura Organizacional Deseada ................................................................ 104

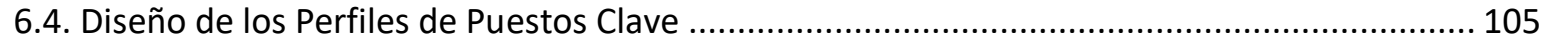

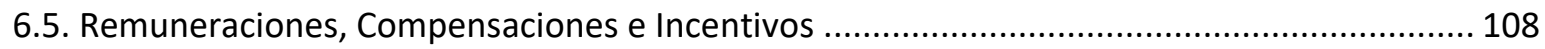

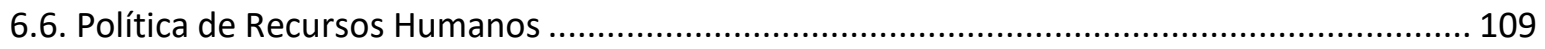

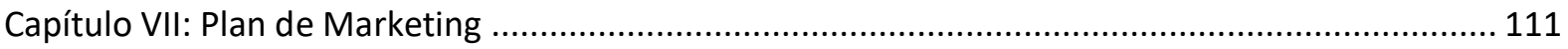




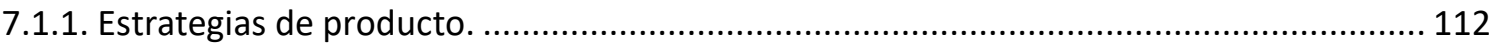

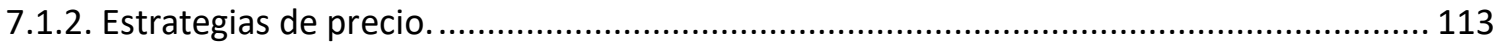

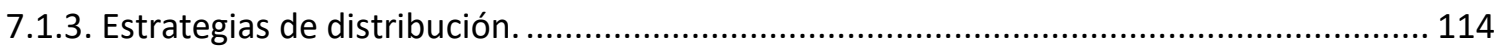

7.1.4. Estrategias de promoción y publicidad (comunicación)................................................. 115

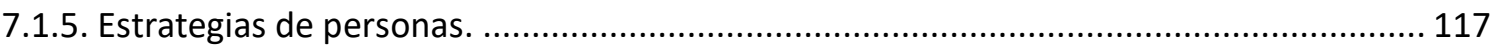

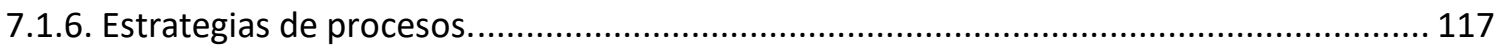

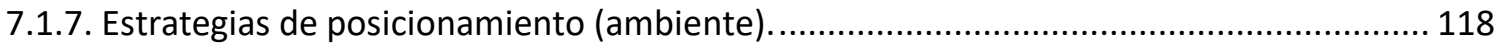

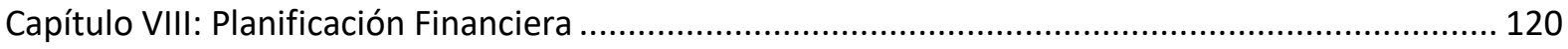

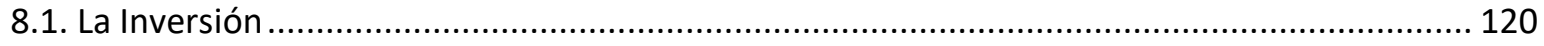

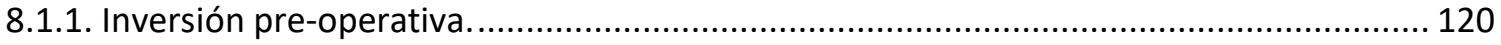

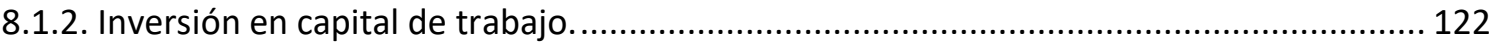

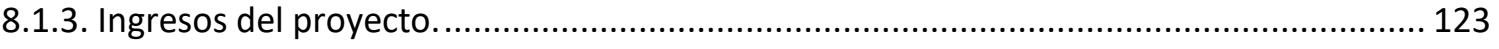

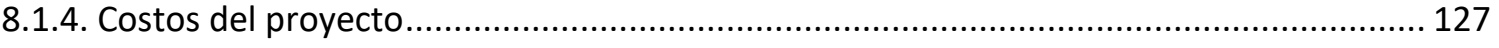

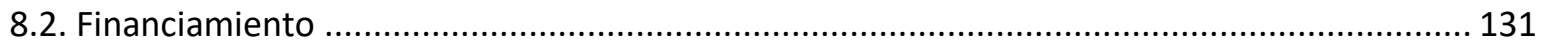

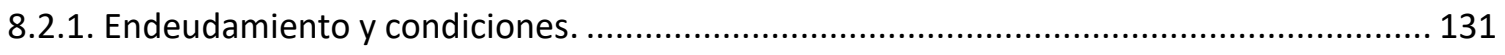

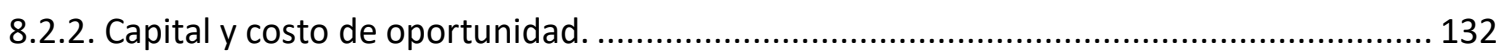

8.2.3. Costo de Capital Promedio Ponderado (WACC por sus siglas en ingles)......................... 134

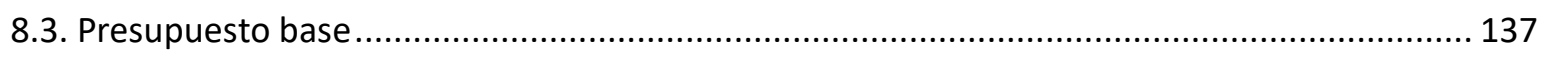

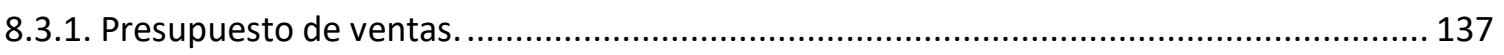

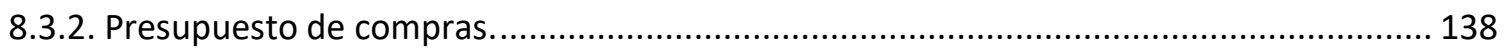

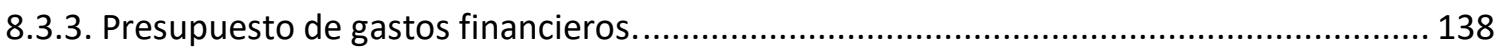

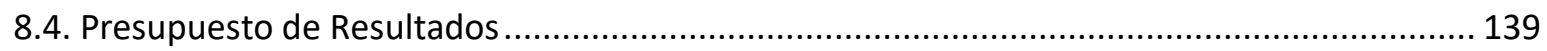

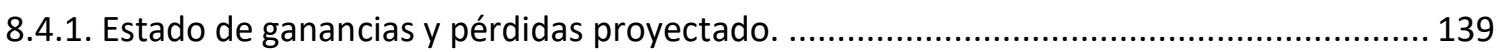

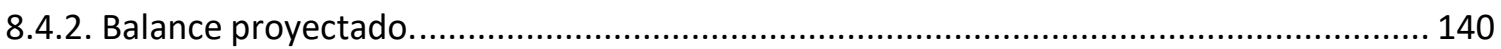

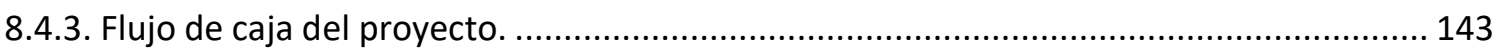

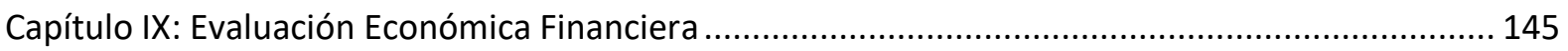

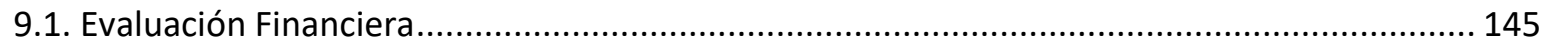

9.1.1. PAYBACK (Período de Recuperación del Capital). ......................................................... 145

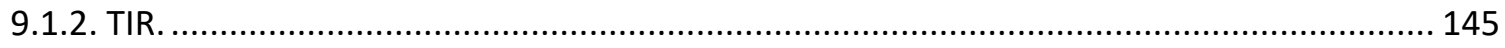

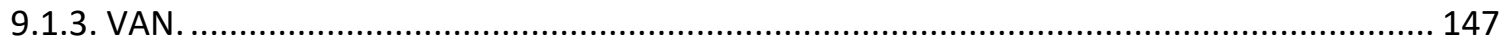

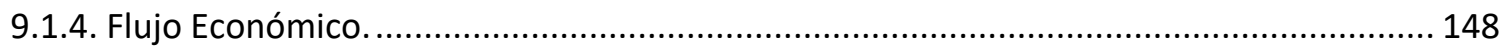

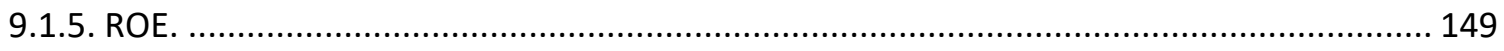

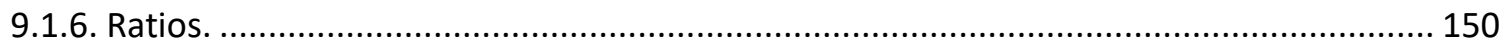

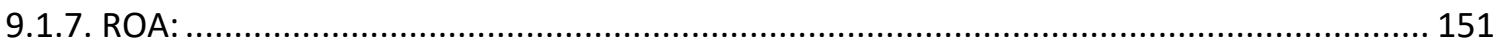

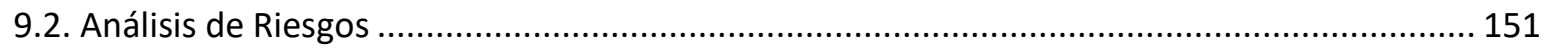


9.3. Análisis de punto de Equilibrio

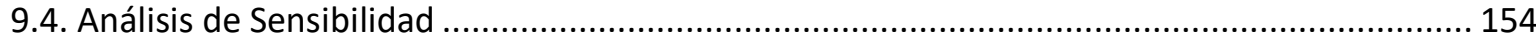

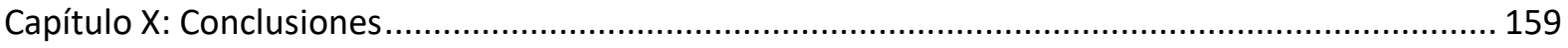

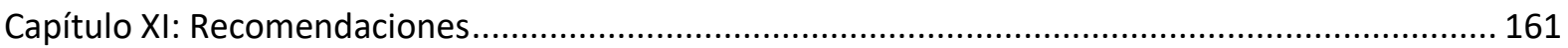




\section{Lista de Tablas}

Tabla 1. Personas naturales dadas de alta, según actividad económica 2017-18.

Tabla 2. Personas naturales dadas de alta por sexo del conductor, según actividad

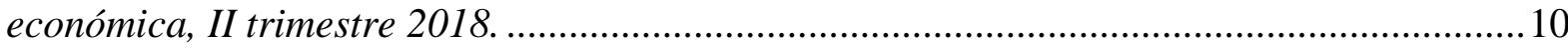

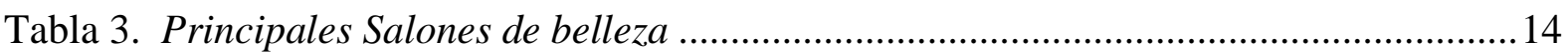

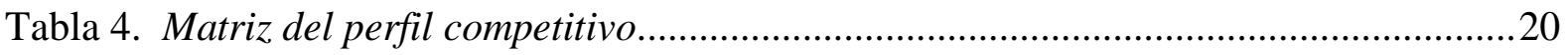

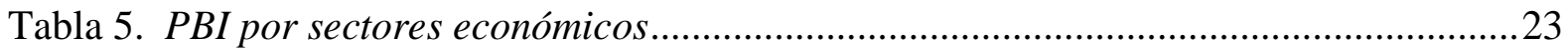

Tabla 6. Lima Metropolitana: Altas de empresas, según organización jurídica, 2017-2018 25

Tabla 7. Lima Metropolitana: Población en edad de trabajar según condición de actividad

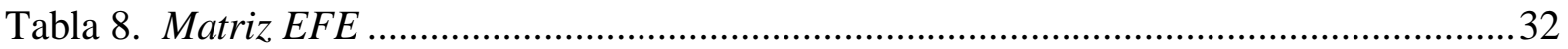

Tabla 9. Cantidad de colaboradores por entidad bancaria en sedes elegidas........................ 36

Tabla 10. Cantidad de colaboradores mujeres por entidad bancaria en sedes elegidas ........ 37

Tabla 11. Criterios de segmentación para la selección de mercado ........................................38

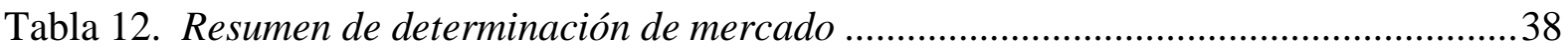

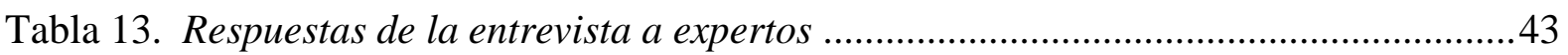

Tabla 14. Validación del uso de servicios en salones de belleza............................................50

Tabla 15. Razón por la cual no asisten a salones de belleza .....................................................51

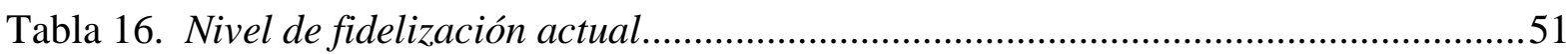

Tabla 17. Motivación para ir a los salones de belleza actual ...............................................52

Tabla 18. Distancia relativa del salón de belleza al que asisten .............................................53

Tabla 19. Tiempo empleado para trasladarse a los salones de belleza .................................53

Tabla 20. Grado de importancia de cercanía de un salón de belleza .....................................54

Tabla 21. Frecuencia de asistencia a salones de belleza ...................................................55

Tabla 22. Frecuencia de visita mensual a salones de belleza ...............................................55

Tabla 23. Tiempo de servicio en salones de belleza ...........................................................56

Tabla 24. Orden de preferencia de servicios solicitados en salones de belleza ......................57

Tabla 25. Frecuencia del uso del servicio de manicura ..........................................................57

Tabla 26. Frecuencia de visita mensual por el servicio de manicura .....................................58

Tabla 27. Preferencias del tipo de servicio de manicura ........................................................59

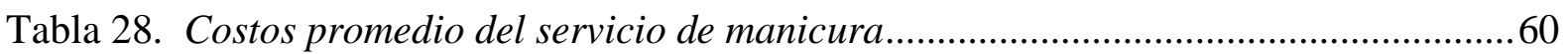

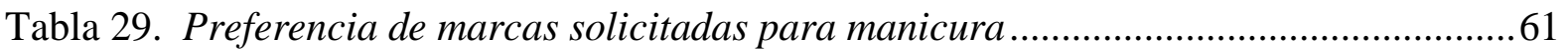

Tabla 30. Frecuencia del uso de servicios para el cabello.....................................................62

Tabla 31. Frecuencia del uso del servicio para el cabello ...................................................62

Tabla 32. Costo promedio de los servicios para el cabello solicitado ....................................63

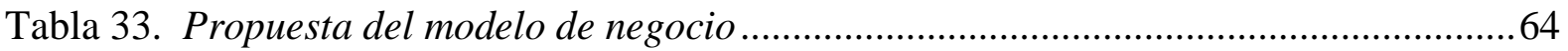

Tabla 34. Razón por la cual no aceptaría el modelo de negocio propuesto ............................65

Tabla 35. Incremental dispuesto a pagar en el modelo de negocio propuesto .........................65

Tabla 36. Horarios preferidos para atenderse en el modelo de negocio propuesto ...............66

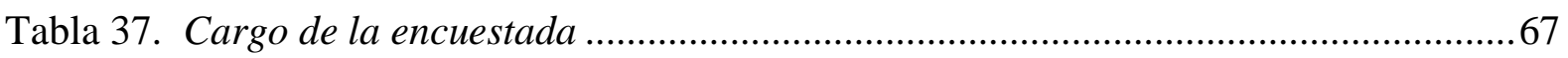

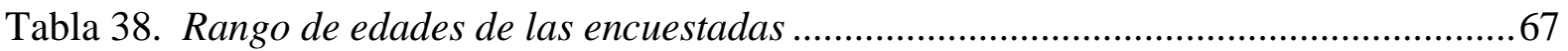

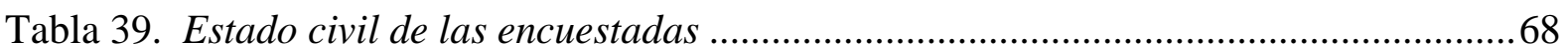

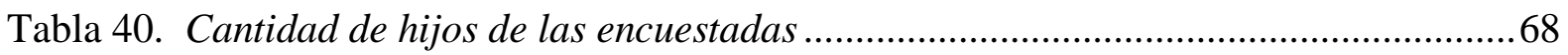




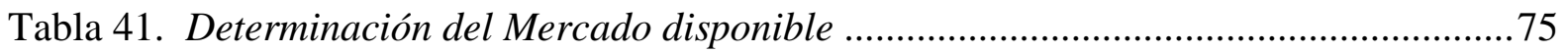

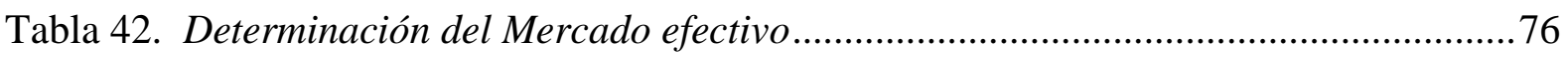

Tabla 43. Determinación de la capacidad máxima instalada .................................................77

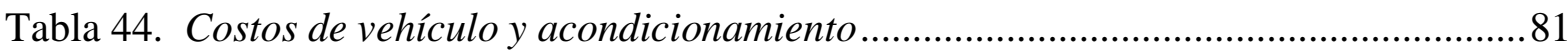

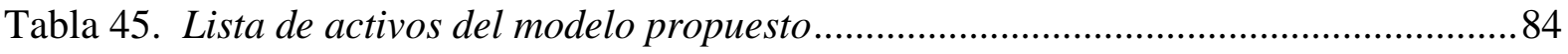

Tabla 46. Tiempos de atención del flujo de procesos ..............................................................91

Tabla 47. Misión, Visión, Principios y Valores .................................................................. 100

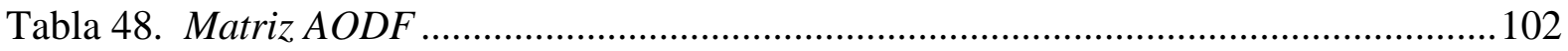

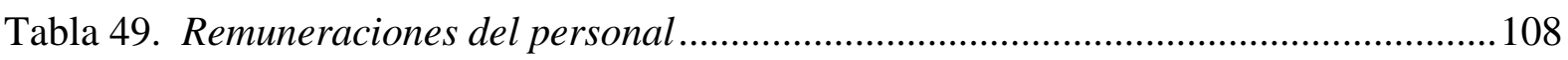

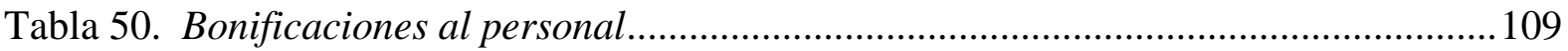

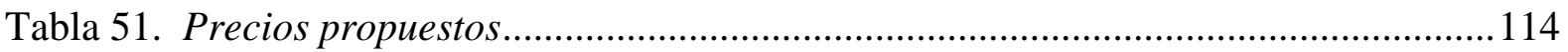

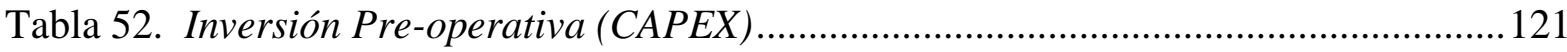

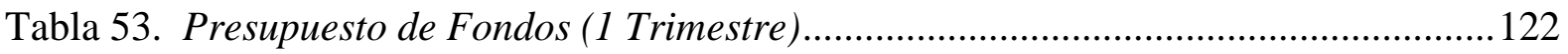

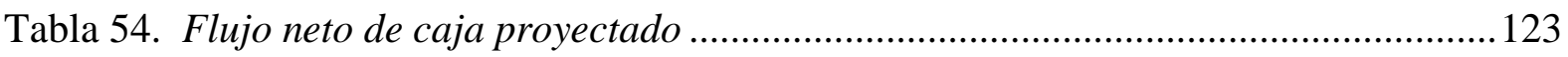

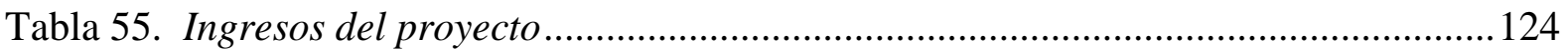

Tabla 56. Capacidad de producción diaria por vehículo .......................................................125

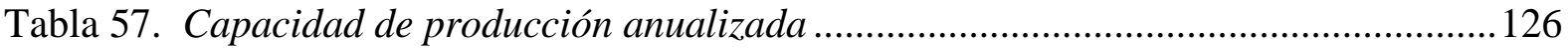

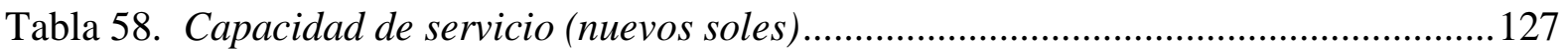

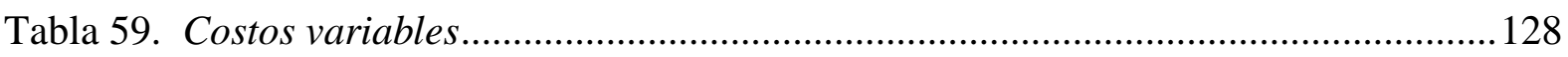

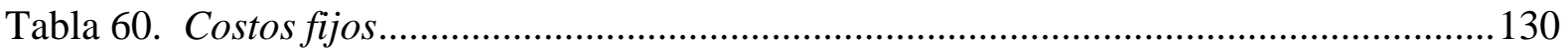

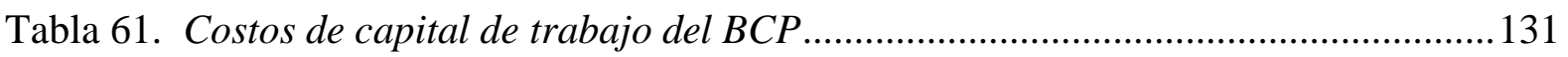

Tabla 62. Costos de capital de trabajo del Banco Continental ............................................ 132

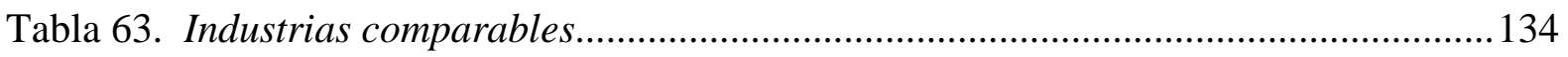

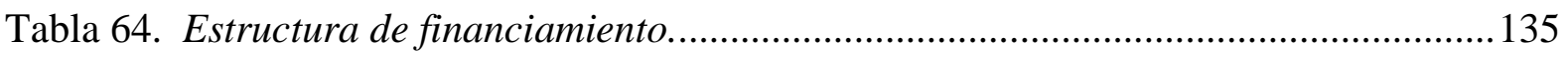

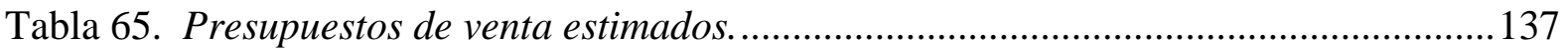

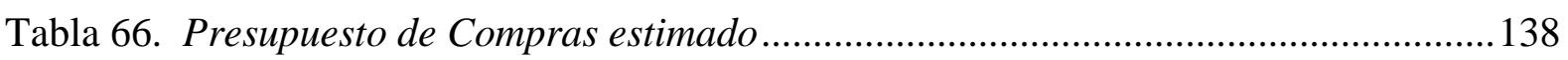

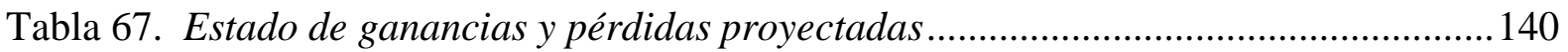

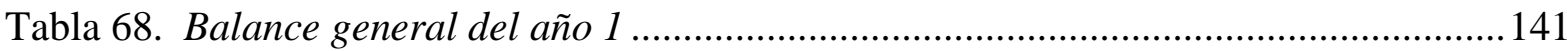

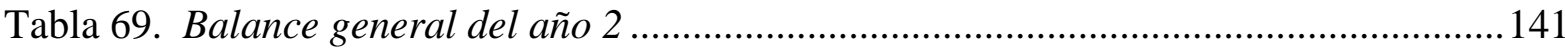

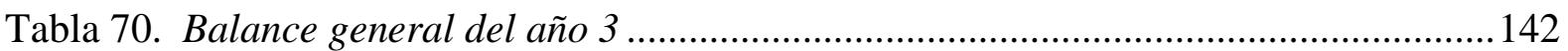

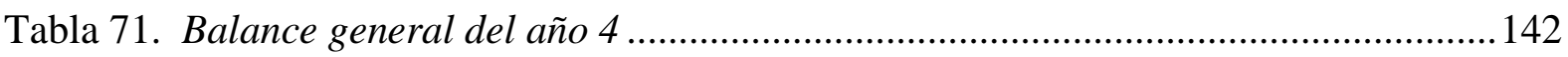

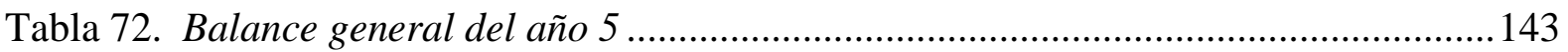

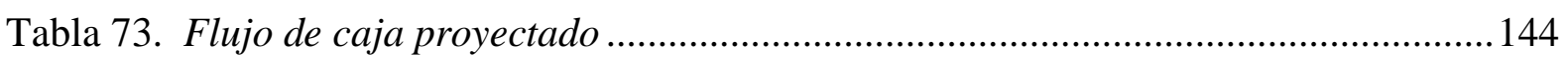

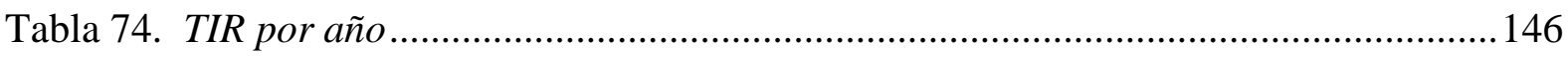

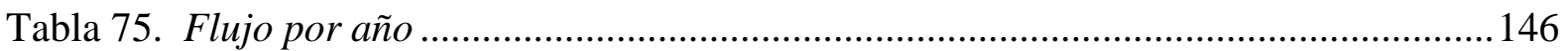

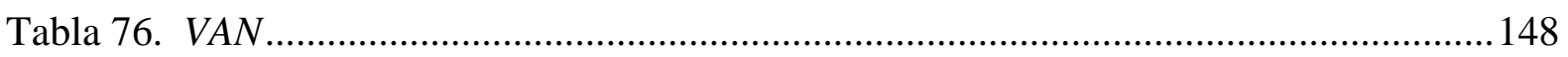

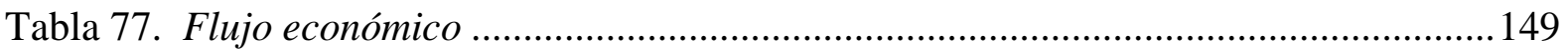

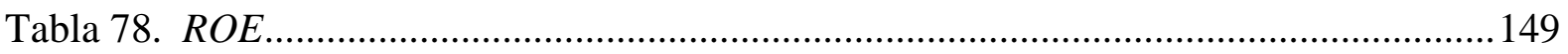

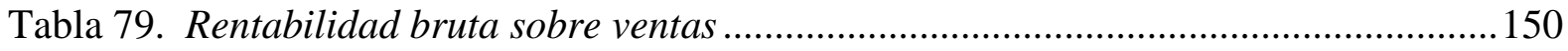

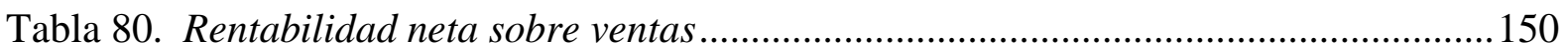

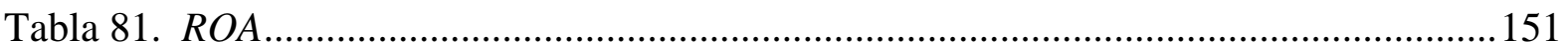

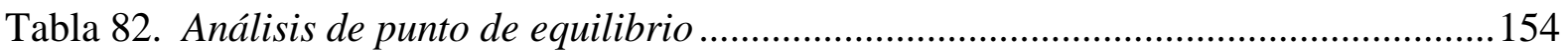

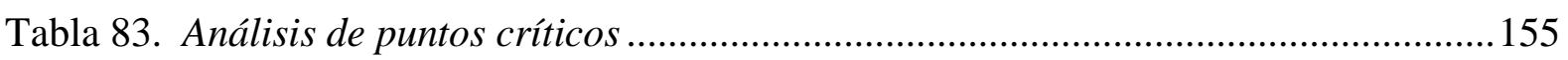

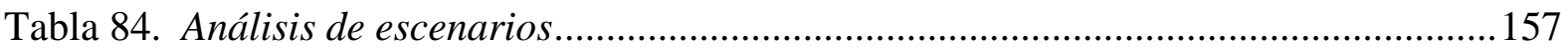


Tabla 85. VPN

Tabla 86. TIR 158

Tabla 87. Resultado del análisis de escenarios 


\section{Lista de Figuras}

Figura 1 - Perú: altas de empresas, según actividad económica, II trimestre 2018

Figura 2 - Lima Metropolitana: altas de empresas, según actividad económica, II trimestre

2018

Figura 3 - Lima Metropolitana: bajas de empresas, según actividad económica, II trimestre

2018

Figura 4 - Análisis de horarios de atención vs cargos de encuestadas

Figura 5 - Análisis de horarios de atención vs cercanía

Figura 6 - Análisis de horarios de atención vs cantidad de hijos

Figura 7 - Ficha técnica Bus JAC 6750 K - Nota: Desco Maq [en línea]

https://camionesjac.cl/.

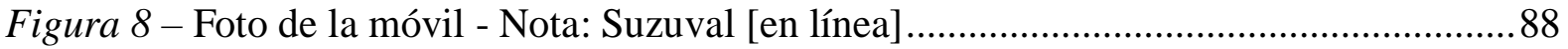

Figura 9 - Dimensiones de la móvil - Nota: Suzuval [en línea] ............................................ 88

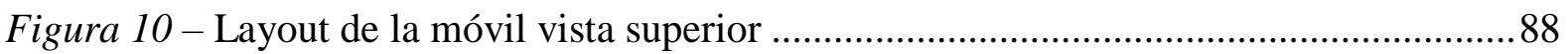

Figura 11 - Dimensiones de silla del layout de la móvil vista superior .................................. 89

Figura 12 - Dimensiones de mesa del layout de la móvil vista superior ............................... 89

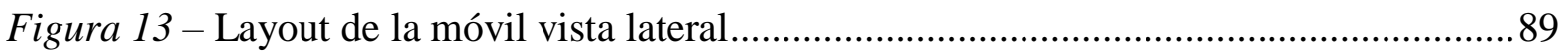

Figura 14 - Dimensiones de silla de layout de la móvil vista lateral ..................................... 89

Figura 15 - Dimensiones de mesa de layout de la móvil vista lateral ...................................90

Figura 16 - Modelo de mesa de trabajo - Nota: EquipoBellaza [en línea] .............................90

Figura 17 - Modelo de silla de trabajo - Nota: EquipoBelleza [en línea]................................90

Figura 18 - Flujo de proceso de atención de clientes ........................................................91

Figura 19 - Mapa de Lima metropolitana - Nota: Pinterest.................................................95

Figura 20 - Dirección legal - Nota: Google Maps ….............................................................96

Figura 21 - Mapa de desplazamiento por distrito - Nota: Google Maps ................................97

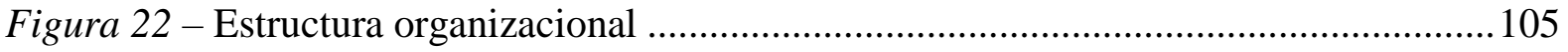

Figura 23 - Propuesta de valor del modelo de negocio .....................................................106 


\section{Introducción}

El presente Plan de Negocio tiene como objetivo la creación de un Salón de belleza móvil que brinde los servicios de mayor demanda a los clientes, dentro de las instalaciones de sus centros laborales.

El proyecto brindará a las empresas la posibilidad de contar, por un determinado tiempo, con un Salón de Belleza dentro de las instalaciones de su centro laboral que favorezca el clima laboral y contribuya a mejorar el bienestar personal de sus trabajadores.

Las empresas actualmente buscan retener y atraer el talento humano a través de beneficios, estrategias que impactan directamente en los trabajadores. El presente modelo de negocio se orienta a colaborar con estas empresas, brindándoles la oportunidad de contar con este servicio dentro de sus instalaciones sin generar costos adicionales por infraestructura.

En Perú existen más de 34,000 salones de belleza a nivel nacional, donde alrededor del 40\% se concentran en la Provincia de Lima y la Provincia Constitucional del Callao. La demanda por salones de belleza genera que el rubro se mantenga dinámico, con altas y bajas que dejan un saldo positivo de salones activos. Si bien el número de empresas es representativo, el presente plan resulta innovador debido que no se identificó un modelo similar en el mercado.

Los trabajadores a pesar de la carga y estrés buscan equilibrar su vida laboral y personal, factor determinante al momento de decidir en qué empresa trabajar. En esa búsqueda del bienestar personal se incluye el verse y sentirse bien, por ello disponen de su tiempo para acudir a salones de belleza. Este tiempo que destinan incluye un adicional por traslado al salón, el cual se incrementa según la distancia, día y hora, así como también por el tráfico de la ciudad.

El proyecto está dirigido a trabajadores de las entidades financieras que por la naturaleza de sus funciones y estilo de vida optan con cierta regularidad por los servicios de belleza de 
mayor demanda. La investigación cuantitativa realizada arrojó que más del $80 \%$ de personas encuestadas se atenderían en un salón de belleza dentro de las instalaciones. Asimismo, se confirmó que las empresas de este sector buscan generar convenios o alianzas con empresas de otros sectores que brinden productos o servicios de valor para sus trabajadores.

La propuesta consiste en brindar estos servicios de belleza en la unidad móvil, perfectamente acondicionada para la atención de los clientes, la cual se ubicará por un determinado período de tiempo dentro de las instalaciones de dos entidades financieras de Lima Metropolitana. Los servicios que se ofrecerán en el Salón de belleza móvil son manicura, planchado y cepillado de cabello porque son de atención rápida y no demandan mucho espacio, lo que hace factible su ejecución dentro de la móvil. El salón de belleza móvil ofrecerá una experiencia distinta, al brindar a los clientes una propuesta cercana, ágil y de calidad.

La visión del proyecto es convertirse en la principal cadena de salones de belleza brindando servicios de calidad, teniendo como estrategias potenciar las fortalezas, reducir las debilidades, aprovechar las oportunidades y minimizar las amenazas. Destacando la seguridad, agilidad y cercanía como ventajas competitivas.

Las estrategias de marketing estarán enfocadas en el posicionamiento en el mercado de la marca tomando en cuenta los factores más valorados por el público objetivo según la investigación realizada: agilidad y calidad. Las estrategias de producto, precio, distribución, promoción y publicidad, personas, procesos y posicionamiento se desarrollaron bajo los objetivos de la propuesta.

La inversión del proyecto estará compuesta por capital propio proveniente de los socios y por financiamiento crediticio en misma proporción. El resultado del estudio financiero indica el tiempo en que se recuperará la inversión y confirma la viabilidad del plan. 


\section{Capítulo I: Generalidades}

\subsection{Antecedentes}

Hoy en día el avance tecnológico, la globalización y el crecimiento empresarial han permitido diversas oportunidades laborales, lo que ha impulsado a la sociedad a vivir muy rápido, pasar más horas en los trabajos y dedicar menos tiempo a la familia, el descanso y el cuidado personal.

Actualmente, las empresas desean mantener índices elevados de clima laboral dentro de sus organizaciones, además buscan ser consideradas atractivas para poder atraer y retener al talento humano. Es por ello que el enfoque empresarial ha cambiado. Las empresas destinan esfuerzos para generar programas de beneficios que favorezcan el equilibrio personal - laboral de sus colaboradores. Han descubierto que al velar por el bienestar del personal obtienen mejores índices de productividad y fidelización organizacional.

La imagen que proyecta el trabajador es vista por la sociedad como la imagen de la empresa, es por ello que varias organizaciones mantienen pautas de presentación personal. Asimismo, algunos de los beneficios que otorgan están orientados a mantener y elevar la imagen personal de sus trabajadores.

Tomando en cuenta lo anterior se evidencia que en los últimos años han aumentado las empresas de bienes y servicios, entre ellas las empresas de servicios profesionales en el campo de la belleza y en todo lo referente a cuidado personal, salud y estética que ofrecen tratamientos tradicionales y alternativos para mantener la salud y belleza física, lo cual favorece la imagen personal.

Esto ha empujado a que los Spa, del latín "Salus per aquam" o salud mediante el agua (Translatio y Cultura, 2015), se hayan posicionado como una de las primeras opciones relacionadas a la búsqueda del confort y relajación, además de brindar servicios de cuidado personal que impactan favorablemente en la salud e imagen de las personas. 
La búsqueda de bienestar personal no es ajena a la mujer actual. La moda, belleza y competitividad laboral la obligan a mantener una presentación impecable en todo momento, en todo lugar y en cada detalle. Los esfuerzos por mantener una buena imagen personal la motivan a visitar salones de belleza con la finalidad de realizarse aquellos tratamientos que la hagan sentirse y verse bien.

El tiempo de atención en un salón de belleza oscila entre los 45 y 90 minutos, dependiendo de los tratamientos que se soliciten, y la frecuencia de visita al salón es en promedio cada dos semanas. Si se requiere algún tratamiento se debe asistir al salón de belleza lo cual demanda inversión de tiempo (tiempo de espera y desplazamiento) y los costos relacionados al transporte, de ser el caso.

\subsection{Determinación del Problema u Oportunidad}

En la actualidad las empresas buscan mejorar el clima laboral estableciendo diversas estrategias que tienen como principal enfoque mejorar la calidad de vida de los colaboradores, a través del equilibrio trabajo/familia, con la finalidad de aumentar su productividad.

Bajo este enfoque algunas empresas han optado por implementar diversos servicios dentro de sus instalaciones tales como lavandería, restaurante, salón de belleza, sala de descanso, entre otros, los cuales permiten optimizar el tiempo de sus colaboradores. Otras empresas que persiguen los mismos objetivos no pueden implementar este tipo de servicios en sus instalaciones debido a limitaciones de espacio y/o presupuesto.

Por otro lado, el mercado de la belleza ha crecido y ganado un espacio importante dentro de los intereses de las personas más aún en la forma de vida de la mujer trabajadora actual. Actualmente, las trabajadoras de los diversos rubros empresariales destinan parte de su tiempo fuera del horario laboral para la atención de su imagen personal dejando de lado otras actividades o reduciendo la frecuencia de las atenciones por falta de tiempo. Otro de los motivos relevantes que afecta la frecuencia de visita a los salones de belleza es la inseguridad 
ciudadana, de la cual pueden ser víctimas durante el desplazamiento al salón o durante la atención en el mismo.

Conociendo las limitaciones expuestas se considera necesario establecer un salón de belleza móvil en donde se brinden servicios sin necesidad de que el cliente se desplace fuera de las instalaciones de su centro de labores. Es por ello que se presenta la oportunidad de brindarles la atención con agilidad y calidad, dentro de sus centros de trabajo.

\subsection{Justificación del Proyecto}

El proyecto Salón de belleza móvil tiene como finalidad colaborar con aquellas empresas que presentan limitaciones de espacio y/o presupuesto y buscan elevar sus índices de eficiencia y productividad, a su vez ser reconocidas como un lugar donde la mayoría de personas desearían trabajar teniendo como reto atraer talento externo, evitar la fuga del talento interno y consolidar su imagen empresarial en el mercado.

Actualmente el trabajador a pesar del estrés, competitividad laboral y tiempos ajustados, busca equilibrio entre su vida familiar y laboral, tema que es actualmente fundamental a la hora de decidir en qué empresa trabajar. Asimismo, se busca atender a las mujeres trabajadoras que desean mantener una imagen personal impecable pero que por falta de tiempo y/o temor a ser víctimas de la inseguridad ciudadana deciden reducir la frecuencia de visitas a los salones de belleza.

\subsection{Objetivos Generales y Específicos}

\subsubsection{Objetivos Generales.}

Diseñar un plan de negocios que determine la viabilidad del presente proyecto para la Creación de un Salón de belleza móvil. 


\subsubsection{Objetivos Específicos.}

- Validar con expertos en la industria el modelo de negocio propuesto y realizar los ajustes necesarios que aseguren su viabilidad y aceptación en el mercado.

- Verificar a través de herramientas de investigación que el modelo de negocio propuesto será aceptado por el mercado potencial.

- Demostrar teóricamente la viabilidad del negocio en términos financieros.

\subsection{Alcances y Limitaciones de la Investigación}

El proyecto está dirigido a dos sedes que corresponden a dos entidades financieras interesadas en mejorar sus indicadores de clima laboral, eficiencia y productividad, que presentan la posibilidad de brindar un espacio físico apropiado (estacionamiento, patio de entrada, zona de receso, etc.) donde ubicar el Salón de belleza móvil para atender a sus colaboradoras, sin afectar las labores en sus sedes.

Por otro lado, en la recopilación y búsqueda de información solo se obtuvieron datos estadísticos de los salones de belleza tradicionales y no sobre el modelo innovador propuesto. Es por ello que la información se generará con las entrevistas, focus group y encuestas que se realicen como parte del presente proyecto. 


\section{Capítulo II: Estructura Económica del Sector}

\subsection{Descripción del Estado Actual de la Industria}

La estabilidad y condiciones económicas favorables presentadas en los últimos tiempos en el país propicio la creación de proyectos de inversión, tal es así que al cierre del II trimestre del 2018 el número de empresas activas alcanzó los 2`379,455 lo que representa un aumento de 7,4\% respecto al mismo período del año anterior. La actividad económica bajo el nombre "Salones de Belleza", registro un saldo de 823 altas, el cual es la diferencia entre el número de empresas creadas o activas menos las dadas de baja en el período analizado.

El rubro registró la segunda mayor variación de altas respecto al período similar del año anterior con un 4,5\%, solo por detrás de "transporte y almacenamiento" con el 27,1\%. Cabe señalar que "Salones de Belleza" fue la que menos bajas presentó con solo un 0,6\%.

Las altas en la Provincia de Lima representaron el $42.2 \%$ del total, lo que significa que 4 de cada 10 empresas inician actividades en esta provincia. Cabe indicar entre Lima y Callao la concentración es de 45,2\%.

A continuación, se detalla el número de empresas que iniciaron actividades en Lima Metropolitana en el II trimestre de 2018 (ver figura 1).

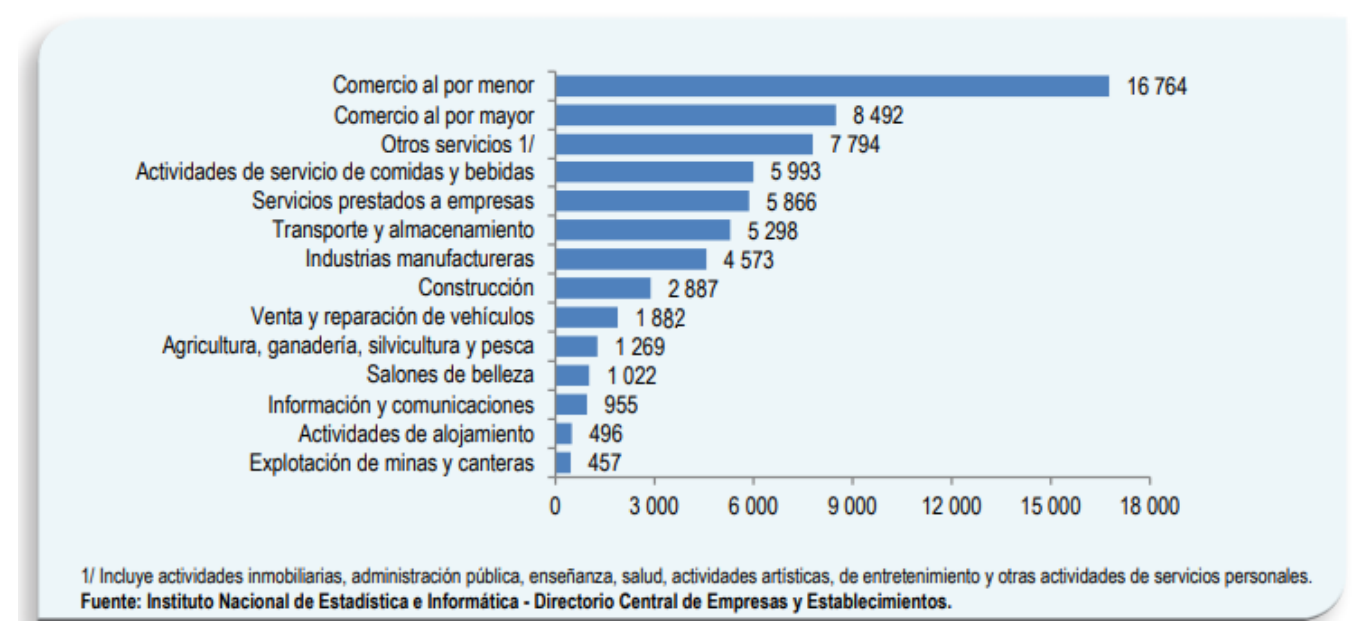

Figura 1- Perú: altas de empresas, según actividad económica, II trimestre 2018 (INEI, Informe Técnico 3 Demografia Empresarial - II Trimestre 2018, 2018) 
De acuerdo a la ilustración 2 "Personas naturales dadas de alta, según actividad económica 2017 - 18, “Salones de Belleza” representó el tercer mayor crecimiento en empresas dadas de alta por personas naturales con 5,3\%, solo detrás de "Transporte y almacenamiento" y "Agricultura, ganadería, silvicultura y pesca” con $24,1 \%$ (ver tabla 1 ). 
Tabla 1.

Personas naturales dadas de alta, según actividad económica 2017-18.

\begin{tabular}{|c|c|c|c|c|}
\hline Actividad Económica & $\begin{array}{c}2017 \\
\text { II Trim } \\
\end{array}$ & $\begin{array}{c}2018 \\
\text { II Trim } \\
\end{array}$ & $\begin{array}{l}\text { Estructura \% } \\
\text { II Trim. } 2018 \\
\end{array}$ & $\begin{array}{c}\text { Va. \% } \\
\text { II Trim. 2018/17 }\end{array}$ \\
\hline Total & 43,735 & 39,812 & 100.0 & -9.0 \\
\hline Agricultura, ganadería, silvicultura y pesca & 474 & 588 & 1.5 & 24.1 \\
\hline Explotación de minas y canteras & 1,737 & 217 & 0.5 & -87.5 \\
\hline Industrias manufactureras & 3,131 & 2,763 & 7.0 & -11.8 \\
\hline Construcción & 365 & 289 & 0.7 & -20.8 \\
\hline Venta y reparación de vehículos & 1,324 & 1,250 & 3.1 & -5.6 \\
\hline Comercio al por mayor & 4,888 & 4,996 & 12.5 & 2.2 \\
\hline Comercio al por menor & 15,694 & 14,419 & 36.2 & -8.1 \\
\hline Transporte y almacenamiento & 2,639 & 3,642 & 9.2 & 38.0 \\
\hline Actividades de alojamiento & 384 & 341 & 0.9 & -11.2 \\
\hline Actividades de servicio de comidas y bebidas & 5,690 & 5,220 & 13.1 & -8.3 \\
\hline Información y comunicaciones & 296 & 246 & 0.6 & -16.9 \\
\hline Servicios prestados a empresas & 1,778 & 1,428 & 3.6 & -19.7 \\
\hline Salones de belleza & 864 & 910 & 2.3 & 5.3 \\
\hline Otros servicios $1 /$ & 4,471 & 3,503 & 8.8 & -21.7 \\
\hline
\end{tabular}

1/ Incluye financieras, seguros, inmobiliarias, administración pública, enseñanza, salud, actividad artística, de entretenimientos y otras actividades de servicio profesional 
Asimismo, "Salones de Belleza" dirigidos por mujeres correspondieron al 69.7\% del total (ver tabla 2).

Tabla 2.

Personas naturales dadas de alta por sexo del conductor, según actividad económica, II trimestre 2018.

\begin{tabular}{|c|c|c|c|c|c|c|}
\hline \multirow{2}{*}{ Actividad económica } & \multirow{2}{*}{ Total } & \multirow{2}{*}{$\%$} & \multicolumn{4}{|c|}{ Sexo } \\
\hline & & & Hombres & $\%$ & Mujeres & $\%$ \\
\hline Total & 39,812 & 100.00 & 18,969 & 47.6 & 20,843 & 52.4 \\
\hline Agricultura, ganadería, silvicultura y pesca & 588 & 100.00 & 400 & 68.0 & 188 & 32.0 \\
\hline Explotación de minas y canteras & 217 & 100.00 & 171 & 78.8 & 46 & 21.2 \\
\hline Industrias manufactureras & 2,763 & 100.00 & 1,605 & 58.1 & 1,158 & 41.9 \\
\hline Construcción & 289 & 100.00 & 238 & 82.4 & 51 & 17.6 \\
\hline Venta y reparación de vehículos & 1,250 & 100.00 & 884 & 70.7 & 366 & 29.3 \\
\hline Comercio al por mayor & 4,996 & 100.00 & 2,145 & 42.9 & 2,851 & 57.1 \\
\hline Comercio al por menor & 14,419 & 100.00 & 5,559 & 38.6 & 8,860 & 61.4 \\
\hline Transporte y almacenamiento & 3,642 & 100.00 & 2,867 & 78.7 & 775 & 21.3 \\
\hline Actividades de alojamiento & 341 & 100.00 & 170 & 49.9 & 171 & 50.1 \\
\hline Actividades de servicio de comidas y bebidas & 5,220 & 100.00 & 1,944 & 37.2 & 3,276 & 62.8 \\
\hline Información y comunicaciones & 246 & 100.00 & 133 & 54.1 & 113 & 45.9 \\
\hline Servicios prestados a empresas & 1,428 & 100.00 & 796 & 55.7 & 632 & 44.3 \\
\hline Salones de belleza & 910 & 100.00 & 276 & 30.3 & 634 & 69.7 \\
\hline Otros servicios $1 /$ & 3,503 & 100.00 & 1,781 & 50.8 & 1,722 & 49.2 \\
\hline
\end{tabular}

1/ Incluye financieras, seguros, inmobiliarias, administración pública, enseñanza, salud, actividad artística, de entretenimientos y otras actividades de servicio profesional

Nota: (INEI, Informe Técnico 3 - Demografia Empresarial - II Trimestre 2018, 2018) 


\subsubsection{Segmentación de la industria.}

Se puede segmentar la industria de la belleza en dos grandes rubros los cuales se describen a continuación:

Productos. - aquellos que son utilizados para el cuidado personal, tales como:

- Aceites esenciales, resinoides; oleorresinas; disoluciones concentradas de aceites y subproductos

- Mezclas de sustancias odoríferas y mezclas, incluidas las disoluciones alcohólicas.

- Perfumes y aguas de tocador (excluidas lociones para después del afeitado y desodorantes corporales)

- Preparaciones de belleza, maquillaje y para el cuidado de la piel, incluido las preparaciones anti solares y las bronceadoras; preparaciones para manicuras o pedicuras.

- Preparaciones capilares

- Preparaciones para higiene bucal o dental, incluido los polvos y cremas para la adherencia de dentaduras; hilo dental

- Preparaciones para afeitar y antes o después del afeitado, desodorantes corporales, preparaciones para el baño, depilatorios y demás preparaciones de perfumería, de tocador o de cosmética.

Este segmento pertenece a la partida 33 del código arancelario de empresas dedicadas a la producción de acuerdo al Sistema Integrado de Información de Comercio Interior SIICEX (SIICEX, s.f.).

Estos productos son distribuidos entre los diferentes mercados que pueden ser de consumo directo o a través de servicios proporcionados por los centros de belleza.

Servicios. - Este rubro según el CIIU que por sus siglas significa (Clasificación Industrial Internacional Uniforme) está definido por la clase 9602 Peluquería y otros 
tratamientos de belleza de acuerdo al INEI (INEI, Clasificación Industrial Internacional Uniforme, 2010).

Se pueden encontrar una alta cantidad de variedad de ellos los cuales de brindan en los diferentes centros de la belleza como peluquerías, Spa's, centros de relajación y masajes, centros para el cuidado personal y comprende las siguientes actividades:

- Lavado, corte, recorte, peinado, teñido, coloración, ondulación y alisado del cabello y otras actividades similares para hombres y mujeres.

- Afeitado y recorte de la barba.

- Masajes faciales, manicura y pedicura, maquillaje, etcétera.

\subsubsection{Empresas que la conforman.}

El sector de cosméticos e higiene está conformado por dos grandes grupos de empresas, fabricantes de productos y salones de belleza. Dentro del segundo grupo están incluidas las peluquerías, centros de masajes, estéticas y Spa's.

Entre las más importantes por cada grupo se destacan:

Fabricantes de productos con mayor presencia en el mercado peruano:

- Unique: empresa que manufactura productos de belleza y cuidado personal para hombre, mujeres y niños. En 2012 sumó ocho centros de entrenamiento en las ciudades de Lima, Trujillo, Chiclayo, Piura, Arequipa e Ica (Gestión, Los dueños de Belcorp y Yanbal serían los más ricos del Perú, 2012).

- L'Bel: que junto con Unique representan el 45\% del mercado de cosméticos en el mercado (Gestión, Los dueños de Belcorp y Yanbal serían los más ricos del Perú, 2012).

- OPI: empresa reconocida a nivel internacional debido a su durabilidad, resistencia, calidad y variedad de colores. Ofrece una línea completa de artículos entre los que 
también se incluyen lociones, productos de manicuras, limas, entre otros ((Facebook), s.f.).

\section{Salones de Belleza:}

- Marco Aldany: Empresa española que cuenta con más de 400 salones y 4,000 empleados en todo el mundo, la franquicia en el Perú tiene presencia en Lima y provincias y llega a facturar hasta 200 mil dólares al mes (N, 2015).

- Montalvo Spa: con más de 60 locales en Perú factura alrededor de S/30 millones al año (Gestión, Montalvo Spa factura alrededor de S/ 30 millones, 2012).

- SOHO Spa: Empresa peruana fundad en el año 2009, actualmente cuenta con nueve locales, cinco en lima y cuatro en provincias.

- SPECCHI SALON SPA: Empresa peruana que inició actividades en el año 1998 y que cuenta actualmente con seis salones de belleza (ver tabla 3).

A nivel nacional existen 30,000 salones de belleza el 50\% se encuentra en Lima de esos 15,000, solo son formales 9,500 salones (Gestión, El 43\% de los 15 mil centros de belleza en Lima es informal, 2012). 
Tabla 3.

Principales Salones de belleza

Razón Social

Marco Aldany Perú S.A.

\section{Servicios brindados}

Peluquería y estética, manicura,

pedicura, hidratación capilar.

Peluquería, botox, masajes, manicura, pedicure, entre otros.

Cortes, cepillado, alisado, botox,

SPECCHI S.A.C. manicura, pedicure, maquillaje, spa.
Núm. locales

35

60

6

\section{Estilo Único S.A.C. Estilo Único S.A.C. Soho Color \\ Sin \\ Soho Color Salón y Spa Salón y Spa \\ Información}

Nota: (Network, Marco Aldany y Montalvo siguen apostando por Perú, 2017) y (Gestión, Montalvo Spa factura alrededor de S/ 30 millones, 2012)

\subsection{Tendencias de la industria (crecimiento, inversiones)}

Actualmente, la industria de la belleza y el cuidado personal ha crecido significativamente en el país. El desarrollo de las clases socio económicas, la estabilidad económica y la globalización, entre otros factores, han motivado su desarrollo y han vuelto a la región un escenario atractivo para esta industria.

Las personas asiduas a los salones de belleza no solo buscan servicios como corte de cabello, peinado, laceado, depilación, manicura, pedicura, entre otros; sino además cuidar su salud con masajes, aromaterapia, yoga y otros tratamientos alternativos (Correo, Rubro de belleza mueve 50 mil locales en Perú, 2015).

En estos tiempos el consumidor busca productos y tratamientos diferenciados y de calidad y a su vez se informa sobre los nuevos productos y tendencias de belleza. Es por ello, que prefiere un salón de belleza que brinde servicios y productos de prestigio (Correo, Una peluquería genera ganancias desde S/. 9 mil, 2015). 
Cifras oficiales reveladas por el gobierno de Perú confirman que la industria de la belleza, cosmética e higiene creció un 8,1\% durante 2017 y facturó poco más de 7,080 millones de soles, cerca de 2,380 millones de dólares. La perfumería toma la delantera y se coloca entre los rubros de mayor crecimiento (Network, Crece el mercado de la belleza y perfumería en Perú en 2017, 2018).

Dentro de la categoría de perfumes, las ventas de productos de lujo representan un $18 \%$ del total del comercio y experimentaron un crecimiento del $2 \%$ en su facturación interanual. Por el momento el comercio se concentra en 28 marcas internacionales.

Globalmente el mercado de belleza en Perú está dominado por L'Oréal, Revlon y Estée Lauder en sus respectivos rubros, así como Belcorp y Avon, los dos gigantes locales de la belleza con modelo de venta directa.

Las tiendas por departamento son los canales de comercialización de los cosméticos y la perfumería con mayor oferta, tanto en sus puntos físicos como en las plataformas virtuales, seguido por la venta directa (puerta a puerta) y las tiendas especializadas. Según información revelada por la Cámara de Comercio sectorial cosmética e higiene, en Perú se destina entre un $10 \%$ y un $15 \%$ del salario mensual a productos de belleza.

En el II trimestre del 2018, el número de empresas dadas de alta dedicadas a la industria de la belleza en Lima metropolitana fue de 571 (ver figura 2) versus 115 (ver figura 3) dadas de baja con referencia al mismo período del año anterior, lo que demuestra que el sector se encuentra en un crecimiento sostenido. 


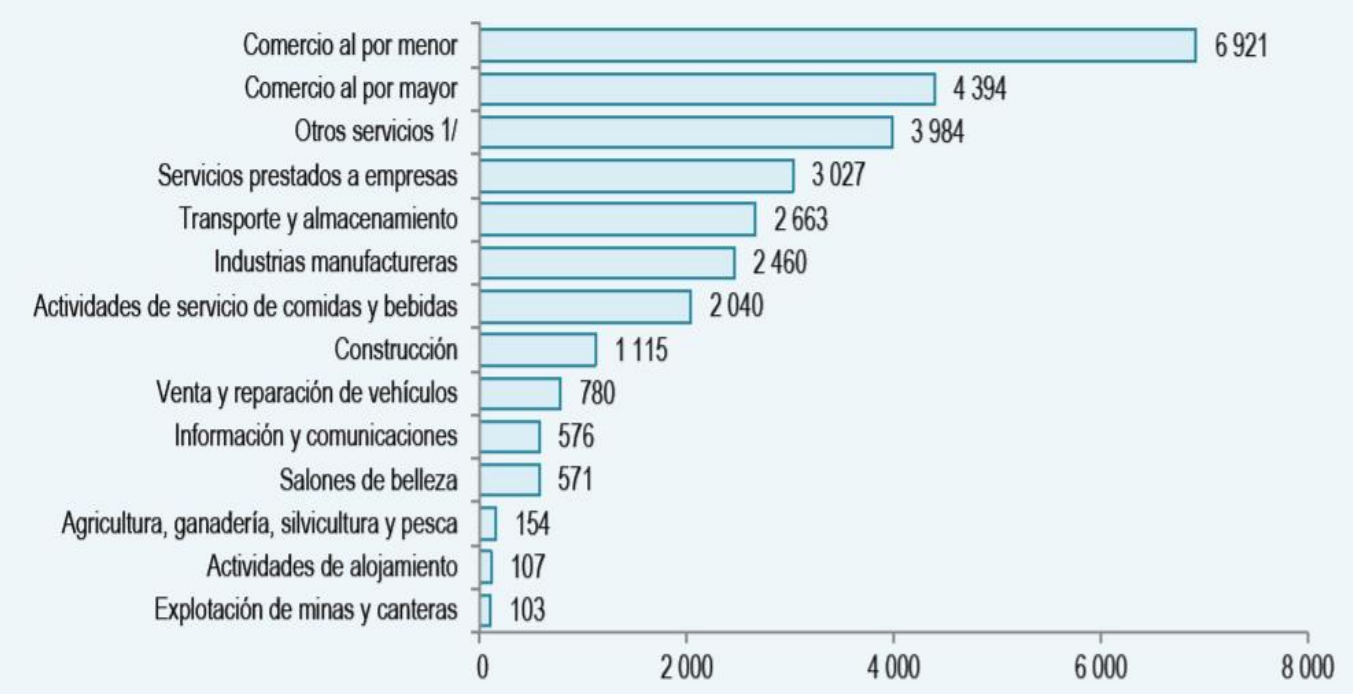

$1 /$ Incluye financieras, seguros, inmobiliarias, administración püblica, enseñanza, salud, actividades artisticas, de entretenimiento y otras actividades de servicios personales. Figura 2 - Lima Metropolitana: altas de empresas, según actividad económica, II trimestre 2018 (INEI, Informe Técnico 3 - Demografia Empresarial - II Trimestre 2018, 2018)

En cuanto a la tendencia de la industria dentro de los centros laborales, solo una empresa del sector financiero privado actualmente cuenta con diferentes estaciones de servicio dentro de la empresa, tales como gimnasio, lavandería, tienda de tecnología, peluquerías, entre otras. A estos servicios los colaboradores pueden acceder en cualquier horario. Este tipo de propuesta si bien es innovadora en el país, en Estados Unidos y otros países de Europa es un formato que ha ganado popularidad. Esta tendencia en las empresas tiene como propósito retener y atraer el talento humano (Diario Gestión, 2013).

Otras empresas del rubro si bien no cuentan con estos servicios dentro de sus instalaciones, han optado por poner a disposición ferias internas donde se ofertan productos a precios promocionales en beneficio de sus trabajadores. El propósito es el mismo, retener el talento interno. 


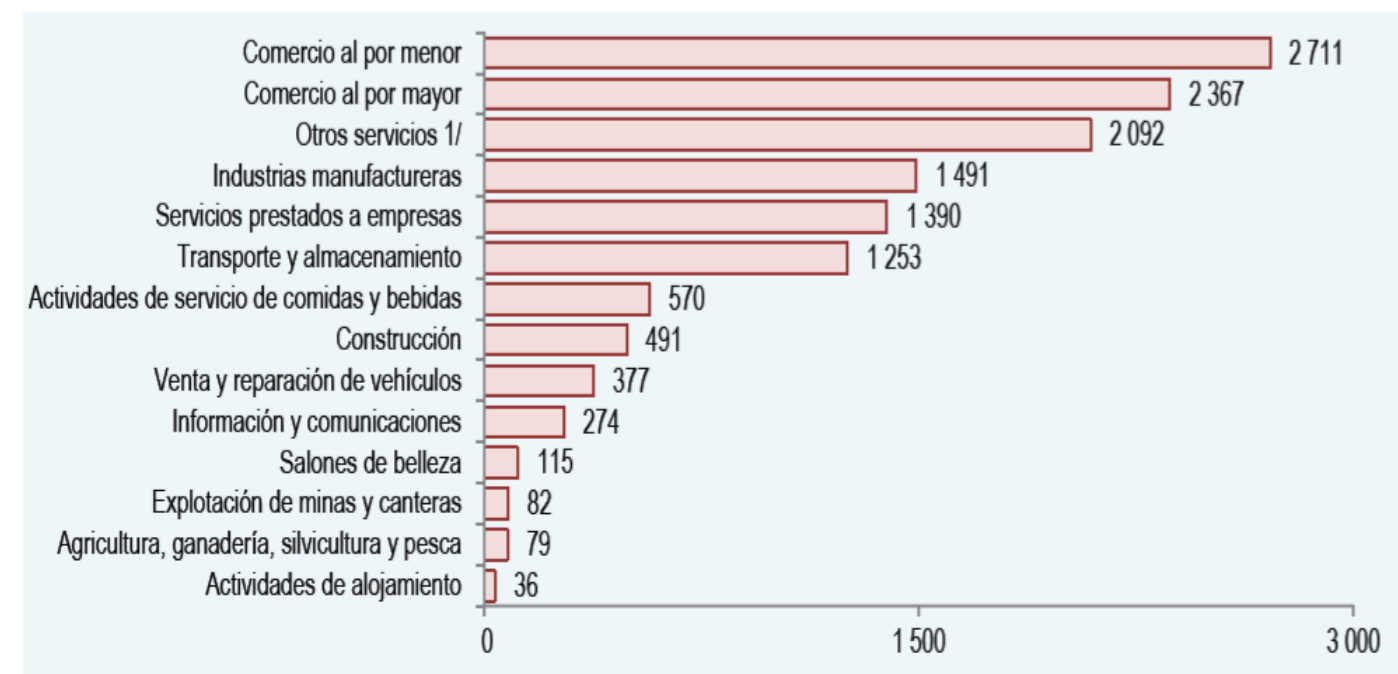

duye financieras, seguros, inmobiliarias, administración pública, enseñanza, salud, actividades artisticas, de entretenimiento y otras actividades de servicios personales

Figura 3 - Lima Metropolitana: bajas de empresas, según actividad económica, II trimestre 2018 (INEI, Informe Técnico 3 - Demografia Empresarial - II Trimestre 2018, 2018)

\subsection{Análisis de la Competencia}

\subsubsection{Empresas que ofrecen el mismo servicio.}

Se realizó la búsqueda de modelos de negocio con características similares al propuesto en diferentes fuentes como internet, entorno personal y laboral, sin encontrar uno similar. Sin embargo, se encontraron dos empresas cuyos modelos de negocio presentan ciertas semejanzas; "Mía Spa” y "Montalvo Spa".

"Mía Spa" es una empresa que comenzó a ofrecer inicialmente el concepto de un spa a domicilio, en julio del 2009. Con el tiempo empezó a crecer e incursionar a nivel de empresas brindando servicios, en ocasiones importantes o especiales, donde se beneficia a los colaboradores que reciben el servicio de forma gratuita debido a que el costo es asumido por el empleador (Perú21, 2010).

La gran diferencia entre "Mía Spa" y la propuesta es que la primera centra sus esfuerzos en atender a clientes en sus domicilios y la segunda atenderá a los clientes en sus centros de labores.

Como semejanza se puede señalar que ambos modelos tienen como clientes a empresas, pero con una diferencia puntual: "Mía Spa" vende el servicio a la empresa y 
los beneficiados son sus colaboradores. La propuesta tendrá como clientes a los colaboradores de las empresas con las cuales se firme el acuerdo de servicio para atender en sus instalaciones.

"Montalvo Spa" es una empresa que ha ganado con el tiempo gran prestigio y cuenta con más de 60 locales en todo el país (Montalvo Spa S. d., s.f.). Básicamente su negocio se centra en sus locales, es decir, sus clientes asisten a los locales. Por otro lado, cuenta con un producto llamado "Plan empresarial" (Montalvo Spa S. d., s.f.) el cual es similar a "Mía Spa", es decir, las empresas contratan el servicio en ocasiones especiales y sus colaboradores se atienden sin costo.

El servicio que ofrece tanto "Mía Spa" como "Montalvo Spa" guarda cierta semejanza a la propuesta dado que está orientado a los colaboradores de las empresas. Cabe señalar que esta empresa se incluye en la investigación debido al modelo de negocio similar que mantiene y no porque sea una empresa representativa en el rubro.

\subsubsection{Matriz del Perfil Competitivo.}

La Matriz del Perfil Competitivo (David, 2013) facilita la compresión del entorno de la empresa dado que permite identificar a los principales competidores y compararlos a través de los factores críticos de éxito. Los factores críticos son las áreas o puntos en los cuales la empresa debe centrar su atención para lograr el éxito dentro de una industria en particular. Estos factores pueden ser externos o internos.

La matriz se generó en base a dos puntos:

- Información obtenida de las empresas "Mía Spa" y "Montalvo Spa". Así también información recogida en las entrevistas realizadas a gerentes de las empresas "Soho Color" y "Montalvo Spa". Estas empresas se escogieron porque presentan modelos de negocio con ciertas semejanzas al modelo propuesto, las cuales se han descrito previamente en el presente trabajo. 
- Resultado de las entrevistas.

Como resultado se obtuvieron los siguientes factores de éxito:

- Cercanía a los clientes, al público objetivo. Factor importante por el cual las empresas instalan sucursales en diferentes partes de la ciudad/país con la finalidad de cubrir la demanda y posicionarse como empresa líder del sector. Este factor se identificó con las respuestas a gerentes de las empresas del rubro a la pregunta ¿Cómo determinaron la ubicación de sus locales?

- Satisfacción del cliente, factor que engloba la experiencia completa de la atención en términos de ubicación, ambiente, productos y servicio. El cliente percibe beneficios en su imagen y salud. Este factor se identificó con las respuestas a gerentes de empresas del rubro a la pregunta ¿Qué es lo que buscan sus clientes al acudir a sus establecimientos?

- Diversidad en los servicios, brindando diferentes tratamientos, convencionales y alternativos, debido a que los clientes buscan satisfacer todas sus necesidades de belleza y salud en un solo lugar. Este factor se identificó con las respuestas a gerentes de empresas del rubro a la pregunta ¿Cuáles son los servicios que más solicitan sus clientes?

- Promoción, como parte del plan de marketing, es un factor importante para dar a conocer la marca, servicios y beneficios que ofrece la empresa. Este factor se identificó con las respuestas de los gerentes de empresas del rubro a la pregunta ¿Cómo se fijan los precios de los servicios prestados?

- Personal especializado que contribuye con la satisfacción y fidelización del cliente. Este factor se identificó con las respuestas de los gerentes de las empresas del rubro a la pregunta ¿Qué es lo que buscan sus clientes al acudir a sus establecimientos? 
En base al juicio experto de los entrevistados se confirma que en el modelo de negocio planteado destaca el siguiente factor de diferenciación (ver tabla 4).

- Cercanía a los clientes

Con la información obtenida se generó la siguiente matriz:

Tabla 4.

Matriz del perfil competitivo

\begin{tabular}{|c|c|c|c|c|c|}
\hline \multirow[b]{2}{*}{ Factores críticos para el éxito } & \multirow[b]{2}{*}{ Ponderación } & \multicolumn{2}{|c|}{ Mía Spa } & \multicolumn{2}{|c|}{ Spa Montalvo } \\
\hline & & Calificación & Puntuación & Calificación & Puntuación \\
\hline Cercanía a los clientes & 0.30 & 2 & 0.60 & 3 & 0.90 \\
\hline Satisfacción del cliente & 0.25 & 3 & 0.75 & 3 & 0.75 \\
\hline Diversidad en los servicios & 0.15 & 2 & 0.30 & 4 & 0.60 \\
\hline Promoción de los servicios & 0.15 & 3 & 0.45 & 2 & 0.30 \\
\hline Personal especializado & 0.15 & 3 & 0.45 & 3 & 0.45 \\
\hline Total & 1.00 & & 2.55 & & 3.00 \\
\hline
\end{tabular}

A cada factor crítico de éxito se le asigna una ponderación de acuerdo al nivel de importancia que tiene el factor para la empresa, el cual oscila entre el 0 (poco importante) y el 1 (muy importante). La suma de las ponderaciones asignadas a los factores debe dar 1.

La calificación se asigna en base al análisis de cada empresa en relación al factor, es decir en base a las fortalezas y debilidades. Esta calificación va del 1 a 4 y significan lo siguiente: 1 - debilidad principal, 2 - debilidad menor, 3 - fortaleza menor y 4 fortaleza principal.

La puntuación se obtiene de la multiplicación de la ponderación por la calificación, lo cual da como resultado la fortaleza o debilidad de la empresa en relación a cada factor. La ponderación asignada a los factores críticos de éxito obedece al juicio experto de los entrevistados. 
Los resultados obtenidos muestran que la propuesta de negocio cumple con varios de los factores críticos de éxito que obtuvieron mayor calificación como Diversidad de Servicios, Cercanía a los clientes, Satisfacción del cliente y Personal especializado. Cabe señalar que la presente propuesta de negocio cumple con estos factores donde la cercanía se facilita debido a que los servicios variados se brindarán dentro de las instalaciones del centro laboral de las clientes. Asimismo, tiene como premisa principal satisfacer al cliente con una atención ágil, segura y de calidad, lo cual también se logra al contar con el personal especializado.

En cuanto al factor Diversidad en los servicios, en el modelo de negocio se consideran solo tres tipos de servicios: manicura, cepillado y planchado del cabello en base a la demanda y tiempo de atención al cliente. La Promoción de los servicios se realizará a través de los canales de comunicación internos de las empresas con las cuales se firme el acuerdo de servicio.

\subsection{Análisis del Contexto Actual y Esperado.}

En este punto se describe el contexto en el cual se desarrollará el modelo de negocio, es decir, condiciones bajo las cuales se desarrollará y brindará el servicio en los aspectos Político - Gubernamental, Económico, Legal y Cultural. La comprensión de cada uno de ellos y, a su vez, en conjunto ayudará a comprender los motivos que dan origen a la propuesta.

\subsubsection{Análisis político-gubernamental.}

Durante los últimos 10 años el Perú tuvo una de las economías de más rápido crecimiento en América con una tasa de crecimiento promedio de 5.9\% y una inflación de 2.9\% (Banco Mundial, s.f.), el país no hizo más que afianzar su avance hacia la estabilidad en todos los aspectos. Adicionalmente, las políticas dictadas por las autoridades fueron propicias para las inversiones tanto internas como externas y las acciones tomadas por los gobiernos de turno para promover a las PYMES se tradujeron 
en programas masivos de capacitación técnica, estas acciones sumadas a la simplificación de los requisitos para constituir las empresas, disminuyeron las barreras de entrada en casi todos los sectores. Adicionalmente, el precio de autos en general e insumos para negocios pequeños en el rubro de belleza se mantuvo estable debido a la gran oferta de los mismos.

Las políticas de apertura al mercado dictadas en la última década del siglo pasado tuvieron como finalidad reinsertar al país en el mercado internacional lo que simplificó los trámites para las importaciones y exportaciones. Esto impactó positivamente en la industria de la belleza al facilitar la importación de productos de prestigio y reconocimiento internacional, con lo cual las empresas dedicadas a esta actividad lograron alinearse con las tendencias globales.

El ambiente político es una variable fundamental para el futuro cercano. La coyuntura electoral del primer semestre de 2016 impulsó a los grandes grupos económicos a mantener preferencias políticas, lo cual propició la creación de leyes que permitieron desarrollar la industria.

Otro punto importante son las políticas de seguridad. Actualmente, existe un Plan Nacional de Seguridad Ciudadana 2013 - 2018 (Mincetur, 2013), sin embargo, las autoridades electas deberán reducir los índices de inseguridad y satisfacer las necesidades actuales de la población, la cual demanda la intervención activa de los representantes locales. Ante esto, es tarea del gobierno actual implementar políticas adecuadas, promoviendo la participación civil y de los entes involucrados; y velar por el cumplimiento de las mismas.

\subsubsection{Análisis económico}

Según lo indicado en el punto anterior, el continuo crecimiento económico del país ha permitido que el PBI muestre cifras positivas a lo largo de estos años, y aunque cada 
vez este crecimiento es menor, los expertos coinciden en que las políticas económicas adoptadas por las autoridades han sido apropiadas para el sector empresarial. En febrero 2019 el BCR proyectó el crecimiento del PBI de 3.8\% a 3.9\% (Diario El Peruano, 2019).

Si junto con la tasa de crecimiento del PBI de los últimos años se toma en cuenta el crecimiento de la actividad económica salones de belleza, el cual al cierre del primer trimestre del año 2018 llegó al 4.8\%, se puede afirmar que se avizora un panorama favorable para las inversiones en este rubro.

Como se muestra en la tabla 5, a diciembre del 2018 el PBI fue de 4.0\% según el Banco Central de Reserva del Perú (BCRP, Notas de Estudio del BCRP - Actividad Económica: Junio, 2019).

Tabla 5.

PBI por sectores económicos

\begin{tabular}{|c|c|c|c|c|c|}
\hline (Variació & $\begin{array}{r}\text { PRODU } \\
\text { n porcentual resp }\end{array}$ & $\begin{array}{l}\text { O BRUTO I } \\
\text { to a simila }\end{array}$ & $\begin{array}{l}\text { RNO } \\
\text { ríodo del }\end{array}$ & o anterior) & \\
\hline & Estructura & & 2018 & & 2019 \\
\hline & PBI $2018^{1 /}$ & Ene. & Dic. & Año & Ene. \\
\hline Agropecuario & 5.5 & 5.2 & 2.6 & 7.5 & 3.5 \\
\hline Agricultura & 3.3 & 8.2 & -0.1 & 9.0 & 2.5 \\
\hline Pecuario & 1.5 & 1.5 & 6.3 & 5.4 & 4.9 \\
\hline Pesca & 0.5 & 12.4 & 225.9 & 39.7 & -31.3 \\
\hline Mineria e hidrocarburos & 13.2 & -1.6 & -1.2 & -1.3 & -1.3 \\
\hline Minería metálica & 9.4 & -2.0 & -1.7 & -1.5 & -1.5 \\
\hline Hidrocarburos & 1.4 & 1.1 & 1.4 & 0.0 & -0.7 \\
\hline Manifactura & 12.7 & -0.1 & 12.4 & 6.2 & -5.6 \\
\hline Primaria & 3.0 & 2.1 & 46.8 & 13.2 & -28.2 \\
\hline No primaria & 9.6 & -1.0 & 1.7 & 3.7 & 3.7 \\
\hline Electricidad y agua & 1.8 & 0.2 & 7.4 & 4.4 & 5.4 \\
\hline Construcción & 5.9 & 8.6 & 4.6 & 5.4 & 0.9 \\
\hline Comercio & 10.7 & 2.4 & 2.5 & 2.6 & 2.5 \\
\hline Total Servicios & 49.7 & 4.4 & 4.2 & 4.4 & 4.2 \\
\hline$\underline{\text { PBI Global }}$ & $\underline{100.0}$ & $\underline{2.9}$ & $\underline{4.7}$ & $\underline{4.0}$ & $\underline{\underline{1.6}}$ \\
\hline PBI Primario & 22.2 & 0.7 & 7.3 & 3.3 & -5.2 \\
\hline PBI No Primario & 77.8 & 3.6 & 4.1 & 4.2 & 3.5 \\
\hline
\end{tabular}

1/ Ponderación implicada del año 2017 a precios de 2007

Nota: Instituto Nacional de Estadística e Información, Banco Central de Reserva del Perú 
Por otro lado, las entidades bancarias y financieras mantienen políticas flexibles en el otorgamiento de créditos comerciales, apostando por pequeños emprendedores, mediante tasas preferenciales para capital de trabajo o "créditos campaña". Adicionalmente, el país cuenta con un mercado estable y una moneda fuerte frene a los países vecinos, lo cual asegura el interés por parte de los inversionistas internacionales. La suma de todos estos factores anima a realizar inversiones de este tipo, en sectores que se encuentran en franco crecimiento dado que los servicios de alta calidad han dejado de ser solo para los sectores altos. El rubro de servicios, donde se encuentran los salones de belleza, según el Informe de Resultados de Expectativas Económicas de la consultora Global Research Marketing (GRM) se encuentran entre los sectores más atractivos para invertir con un 42\%, detrás de Agroindustria y Educación que mantienen un 47,5\% y 42\%, respectivamente (El Comercio, 2015).

El ingreso de marcas automotrices extrajeras, sobre todo las que provienen del oriente han favorecido la disminución de los precios, este es otro factor que hace posible que la inversión inicial para el Salón de belleza móvil no requiera un capital muy elevado. Además de ampliar el universo de los modelos en el mercado.

Finalmente, a pesar de que las proyecciones económicas se ven prometedoras es innegable que las mejoras aún no son visibles en todos sectores y son justamente estos sectores de donde proviene la mayor cantidad de la fuerza laboral de este rubro. Es por ello que una mejora salarial, por mínima que resulte, trae como consecuencia una alta rotación de personal. Asimismo, la posibilidad e intenciones que tienen estas personas de formar un negocio propio las hace retirarse de las empresas de servicio con suma facilidad. Como se muestra en la tabla 6, en el II trimestre de 2018 el 56.3\% de las empresas dadas de alta fueron registradas por personas naturales (INEI, Boletín Demografía Empresarial en el Perú II Trimestre 2018, 2018). 
Tabla 6.

Lima Metropolitana: Altas de empresas, según organización jurídica, 2017-2018

\begin{tabular}{|c|c|c|c|c|}
\hline \multirow{2}{*}{ Organización jurídica } & \multicolumn{2}{|c|}{2017} & & \multirow{2}{*}{$\begin{array}{l}\text { Var. \% I Trim. } \\
2018 / 17\end{array}$} \\
\hline & I Trim & & & \\
\hline & 68,746 & 66,067 & 100.0 & -3.9 \\
\hline Persona natural & 44,423 & 41,879 & 63.3 & -5.7 \\
\hline Sociedad anónima & 11,398 & 11,642 & 17.6 & 2.1 \\
\hline Sociedad civil & 254 & 307 & 0.5 & 20.9 \\
\hline Sociedad comercial de Resp. Ltda. & 2,117 & 1,784 & 2.7 & -15.7 \\
\hline Empresa individual de Resp. Ltda. & 8,194 & 8,108 & 12.3 & -1 \\
\hline Asociaciones & 1,613 & 1,437 & 2.2 & -10.9 \\
\hline Otros 1/ & 747 & 910 & 1.4 & 21.8 \\
\hline
\end{tabular}

$1 /$ Incluye sociedad en comandita simple, sociedad en comandita por acciones, sociedad colectiva, fundaciones, cooperativas y otros

Nota: Instituto Nacional de Estadística e Información - Dirección Central de Empresas y Establecimientos

\subsubsection{Análisis legal}

En base a lo indicado en el análisis del entorno político - gubernamental, el crecimiento sostenido del PBI en los últimos años se produjo debido a la simplificación de condiciones y requisitos para la creación de pequeñas y medianas empresas; y según lo analizado en el entorno económico, la reducción de las tasas de interés de los bancos para este tipo de negocio y las condiciones dadas por los gobiernos de turno impulsaron el crecimiento de varios sectores, entre ellos el rubro cosméticos e higiene.

Los requisitos legales para la constitución de una empresa se basan en la creación de la personería jurídica, la inscripción en SUNAT, inscripción a la ley Mype a fin de registrar a los trabajadores en planilla, de ser el caso, y la solicitud de licencia de funcionamiento en la municipalidad correspondiente. Asimismo, los trámites para la obtención de permisos de circulación de unidades móviles también se han simplificado. La simplificación de todos estos requisitos legales para la constitución de empresas y para la obtención de permisos impacta positivamente en la implementación del modelo de negocio Salón de belleza móvil al facilitar los trámites iniciales. 
Cabe señalar que desde el 2007 no se han presentado cambios en la legislación relacionada con el otorgamiento de licencias de funcionamiento que otorgan las municipalidades. La Ley 28976 indica que las municipalidades deberán realizar labores de fiscalización de las actividades económicas y la revisión técnica de Seguridad en Defensa Civil Básica. Asimismo, son responsables de otorgar los permisos correspondientes para letreros exteriores de ser el caso, pudiendo el negocio ser objeto de sanción por incumplimiento de las disposiciones legales (El Peruano, 2007). Otra regulación importante es la fiscalizada por el Ministerio de Salud la cual obliga al personal que manipula alimentos o presta servicios al público a contar con el Carnet de Sanidad (Municipalidad de San Isidro, s.f.). Esto último es requisito indispensable para el modelo de negocio Salón de belleza móvil, por ser una empresa del rubro de servicios el personal deberá contar con el carnet indicado. Todo incumplimiento puedo decantar en sanciones para la empresa.

Otras de las facilidades que favorecen a las empresas son las recientes ventajas tributarias que se ofrecen a las Mypes tal como asumir solo el 30\% de los derechos de pagos por trámites ante el Ministerio de Trabajo y Promoción del Empleo, recibir el beneficio del Seguro Integral del Salud (SIS) tanto el empleador como sus colaboradores, exoneración del pago de las tasas municipales por ciertos tramites, entre otros3. Estas facilidades fomentan también la formalización de los negocios.

En resumen, las barreras de entrada para la creación e implementación de este tipo de negocios son mínimas, lo cual favorece la creación de empresas y asimismo constituye una amenaza a nivel de competencia.

\subsubsection{Análisis cultural}

La cultura en el país ha cambiado en los últimos años, estos han empujado la creación y expansión de empresas de calidad, este cambio no solo se da porque las 
empresas buscan entregar un producto o servicio de mejor calidad como un factor de diferenciación, sino que también los clientes demandan productos y servicios de calidad. El aumento en los ingresos de la población se ha traducido en cambios en los gustos y preferencias de las familias, esto hace que no solo consuman más de los productos y servicios que normalmente demandaban, sino que se encuentran en una exploración constante de nuevas ofertas y están dispuestos a pagar precios más altos por servicios y productos que perciben serán de mayor beneficio para ellos. La demanda antes descrita, hace que haya un cambio constante de las tendencias tanto en productos como en servicios debido básicamente a la gran cantidad de competidores que están buscando constantemente innovar sus productos o servicios y así tener cautivos a los consumidores.

El mercado de la salud y de la belleza está creciendo en todo el mundo y Perú no es la excepción, aunque aún queda mucho recorrido. Esto se refleja en el incremento de salones de belleza constituidos por año.

Hoy en día nadie duda que se vive en una sociedad estresada por el trabajo, las cargas financieras, los problemas familiares, entre otros. Las nuevas tecnologías han hecho la vida más fácil, pero como contrapartida han hecho la vida mucho más rápida.

Según el Instituto Nacional de Estadística e Informática (INEI) en su Boletín Estadístico Indicadores Económicos y Sociales (enero 2019) se registraron en Lima Metropolitana más de 7 millones y medio de personas con edad de desempeñar una actividad económica como se muestra en la tabla 7 , es decir, en edad productiva demandante de empleo. De este universo solo el $68.5 \%$ integra la población económicamente activa (PEA). Asimismo, indica que, de cada 100 personas, 7 se encuentran desocupados en busca de empleo (INEI, Lima Metropolitana: Población en edad de trabajar según condición de actividad, 2019). 
Tabla 7.

Lima Metropolitana: Población en edad de trabajar según condición de actividad

\begin{tabular}{|c|c|c|c|c|c|c|c|c|}
\hline \multirow{4}{*}{ CONDICIÓN DEACTIVIDAD } & \multicolumn{4}{|c|}{ ANUAL: } & \multicolumn{4}{|c|}{ TRIMESTRE MÓVIL: } \\
\hline & \multicolumn{4}{|c|}{ ENERO-DICIEMBRE } & \multicolumn{4}{|c|}{ OCTUBRE-NOVIEMBRE-DICIEMBRE } \\
\hline & & & VARIACIÓN & & & & VARIACIÓN & \\
\hline & 2017 & 2018 & $\begin{array}{c}\text { ABSOLUTA } \\
\text { (MILES) }\end{array}$ & $\begin{array}{l}\text { VARIACION } \\
(\%)\end{array}$ & 2017 & 2018 & $\begin{array}{c}\text { ABSOLUTA } \\
\text { (MILES) }\end{array}$ & $(\%)$ \\
\hline Total de población en edad de trabajar (PET) & 7596.1 & 7701.8 & 105.7 & 1.4 & 7640.4 & 7746.2 & 105.8 & 1.4 \\
\hline Población económicamente activa (PEA) & 5204.3 & 5233.2 & 28.9 & 0.6 & 5241.6 & 5307.6 & 66 & 1.3 \\
\hline . Ocupada & 4846 & 4885.1 & 39.1 & 0.8 & 4903.2 & 4982.5 & 79.3 & 1.6 \\
\hline Desocupada & 358.4 & 348.1 & -10.3 & -2.9 & 338.3 & 325.2 & -13.1 & -3.9 \\
\hline Población económicamente no activa (NO PEA) & 2391.7 & 2468.6 & 76.9 & 3.2 & 2398.8 & 2438.5 & 39.7 & 1.7 \\
\hline
\end{tabular}

El Boletín señala que el ingreso promedio mensual proveniente del trabajo de la actividad principal en Lima Metropolitana es de S/1,685.6 soles y que los hombres ganan en promedio S/549 más que las mujeres (INEI, Lima Metropolitana: Población en edad de trabajar según condición de actividad, 2019).

A nivel empresarial también se han presentado cambios sustanciales en gestión del recurso humano, tema que es considerado pilar importante para la sostenibilidad de la empresa. Las empresas en los últimos años han volcado esfuerzos y estrategias en mejorar el clima organizacional. El enfoque no solo abarca el ambiente físico y las herramientas necesarias para el cumplimiento de las labores, también está orientado a mejorar la calidad del recurso humano brindando beneficios tangibles e intangibles que impactan directamente en la productividad y eficiencia de los trabajadores, a su vez tiene un impacto positivo en la imagen o reputación de la empresa.

Los trabajadores buscan en las empresas, además de una política salarial adecuada y oportunidades de líneas de carrera, que la empresa cuente con un programa de beneficios sólido y un buen ambiente laboral. Este punto es totalmente lógico dado que los trabajadores pasan gran parte del tiempo en sus centros de labores. Es por ello que en los últimos años los programas de beneficios que diseñan las empresas incluyen poner a 
disposición de los trabajadores, en muchos casos dentro de las instalaciones de la empresa, los productos y servicios de mayor demanda como son los gimnasios, lavandería, ferias escolares, salones de belleza, entre otros. El modelo negocio Salón de belleza móvil está alineado con esta tendencia.

Por otro lado, los nuevos modelos de negocio que alcanzan un grado importante de aceptación o mejor aún éxito, suelen ser copiados o replicados rápidamente, estas copias de modelo de negocio típicamente usan estrategias de precios bajos para competir.

\subsection{Oportunidades y Amenazas}

El análisis realizado muestra oportunidades y amenazas que se describen a continuación.

\section{Oportunidades:}

- $\quad$ Precios de materiales moderados

- $\quad$ Tendencia positiva del PBI para el 2019

- Amplia oferta de vehículo debido al ingreso nuevas marcas al mercado

- Requiere poca inversión

- Creciente interés por el bienestar e imagen personal

- Empresas interesadas en mejorar su imagen empresarial

- Necesidad del mercado de atenciones oportunas y ágiles

- Inseguridad ciudadana

- Disponibilidad de avances tecnológicos para seguimiento de móviles

- Alta oferta de personal especializado

- Equipo de trabajo recién integrado

\section{Amenazas:}

- Incremento del costo del combustible

- Cambio en las tasas de Impuesto 
- Cambio constante de tendencias

- Modelo de negocio podría poco atractivo para clientes

- $\quad$ Posibles accidentes y/o imprevistos en traslados de la móvil

- $\quad$ Personal especializado en los servicios de alta demanda

En resumen y con base en los puntos mencionados se observa que las oportunidades del plan de negocio se ven favorecidas debido a la apertura de las entidades financieras en cuanto al financiamiento de los micros y pequeños negocios respaldados por las políticas adoptadas en los diferentes gobiernos, lo cual ha permitido un crecimiento sostenido del PBI en los últimos años. Adicionalmente, de la simplificación en los trámites de importación ha generado el incremento en las empresas que se contactan directamente con los fabricantes, lo cual reduce los precios finales a la hora de comprar los equipos a utilizar.

La inseguridad ciudadana que actualmente presenta el país lleva a las personas a tomar mayores precauciones al momento de trasladarse por la ciudad, lo cual puede impactar en la cantidad de actividades que realizan fuera de sus hogares. El modelo de negocio propuesto minimiza el riesgo de los clientes a ser víctimas de robos durante el desplazamiento al salón o durante la atención en el mismo.

En cuanto a las tendencias en temas de salud e imagen personal, éstas han permitido un aumento en la apertura de empresas similares porque las personas buscan mejorar su imagen. Esto ha sido aprovechado por las empresas como parte de su política en temas de clima laboral, que buscan poner a disposición de sus trabajadores ciertos beneficios que reduzcan la alta rotación de personal y mejoren la eficiencia y productividad.

Finalmente, en el tema de oportunidades el ingreso de nuevas marcas al mercado automotriz, que en su mayoría provienen de Asia, ha permitido un aumento en la competencia y oferta de vehículos, lo cual en el mercado se traduce en reducción de los precios. 


\subsection{Matriz EFE}

La Matriz de Evaluación de Factores Externos EFE (David, 2013) permite resumir y evaluar la información política, económica, social, cultural, entre otras.

En la matriz se registran los factores externos claves, oportunidades y amenazas que impactan a la empresa y a la industria a la que pertenece. Cabe indicar que los factores identificados en la matriz corresponden a un momento en el tiempo los cuales pueden variar cambiando los valores consignados.

La ponderación que se asigna a cada factor indica la relevancia que representa para alcanzar el éxito de la empresa dentro del mercado donde se desarrolla. Se asigna una ponderación entre 0.0 y 1.0, donde 0.0 corresponde a no importante y 1.0 a muy importante. La sumatoria de todas las ponderaciones que se asignen debe ser igual a 1.0 (ver tabla 8). 
Tabla 8.

Matriz EFE

\section{Factores Externos Claves}

\section{Oportunidades}

- Precios de materiales moderados

- Tendencia positiva del PBI para el 2018

- Amplia oferta de vehículo debido al ingreso nuevas marcas al mercado

- Requiere poca inversión

- Creciente interés por el bienestar e imagen personal

- Empresas interesadas en mejorar su imagen empresarial

- Necesidad del mercado de atenciones oportunas y ágiles

- Inseguridad ciudadana

- Disponibilidad de avances tecnológicos para seguimiento de móviles

- Alta oferta de personal especializado

- Equipo de trabajo recién integrado

\section{Amenazas}

- Incremento del costo del combustible

- Cambio en las tasas de Impuesto

- Cambio constante de tendencias

- Modelo de negocio podría poco atractivo para clientes

- Posibles accidentes y/o imprevistos en traslados de la móvil

- Personal especializado en los servicios de alta demanda

Total

Nota: Medios de información y revistas especializadas.

\begin{tabular}{|c|c|c|}
\hline Ponderación & Calificación & $\begin{array}{c}\text { Puntuación } \\
\text { ponderada }\end{array}$ \\
\hline 0.07 & 2 & 0.14 \\
0.05 & 2 & 0.10 \\
\hline 0.08 & 2 & 0.16 \\
\hline 0.05 & 4 & 0.20 \\
\hline 0.07 & 3 & 0.21 \\
\hline 0.07 & 3 & 0.21 \\
\hline 0.07 & 2 & 0.14 \\
\hline 0.11 & 4 & 0.44 \\
\hline 0.05 & 2 & 0.10 \\
\hline 0.04 & 2 & 0.08 \\
\hline 0.03 & 2 & 0.06 \\
\hline
\end{tabular}

\begin{tabular}{|l|l|l|}
\hline 0.05 & 1 & 0.05 \\
\hline 0.06 & 1 & 0.06 \\
\hline 0.05 & 1 & 0.05 \\
\hline 0.06 & 2 & 0.12 \\
\hline 0.05 & 2 & 0.10 \\
\hline 0.04 & 2 & 0.08 \\
\hline
\end{tabular}

1.00

2.30

A cada factor se le asigna una clasificación de 1 a 4 puntos, el puntaje está asociado a la eficacia de las estrategias de la empresa. Se asigna 4 = la respuesta es superior, 3 = la respuesta está por encima del promedio, $2=$ la respuesta es promedio y $1=$ la respuesta es deficiente (David, 2013).

Al multiplicar la ponderación con la clasificación se obtiene la puntuación ponderada.

Luego de analizar la matriz EFE se puede identificar que la propuesta presenta un resultado de 2.30, lo que indica que la empresa, a pesar de no estar llegando a un promedio de 2.50, muestra el aprovechamiento de las oportunidades sobe la amenazas que se presentan, ya 
que existen oportunidades con indicadores de 3 y 4 valiendo la pena resaltar el tema de inseguridad ciudadana y la poca inversión como oportunidades.

El puntaje obtenido es el resultado de la evaluación realizada, la cual se muestra en la matriz que antecede.

En la matriz se aprecia que en relación a las oportunidades se otorga una calificación de 4 a la las siguientes:

- Inseguridad ciudadana, debido a que al presentar un modelo de negocio que elimina la variable del desplazamiento de clientes otorga una ventaja insuperable versus los locales tradicionales.

- Requiere poca inversión en comparación con negocios similares de mayor envergadura (locales fijos), siendo el tema de la compra de la móvil y su equipamiento el más representativo.

En la matriz se aprecia que en relación a las oportunidades se otorga una calificación de 3 a las siguientes:

- Creciente interés por el bienestar e imagen personal, debido a que las estrategias de la empresa están orientadas a satisfacer las necesidades del mercado en cuanto a imagen y bienestar, temas que han tomado relevancia en los últimos años por el estilo de vida actual.

- Empresas interesadas en mejorar su imagen empresarial, otra arista importante en la cual se basan las estrategias de la empresa dado que las organizaciones a nivel mundial buscan consolidarse en la sociedad como empresas de prestigio y calidad, resultando crucial el concepto que posean sus trabajadores quienes son el pilar fundamental de toda organización.

En relación a las amenazas se otorga calificación de 1 a cuatro factores en los que se considera que la respuesta de la empresa será deficiente: 
- Incremento del costo del combustible ya que históricamente en el país los precios tienden al alza, independientemente de la situación fuera de las fronteras. Cabe señalar que esto es un factor clave ya que es un insumo primario para poder brindar el servicio móvil.

- Cambios en las tasas del impuesto como por ejemplo el selectivo al consumo el cual afecta también al combustible. La respuesta de la empresa a este factor es deficiente dado que la única acción a realizar sería el cambio a GNV o GLP, lo cual incrementaría la inversión.

- El cambio constante de tendencias en negocios como el propuesto con una capacidad instalada reducida, por muy eficiente que sea, impactaría en gran medida ya que representaría una reestructuración en el modelo de negocio, la cual no estaría contemplada en la inversión a corto plazo.

A los otros factores, oportunidades y amenazas, identificados en la matriz se les ha otorgado la calificación de 2 debido a que las estrategias a implementar para afrontar estos factores se encuentran dentro del promedio. 


\section{Capítulo III: Estudio de Mercado}

"Un mercado es el conjunto de todos los compradores reales y potenciales de un producto o servicio. Tales compradores comparten una necesidad o un deseo en particular, el cual puede satisfacerse mediante relaciones de intercambio.” (Kotler \& Armstrong, 2012)

El estudio de la propuesta se realizará a través de la investigación cualitativa y cuantitativa del mercado, las cuales permitirán conocer la viabilidad del modelo de negocio planteado.

\subsection{Descripción del Producto o Servicio}

La propuesta descrita en el presente plan de negocios se basa en brindar los servicios de belleza de mayor demanda a las colaboradoras del sector financiero privado a través de un Salón de belleza móvil que visitará las instalaciones de sus centros de trabajo.

Para ello se requiere:

- Cerrar previamente un acuerdo de servicio con las empresas del sector financiero en donde se autorice el ingreso del Salón de belleza móvil a sus instalaciones.

- Definir la frecuencia y horarios de atención del Salón de belleza móvil en las instalaciones de las empresas del sector financiero.

- Comprar y adecuar la unidad móvil con módulos para la atención de los servicios y custodia de los productos.

- Comprar el resto de activos y productos necesarios para la atención de los servicios.

- Contratar personal calificado para ejecutar la atención de los servicios.

Los servicios se brindarán a través de un Salón de belleza móvil que visitará las instalaciones de las empresas, lo cual permitirá al cliente recibir un tratamiento ágil, oportuno y de calidad en un ambiente agradable sin alejarse de las instalaciones de su centro de labores. 
Se pretende contribuir con los indicadores de clima laboral de las empresas partícipes al ofrecer un servicio oportuno en sus instalaciones, lo cual será percibido por el colaborador como un beneficio extra otorgado por el empleador.

\subsection{Selección del Segmento de Mercado}

En el presente plan de negocios se utiliza la segmentación a priori, la cual no se basa exclusivamente en estudios previos por lo que se decide analizar directamente el sector financiero privado, más específicamente dos de las sedes principales del Banco de Crédito del Perú (BCP) y de Interbank.

Dentro de las empresas del sector financiero privado se eligen las sedes principales ubicadas en Chorrillos - BCP y en La Victoria - Interbank debido a que concentran una parte importante del personal de áreas administrativas donde alrededor del $50 \%$ del total de colaboradores es personal femenino el cual se explica a continuación.

Según la Súper Intendencia de Banca, Seguros y AFP, existen 63,107 colaboradores empleados en la Banca Múltiple (SBS, 2018). Si se toma en cuenta solo los trabajadores de las sedes antes mencionadas llegamos a la información incluida en la tabla 9.

Tabla 9.

Cantidad de colaboradores por entidad bancaria en sedes elegidas

\section{Empresas $\quad$ Empleados}

Interbank

B. de Crédito del Perú

Total

5,579

En adición a lo mencionado, según el INEI la proporción de mujeres de la PEA de Lima Metropolitana que es 46.2\% (2`439,800 de un total de 5’276,100) (INEI, Informe-tecnico-deempleo-lima-metropolitana-febrero2019. , 2019) Es preciso señalar que la información 
mostrada en la tabla 10 fue proporcionada por los gerentes entrevistados de cada una de las entidades bancarias elegidas para el modelo de negocio la cual se aproxima de forma prácticamente exacta a lo indicado por el INEI en relación a la PEA de Lima Metropolitana.

Tabla 10.

Cantidad de colaboradores mujeres por entidad bancaria en sedes elegidas

\begin{tabular}{lc}
\hline Empresas & Mujeres \\
Interbank & 662 \\
B. de Crédito del Perú & 1,916 \\
Total & 2,578 \\
\hline
\end{tabular}

Asimismo, como se había mencionado en puntos anteriores, el estilo de vida del segmento elegido está orientado a la búsqueda del cuidado de la imagen personal y su nivel de ingresos les permite acceder con una frecuencia regular a estos servicios, en los cuales demandan calidad y agilidad.

Si se toma en cuenta que, en los edificios corporativos de las empresas, que son las ubicaciones a las que apunta este modelo de negocio, trabajan los colaboradores que perciben ingresos más altos en comparación con otras sedes, como las agencias de atención al público por ejemplo, y adonde además se concentra toda la plana gerencial y posiciones medias-altas se puedo inferir que estos colaboradores tienen preferencias que encajan con los servicios propuestos ya que por su costo están directamente relacionados con los ingresos de los mismos. Adicionalmente a lo antes mencionado, se pudo conocer que la población correspondiente a los niveles socioeconómicos A, B y C ha sufrido variaciones al alza (Arellano, 2019), la llamada clase C paso de un 20\% en el año 2000 a un $43 \%$ en 2017; mientras que las clases A y B pasaron de 10\% en su conjunto en el año 2000 a 5\% y 20\% para el 2017 respectivamente. 
En resumen, la selección del segmento de mercado se basa en los criterios de segmentación mostrados en la tabla 11.

Tabla 11.

Criterios de segmentación para la selección de mercado

Geográficos Sedes principales del sector financiero ubicadas en Lima.

Demográficos Concentración del 50\% de trabajadoras.

Conductuales Uso frecuente del servicio.

Adicionalmente, el servicio propuesto está orientado a las colaboradoras de las empresas del sector financiero privado que cuentan con estrategias enfocadas en el recurso humano, destinadas a la búsqueda del bienestar global de sus colaboradores (ver tabla 12).

Tabla 12.

Resumen de determinación de mercado

$\begin{array}{llr}\text { Universo } & \text { Según tabla } 10 & 2,578\end{array}$

Mercado potencial $\quad$ Según pregunta de la encuesta: ¿Asiste Ud. a salones $\quad 2,391$ de belleza?, $321 / 346=92.8 \%$

Mercado disponible Según pregunta de la encuesta: Si tuviera un salón que 2,212 brinde los servicios de manicura, planchado y cepillado de cabello dentro de su centro de labores, ¿se atendería?, 297 / $321=92.5 \%$

Mercado efectivo Según pregunta de la encuesta: ¿Cuánto más estaría dispuesta a pagar en un salón dentro de su centro laboral? $269 / 297=90.6 \%$

Mercado objetivo Según tabla 39 


\subsection{Investigación Cualitativa}

La investigación cualitativa permite conocer la percepción, motivación e intereses de las personas entrevistadas, lo cual sirve de base para las conclusiones del análisis cualitativo y cuantitativo.

Con la investigación de tipo exploratoria se identifican los patrones de consumo y con la investigación orientativa se conoce el entorno.

La investigación impacta también en la determinación de los estimados en temas de presupuesto, al conocer las preferencias y expectativas de los consumidores en relación a la calidad del servicio y características de los productos a utilizar.

\subsubsection{Proceso de muestra}

El modelo de negocio propuesto presenta una demanda derivada dado que no se ofrece directamente los servicios al consumidor final.

En la investigación se utilizaron las herramientas Entrevistas y Focus Group las cuales permitieron identificar a los dos grupos de clientes.

En la primera fase la investigación se basó en realizar entrevistas a dos gerentes del Área de Gestión y Desarrollo Humano de las instituciones financieras que cuentan con instalaciones propicias que facilitan brindar el servicio propuesto.

Se realizaron entrevistas a Bernardo Sambra Graña, Gerente de RRHH del BCP y a Eduardo Barriga, Sub Gerente de Cultura y Bienestar en Interbank. Debido a sus recargadas agendas se realizaron preguntas puntuales sobre las actividades que realizan para crear un ambiente laboral favorable para el trabajador.

La segunda fase en la obtención de información fueron las entrevistas a especialistas en el rubro de salones de belleza, para lo cual se realizaron entrevistas a Carlos Ramirez, Gerente de Operaciones de SOHO Color y a Christian Fernandez, Jefe de Marca del Salón de Belleza Montalvo (ver anexo C). 
La tercera fase fue para identificar al segundo grupo de clientes, quienes son los usuarios finales de los servicios a brindar. Mediante Focus Group a tres grupos integrados por personal femenino de los bancos que son parte del presente proyecto y se pudo conocer los principales factores de éxito y preferencias (ver anexo A).

\subsubsection{Diseño del instrumento.}

Las entrevistas realizadas se diseñaron con el fin de conocer las políticas de la empresa en cuanto a beneficios de este tipo para sus colaboradores. En la entrevista participaron un Gerente y un Sub Gerente del Área de Gestión y Desarrollo Humano de una de los bancos considerado para implementar la idea de negocio (Banco de Crédito del Perú e Interbank) y quienes como parte de sus funciones son responsables de gestionar la creación, desarrollo y propuestas de beneficios para los colaboradores.

Las preguntas y respuestas (resumen) elaboradas fueron:

- ¿Existe una política de bienestar para el trabajador en sus instituciones?

Respuesta. Si existe, esto se traduce con convenios entre las entidades bancarias y algunas empresas que brindan descuentos en sus productos y servicios ofrecidos solo con la presentación de alguna identificación que acredite que el trabajador labora en el banco. Además, cada cierto tiempo se permite el ingreso de empresas que ofrece la venta de productos en los mismos edificios corporativos a precios especiales.

- ¿Estas políticas incluyen beneficios fuera los negociados en sus contratos? ¿Cuáles?

Respuesta. Si, como se mencionó anteriormente se tienen campañas de ofertas para los colaboradores.

- ¿Existen convenios con empresas de diferentes rubros para brindarles a sus trabajadores servicios exclusivos? 
Respuesta. Efectivamente, las ofertas y campañas son de cualquier rubro; venta de perfumes, joyería, entradas al cine y teatro, accesorios de vestir femeninos y masculinos, licores, etc.

- ¿Estos beneficios también son brindados dentro de los locales de trabajo?

Respuesta. Sí, siempre y cuando la logística no sea muy elaborada debido a que ocupan un espacio de libre circulación para el personal del banco.

- ¿Estarían dispuestos a recibir el servicio de Salón de belleza móvil dentro de sus instalaciones?

Respuesta. Sí, siempre y cuando se coordinen oportunamente las necesidades de espacio, en el caso de la propuesta de negocio se muestra una ventaja ya que no se utilizarían espacios de libre circulación dentro del propio edificio.

- ¿En qué horarios cree usted que se puede brindar el servicio?

Respuesta. El tema del horario les es indiferente ya que conocen que las labores que se realizan en las oficinas corporativas son de horario flexible.

- ¿Existen barreras más allá de las legales para realizar el servicio dentro de sus instalaciones?

Respuesta. Ninguna.

- ¿Qué tipos de medio de difusión existen para hacer conocer los beneficios brindados?

Respuesta. Boletines internos (virtuales) murales y volantes (entregados por el propio personal de la empresa interesada en brindar sus servicios).

Las preguntas realizadas estuvieron orientadas a obtener la siguiente información:

- Interés en la propuesta de servicio: interés en contar con el servicio de manicura, cepillado y planchado del cabello dirigido a colaboradoras en horarios previamente pactados que no afecte la productividad. 
- Locación: disponibilidad de espacio en sus instalaciones para la unidad móvil.

- Horarios de atención: tiempo máximo de atención por persona (30 minutos)

- Flexibilidad de horarios: para brindar el servicio desde las 10:00 am. a 05:00 pm.

- Requerimientos técnicos: solicitados por la empresa.

- Permisos: necesarios por parte de las áreas de seguridad de la empresa.

- Difusión interna: por parte de la empresa a sus colaboradoras sobre el servicio.

Las respuestas a estas interrogantes fueron positivas ya que no solo al ser instituciones muy preocupadas por el bienestar de sus empleados, se mostraron abiertos a la posibilidad de recibir negocios de diferentes rubros dentro de sus instalaciones, siempre y cuando cumplan con las condiciones requeridas para ello, sino que se facilitó información muy importante para el delineado de la idea de negocio (ver anexo B).

En cuando a las entrevistas realizadas a los especialistas en el rubro de salones de belleza las preguntas que afianzaron los criterios tomados en cuenta para los FCE de la MPC (ver tabla 4) fueron las siguientes:

- ¿Qué es lo que buscan sus clientes al acudir a sus establecimientos?

- ¿Cuáles son los servicios que más solicitan sus clientes?

- ¿Qué tipo de productos son los más solicitados por los clientes?

- ¿Cómo determinaron la ubicación de sus locales?

- ¿Cómo se fijan los precios de los servicios prestados?

- ¿Cuál es el tiempo promedio de atención para los servicios de manicura?

- ¿La cercanía a los clientes se puede considerar una ventaja diferencial?

Los resultados de ambas entrevistas fueron los siguientes (ver tabla 13).

Las respuestas obtenidas mostraron diferentes criterios en los factores descritos, ya que a pesar de que ambos negocios pertenecen al mismo rubro, están orientadas a diferentes segmentos del mercado. 
Tabla 13.

Respuestas de la entrevista a expertos

Carlos Ramirez - Soho Color

Christian Fernandez - Montalvo

- Lugar para relajarse y obtener un - Servicio de calidad, con personal experimentado buen servicio

- Tratamientos para el cabello, - Cortes de cabello, peinados, manicura y pedicure manicura y pedicure, cortes y peinados

- Tintes para el cabello Koleston de Wella, L'oreal, Garnier

- Tintes para el cabello Wella, L'oreal, Clairol, Garnier

- Esmalte para uñas OPI, Masglo, Esika, Revlon y Unique.

- Tráfico de personas, ubicación cerca a paraderos importantes en los distritos

- Esmalte para uñas OPI, Masglo y Esika.

Los precios son definidos por la ubicación de los locales, varían de acuerdo al distrito. Pero oscilan entre S/ 20 y $\mathrm{S} / 30$ soles dependiendo también del tipo de producto a utilizar.

- Los tiempos promedio son de 25 o 30 minutos, pero depende mucho del estilo solicitado. Si es un servicio express no debería demorar más de 30 minutos por la misma naturaleza de lo buscado por el cliente.

- El estar cerca de los clientes reduce la posibilidad de que estos se trasladen y encuentren locales que brinden servicios similares, sin duda es una ventaja diferencial, más aún si la calidad es superior.

- Dentro de Centros Comerciales y en zonas donde se encuentran oficinas y locales con mucha masa laboral.

- Los precios son definidos por la gerencia ya que son los mismos en todos los locales.

- Los tiempos son muy relativos ya que depende de la familiaridad que llegue a tener el cliente y el empleado; así como del servicio requerido, tratamientos simples van de 20 a 40 minutos, mientras que los más elaborados van de 30 a 50 minutos.

- Definitivamente. La ubicación es un factor sumamente importante y claramente una ventaja diferencial. El hecho de que el cliente no deba trasladarse para encontrar el servicio que requiere es un factor a tomar en cuenta ya que te muestra como una opción siempre disponible; sin embargo, no sirve de nada si el servicio o experiencia no es la buscada. 
Cabe señalar que las entrevistas no fueron en su totalidad estructuradas, lo cual permitió cumplir con las preguntas previamente preparadas y recabar opiniones y sugerencias por parte de los entrevistados (ver anexo D).

La información levantada también servirá de base para futuras entrevistas que se establezcan con responsables de otros bancos del sector financiero donde se apunte a ingresar para brindar el servicio propuesto.

De las respuestas obtenidas por los expertos podemos concluir:

- Se debe brindar más de un servicio a los clientes, calidad en el servicio y contar con personal experimentado.

- Los servicios más demandados son arreglo del cabello, manicura y pedicura.

- Las marcas más solicitadas por los clientes para el cabello son: Lóreal, Clairol, Koleston de Wella, L’oreal, Garnier y para uñas son: OPI, Masglo, Esika y Revlon.

- Los servicios para uñas fluctúan entre S/ 25 y S/ 60.

- La ubicación debe considerar el garantizar el alto tráfico de personas.

- El tiempo promedio de los servicios es de 32 minutos.

- Dependiendo de la ubicación del local se puede asegurar el conocimiento de los gustos del cliente, cuando estos son asiduos.

- La ambientación del local es de suma importancia.

En cuanto al Focus Group las preguntas que se realizaron a las participantes estuvieron enfocadas a identificar:

- Frecuencia de visita al salón para servicio de manicura, cepillado y planchado del cabello

- Precios

- Marcas de productos

- Tipos de servicios 
- Tiempos de espera promedio

- Calidad esperada

- Interés en la propuesta (ahorro de tiempo)

Durante esta reunión el moderador, quien conforma parte del equipo responsable de la propuesta de negocio, tuvo como premisa que cada una de las participantes brindara su opinión acerca del modelo propuesto. Esto con la finalidad de obtener de forma directa las sugerencias de las personas que son parte de las empresas que conforman el público objetivo, información importante que impacta en la probabilidad de lograr la aceptación del servicio de manicura, cepillado y planchado del cabello dentro de los centros de labores.

Asimismo, permitió conocer las preferencias de los posibles clientes en cuanto a marcas, tipos de servicios más solicitados, promedio de precios, ubicación de los locales, servicios adicionales y sobre todo la disposición para atenderse dentro de sus centros de labores en determinados horarios, esta información se contrastó con las respuestas brindadas en las entrevistas con los especialistas.

\subsubsection{Análisis y procesamiento de datos}

Al finalizar las entrevistas se identificó que las empresas del sector financiero contemplan la idea de concesionar ciertos servicios dentro de sus propias instalaciones, los cuales cubran limitaciones internas y beneficien directamente al personal. Algunos servicios como lavanderías, tiendas de regalos, entre otros funcionan actualmente en las empresas del sector.

La limitación principal de las empresas es el espacio físico para brindar directamente estos beneficios a sus colaboradores, lo cual también demanda una inversión de la que no pueden asegurar obtengan el retorno económico y la satisfacción que esperan por parte de los colaboradores. Es justamente este punto el que conversa con 
la propuesta, orientada a cubrir dicha brecha al ofrecer el servicio completo de manicura, cepillado y planchado del cabello, incluyendo locación y equipos, con lo cual solo es necesario que la empresa facilite un espacio disponible, por ejemplo, el estacionamiento y las autorizaciones necesarias para iniciar la ejecución.

En cuanto al horario de funcionamiento deberá ser coordinado previamente con el empleador a través de un acuerdo de servicio donde se consigne las responsabilidades y obligaciones de ambas partes, teniendo como premisa no afectar la productividad de la empresa.

A través del Focus Group se obtuvo información de la frecuencia con la que se requiere el servicio de manicura, cepillado y planchado del cabello, las cuales podrían varían a razón de la edad, carga familiar y el estado civil de las participantes obteniendo como resultado promedio una frecuencia quincenal. Asimismo, se identificó que las mujeres sin hijos y que viven con varios familiares se atienden o estarían dispuestas a optar por el servicio con una frecuencia espaciada, dado que conservarían mejor sus manos al no realizar tareas domésticas con regularidad. En cambio, las mujeres con hijos estarían dispuestas a que se les realice el servicio con mayor frecuencia debido al desgaste natural que sufren sus manos al realizar las labores cotidianas.

Se obtuvo también información del tiempo estimado de espera en los salones de belleza, los cuales varían de acuerdo a la cantidad de clientes que concurren a estos locales y al número de personal especializado con el que cuentan, resultando como tiempo promedio de espera 20 minutos. El tiempo de espera también está relacionado al precio y tipo de servicio que requieren las clientes, debido a que si solicitan un servicio con materiales que no encuentran en todos los locales o con estilos que demoran un poco más en el diseño están dispuestas a esperar más tiempo y a incurrir en un gasto mayor al que realizarían si solo acuden por un servicio básico o de un solo color. 
Durante la reunión se recabó información sobre otros motivos que llevan a las clientes a acudir a este tipo de locales y mencionaron temas como el tipo de instalaciones, la calidad en la atención, precios y promociones, obteniendo como resultado de este último punto costos que varían entre S/ 15 a S/ 50 dependiendo del tipo de servicio de manicura, para el caso del planchado y cepillado el costo promedio del servicio obtenido está alrededor de S/ 30. También mencionaron las marcas de productos que más utilizan y aunque la gran mayoría mencionó una en especial (OPI), surgieron algunas otras opciones que se considerarán en la encuesta realizada.

La persona encargada de moderar el Focus Group consultó sobre la ubicación de los salones de belleza a los que más acuden, es decir, si se encontraban más cerca a sus hogares o a su centro de labores y las opiniones se dividieron. Luego de este punto se les dio la posibilidad de comentar su disposición a atenderse en un local que se ubique dentro de su centro de labores con todas las comodidades y facilidades necesarias para brindar este tipo de servicio, en horarios previamente coordinados con sus empleadores, a lo que se obtuvo respuesta positiva sobre todo en el tema del tiempo que podrían ahorrar al no trasladarse de un lugar a otro, sumado al tráfico y los pocos estacionamientos que existen en Lima.

En resumen, con ambas herramientas se identificó como conclusión principal que la propuesta de negocio es aceptada en el sector, tanto el empleador como las potenciales clientes que forman parte del sector al cual se dirige la propuesta.

Asimismo, esta información permitió obtener las pautas necesarias para el desarrollo de las encuestas, las cuales pasaron a formar parte del análisis cuantitativo.

Ubicación de los locales: por disponibilidad de tiempo optan por salones de uñas cercanos al centro de labores, para poder asistir en días de semana, o al domicilio, donde asisten los fines de semana. 


\subsection{Investigación Cuantitativa}

En la investigación cuantitativa se usará la herramienta encuesta. Para el diseño de esta encuesta se usará como entrada el resultado de la investigación cualitativa. Se ahondará en las variables encontradas en el Focus Group. Variables como frecuencia de visita, tiempo de espera, precios, marcas usadas, tipo de servicios más solicitados, ubicación entre otras.

A su vez, se estima recabar información relevante que permita estimar los costos en los que se incurrirán en el modelo de negocio propuesto, estos costos permitirán determinar el presupuesto pre-operativo y post-operativo de la propuesta.

\subsubsection{Proceso de muestra.}

Para el presente trabajo, se ha utilizado el método de muestreo no probabilístico por conveniencia (Carl McDaniel, Jr. y Roger Gates, 2016) dado que los elementos de la muestra no han sido elegidos de forma aleatoria, es decir, han sido elegidos por conveniencia porque llegar a ellos es fácil y poco costoso los cuales a su vez son restricciones de este estudio.

Dado que se utilizará un método del muestreo no probabilístico, el tamaño mínimo debería ser de 500 muestras (Malhotra, Naresh K., 2020), sin embargo por las restricciones antes mencionadas se hicieron tantas como se pudieron hacer llegado a una muestra de 346 personas.

\subsubsection{Diseño de instrumento.}

Para el desarrollo de la encuesta se consideraron grupos de preguntas, cada grupo con un propósito definido (ver anexo E).

La primera pregunta que conforma el primer grupo de preguntas valida el uso del servicio de manicura, cepillado y planchado del cabello en un centro especializado. 
El segundo grupo está conformado por seis preguntas que recogen información acerca de la frecuencia, cercanía, tiempos, fidelización e importancia de acudir a salones de belleza.

Las siguientes cuatro preguntas que conforman el tercer grupo de preguntas recogen información acerca de la frecuencia, tipo de servicio, costos y marcas solicitadas en relación al servicio de manicura.

Las siguientes tres preguntas que conforman el cuarto grupo de preguntas recogen información acerca de la frecuencia, tipo de servicio y costos en relación al servicio de cepillado y planchado de cabello.

Las siguientes tres preguntas que conforman el quinto grupo presentan el modelo de negocio propuesto con el fin de conocer el nivel de aceptación, pago adicional y los horarios en lo que preferirían tomar el servicio.

Asimismo, se incluyen dos preguntas que tienen como fin conocer el motivo por el cual algunas encuestadas manifestarían que no asisten a salones de belleza y no tienen interés en el modelo de negocio propuesto.

Finalmente se tiene el sexto grupo de preguntas que recaba información general de la encuestada.

La encuesta fue realizada a través del servicio gratuito proporcionado por los formularios de Google (ver anexo F) el cual permite la distribución de las encuestas de manera rápida y proporciona resultados en tiempo real. Las encuestas fueron distribuidas entre mujeres que laboran en entidades bancarias realizando funciones administrativas.

Cabe indicar que en algunas preguntas se utilizó escala dicotómica para obtener información directa acerca del interés en el servicio propuesto y para facilitar la experiencia del usuario en relación a la encuesta. Asimismo, con este tipo de escala se evita tratar con respuestas neutras las cuales pueden dificultar el análisis. 


\subsubsection{Análisis y procesamiento de datos.}

De acuerdo al punto 3.3.1, la cantidad de encuestas requeridas es de 338 y la cantidad de encuestas realizadas fue de 346.

A continuación, se detalla el resultado de las encuestas según cada pregunta (ver tabla 14):

- Pregunta 1.- ¿Asiste Ud. a salones de belleza?

Tabla 14.

Validación del uso de servicios en salones de belleza

\section{Respuestas Cantidad Porcentaje}

No

25

$7.1 \%$

Si

321

$92.9 \%$

Total

346

$100 \%$

Esta pregunta sirvió como filtro para conocer la cantidad de encuestadas que actualmente acuden a salones de belleza. Las que respondieron "Sí" continuaron con las demás preguntas de la encuesta. A las que contestaron "No" se les preguntó la razón/motivo de su respuesta: 
- Pregunta sobre la razón o motivo por el cual no asiste a salones de belleza ¿Por qué no? (ver tabla 15)

Tabla 15.

Razón por la cual no asisten a salones de belleza

\begin{tabular}{lcc}
\hline Respuestas & Cantidad & Porcentaje \\
\hline Falta de tiempo para ir al salón & 15 & $60.0 \%$ \\
No tengo un salón cercano & 5 & $22.0 \%$ \\
Yo misma me atiendo & 5 & $22.0 \%$ \\
Total & & $\mathbf{1 0 0 \%}$
\end{tabular}

Las encuestadas que hayan marcado las opciones "Falta de tiempo" o "Lugares poco higiénicos" son consideradas como potenciales clientes, por ello se las deriva a la pregunta 15 de la sección relacionada al modelo del negocio propuesto. Si marcan las otras dos posibles respuestas se las deriva al último grupo de preguntas relacionadas a información general de la encuestada.

En la siguiente sección se obtiene información sobre la frecuencia, ubicación, tiempos, fidelización e importancia de contar un salón de belleza cercano.

- $\quad$ Pregunta 2.- ¿Acude Ud. siempre al mismo salón de belleza? (ver tabla 16)

Tabla 16.

Nivel de fidelización actual

\begin{tabular}{lcc}
\hline Respuestas & Cantidad & Porcentaje \\
\hline Sí & 183 & $57.0 \%$ \\
No & 138 & $43.0 \%$ \\
Total & 213 & $100 \%$ \\
& & \\
\hline
\end{tabular}


Según se observa, la fidelización actual de las encuestadas un poco más de la mitad, será importante analizar más adelante cuántas encuestadas aceptarían el modelo de negocio propuesto de este grupo fidelizado.

- $\quad$ Pregunta 3.- ¿Por qué acude a estos salones de belleza en particular? (ver tabla 17)

Tabla 17.

Motivación para ir a los salones de belleza actual

\begin{tabular}{lcc}
\hline Respuestas & Cantidad & Porcentaje \\
\hline Cercanía & 122 & $66.7 \%$ \\
Rapidez en la atención & 64 & $35.0 \%$ \\
Amabilidad del personal & 29 & $15.8 \%$ \\
Conversación del personal & 22 & $12.0 \%$ \\
Confianza en la calidad de los servicios & 87 & $47.5 \%$ \\
Ya me conocen & 58 & $31.7 \%$ \\
Precio & 62 & $33.9 \%$ \\
Total & $\mathbf{1 8 3}$ & \\
\hline
\end{tabular}

En este cuadro se observa que la principal razón de la fidelización de las encuestadas hacia los salones de belleza es la cercanía a estos, este dato es muy importante de cara a la propuesta de negocio del presente trabajo. 
- $\quad$ Pregunta 4.- Los salones de belleza a los que asiste generalmente (ver tabla 18):

Tabla 18.

Distancia relativa del salón de belleza al que asisten

\begin{tabular}{lcc}
\hline Respuestas & Cantidad & Porcentaje \\
\hline Están cerca de su casa & 197 & $61.4 \%$ \\
Están cerca de su trabajo & 45 & $14.0 \%$ \\
No está cerca a casa ni al trabajo & 79 & $24.6 \%$ \\
Total & $\mathbf{3 2 1}$ & $\mathbf{1 0 0 \%}$ \\
\hline
\end{tabular}

La mayor parte de las encuestadas acude a salones de belleza cercanos a su casa. En adición a esto, se observa que de las 197 encuestadas que acuden a salones de belleza cercanos a su casa, el 89.3\% (109 de 122) valoraron la Cercanía según la pregunta anterior.

- $\quad$ Pregunta 5.- ¿Cuánto tiempo emplea Ud. para trasladarse al salón de belleza? (ver tabla 19)

Tabla 19.

Tiempo empleado para trasladarse a los salones de belleza

Respuestas Cantidad Porcentaje

\begin{tabular}{lll}
\hline Hasta 10 minutos & 103 & $32.1 \%$
\end{tabular}

De 10 a 20 minutos $\quad 98 \quad 30.5 \%$

De 20 a 30 minutos $\quad 79 \quad 24.6 \%$

De 30 a una hora

$35 \quad 10.9 \%$

Más de una hora

$6 \quad 1.9 \%$

Total

$321 \quad 100 \%$


E1 $87.2 \%$ de las encuestadas emplean menos de media hora en trasladarse a salones de belleza, se puede inferir que valoran mucho el tiempo.

- $\quad$ Pregunta 6.- ¿Qué tan importante es tener un salón de belleza cerca de Ud.?

Las respuestas a esta pregunta están en base a la escala de Likert, donde 1 corresponde a No importante y 5 a Muy importante (ver tabla 20).

Tabla 20.

Grado de importancia de cercanía de un salón de belleza

\begin{tabular}{lcc}
\hline Respuestas & Cantidad & Porcentaje \\
\hline 1 - Nada importante & 3 & $0.9 \%$ \\
2 - Poco importante & 7 & $2.2 \%$ \\
3 - Me es indiferente & 43 & $13.4 \%$ \\
4 - Importante & 157 & $48.9 \%$ \\
5 - Muy importante & 111 & $34.6 \%$ \\
Total & $\mathbf{3 2 1}$ & $\mathbf{1 0 0 \%}$ \\
\end{tabular}

Para el $83.5 \%$ de las encuestadas es importante tener un salón de belleza cerca, respuesta que va alineada con las preguntas relacionadas con el tiempo de traslado y preferencia de salón. 
- $\quad$ Pregunta 7.- ¿Con qué frecuencia acude Ud. a salones de belleza? (ver tabla 21)

Tabla 21.

Frecuencia de asistencia a salones de belleza

\begin{tabular}{lcc}
\hline Respuestas & Cantidad & Porcentaje \\
\hline Semanalmente o con más frecuencia & 18 & $5.6 \%$ \\
Quincenalmente & 91 & $28.3 \%$ \\
Cada tres semanas & 120 & $37.4 \%$ \\
Mensualmente & 85 & $26.5 \%$ \\
Menos de una vez al mes & 7 & $2.2 \%$ \\
Total & & $\mathbf{1 0 0 \%}$
\end{tabular}

Con los datos de esta tabla se ha calculado frecuencia de visita mensual y semanal a salones de belleza (ver tabla 22).

Tabla 22.

Frecuencia de visita mensual a salones de belleza

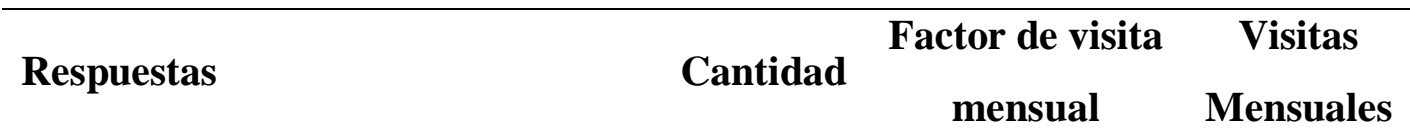

\begin{tabular}{lccc}
\hline Semanalmente o con más frecuencia & 18 & 4.00 & 72 \\
$\begin{array}{lcc}\text { Quincenalmente } \\
\text { Cada tres semanas }\end{array}$ & 91 & 2.00 & 182 \\
Mensualmente & 120 & 1.33 & 160 \\
Total & 85 & 1.00 & 85 \\
& $\mathbf{3 1 4}$ & & $\mathbf{4 9 9}$ \\
\hline
\end{tabular}

Según la tabla de arriba podrían haber hasta 499 visitas para 314 encuestadas, lo que significa que en promedio dichas personas asistirían 1.6 veces al mes. 
Las siguientes cuatro preguntas tuvieron como finalidad conocer las preferencias de las encuestadas en cuanto al cuidado de las manos: frecuencia, costos, marcas y servicios de manicura solicitados.

- $\quad$ Pregunta 8.- ¿Cuánto tiempo invierte Ud. en el salón de belleza? (ver tabla 23)

Tabla 23.

Tiempo de servicio en salones de belleza

\begin{tabular}{lcc}
\hline Respuestas & Cantidad & Porcentaje \\
\hline Hasta 30 minutos & 14 & $4.4 \%$ \\
Hasta 1 hora & 123 & $38.3 \%$ \\
Hasta 2 horas & 142 & $44.2 \%$ \\
Más de 2 horas & 42 & $13.1 \%$ \\
Total & $\mathbf{3 2 1}$ & $\mathbf{1 0 0 \%}$ \\
\hline
\end{tabular}

Según esta tabla, cerca del $95.6 \%$ de las encuestadas invierten de una hora a más en los salones de belleza más allá del tiempo de traslado. Se puede inferir que durante este tiempo deja de lado otras actividades o tiempo en familia para poder atenderse en el salón. 
- Pregunta 9.- En términos de frecuencia con que los solicita, ordene estos servicios (ver tabla 24)

Tabla 24.

\begin{tabular}{lcccc} 
Orden de preferencia de servicios solicitados en salones de belleza \\
\hline Respuestas & $\mathbf{1}$ & $\mathbf{2}$ & $\mathbf{3}$ & $\mathbf{4}$
\end{tabular}

\begin{tabular}{lllll}
\hline Manicure & 262 & 35 & 11 & 13
\end{tabular}

$\begin{array}{lllll}\text { Planchado / Cepillado } & 73 & 161 & 60 & 27\end{array}$

$\begin{array}{lllll}\text { Corte de cabello } & 15 & 62 & 143 & 101\end{array}$

$\begin{array}{lllll}\text { Tratamientos faciales } & 16 & 41 & 97 & 167\end{array}$

El orden de preferencia de los servicios consultados en la encuesta es: en primer lugar la manicura, luego los tratamientos faciales, a continuación el planchado / cepillado y finalmente el corte de cabello.

- $\quad$ Pregunta 10.- ¿Con qué frecuencia solicita el servicio de manicura? (ver tabla 25)

Tabla 25.

Frecuencia del uso del servicio de manicura

Respuestas Cantidad Porcentaje

\begin{tabular}{lcc}
\hline Semanalmente o con más frecuencia & 12 & $3.7 \%$ \\
Quincenalmente & 127 & $39.6 \%$ \\
Cada tres semanas & 91 & $28.3 \%$ \\
Mensualmente & 70 & $21.8 \%$ \\
Menos de una vez al mes & 18 & $5.6 \%$ \\
Nunca & 3 & $0.9 \%$ \\
Total & $\mathbf{3 2 1}$ & $\mathbf{1 0 0 \%}$ \\
\hline
\end{tabular}


Con los datos de esta tabla se ha calculado frecuencia de visita mensual y semanal a salones de belleza para el servicio de manicura (ver tabla 26).

Tabla 26.

Frecuencia de visita mensual por el servicio de manicura

\begin{tabular}{lccc}
\hline Respuestas & Cantidad & $\begin{array}{c}\text { Factor de } \\
\text { visita mensual }\end{array}$ & $\begin{array}{c}\text { Visitas } \\
\text { Mensuales }\end{array}$ \\
\hline Semanalmente o con más frecuencia & 12 & 4.00 & 48.00 \\
Quincenalmente & 127 & 2.00 & 254.00 \\
Cada tres semanas & 91 & 1.33 & 121.33 \\
Mensualmente & 70 & 1.00 & 70.00 \\
Total & $\mathbf{3 0 0}$ & & $\mathbf{4 9 3}$ \\
\end{tabular}

Según la tabla de arriba podrían haber hasta 493 visitas para 300 encuestadas, lo que significa que en promedio dichas personas asistirían 1.6 veces al mes por el servicio de manicura. 
- Pregunta 11.- ¿Qué tipo de servicio de manicura solicita con mayor frecuencia? (ver tabla 27)

Tabla 27.

Preferencias del tipo de servicio de manicura

\begin{tabular}{lcc}
\hline Respuestas & Cantidad & Porcentaje \\
\hline Acrílicas & 12 & $3.7 \%$ \\
Con diseño & 33 & $10.3 \%$ \\
Francesa & 66 & $20.6 \%$ \\
Gel & 55 & $17.1 \%$ \\
Un solo color & 155 & $48.3 \%$ \\
Total & $\mathbf{3 2 1}$ & $\mathbf{1 0 0 \%}$ \\
\hline
\end{tabular}

El servicio más solicitado es el de "Un sol color", servicio que requiere menor tiempo en comparación a los otros servicios. Este dato es importante de cara a la cantidad de atenciones diarias, por hora, que podría ejecutar el modelo de negocio propuesto. 
- $\quad$ Pregunta 12.- ¿Cuánto es el precio que usted paga en promedio por servicio de manicura? (ver tabla 28)

Tabla 28.

Costos promedio del servicio de manicura

\begin{tabular}{lcc}
\hline Respuestas & Cantidad & Porcentaje \\
\hline Menos de S/20 & 14 & $4.4 \%$ \\
Entre S/20 y S/30 & 207 & $64.5 \%$ \\
Entre S/30 y S/45 & 55 & $17.1 \%$ \\
Más de S/45 & 45 & $14.0 \%$ \\
Total & $\mathbf{3 2 1}$ & $\mathbf{1 0 0 \%}$ \\
\hline
\end{tabular}

En relación al costo, el $64.5 \%$ de las encuestadas pagan por el servicio entre S/20 y $\mathrm{S} / 30$, el cual es un precio intermedio, se puede inferir que las encuestadas buscan calidad y buen servicio, más no precios bajos necesariamente. 
- $\quad$ Pregunta 13.- ¿Qué marca de productos para manicura solicita habitualmente? (ver tabla 29)

Tabla 29.

Preferencia de marcas solicitadas para manicura

\begin{tabular}{lcc}
\hline Respuestas & Cantidad & Porcentaje \\
\hline Esika & 22 & $6.9 \%$ \\
Masglo & 103 & $32.1 \%$ \\
OPI & 170 & $53.0 \%$ \\
Revlon & 14 & $4.4 \%$ \\
Unique & 12 & $3.7 \%$ \\
Total & $\mathbf{3 2 1}$ & $\mathbf{1 0 0 \%}$ \\
\hline
\end{tabular}

Es contundente que el $53 \%$ de encuestadas prefieren la marca OPI, probablemente por su calidad y variedad de colores.

Las siguientes tres preguntas tuvieron como finalidad conocer las preferencias de las encuestadas sobre los servicios para el cabello (frecuencia, tipo de servicio y costos) sin considerar servicios de tinturado o tratamientos. 
- Pregunta 14.- ¿Con qué frecuencia solicita los servicios de planchado y/o cepillado de cabello? (ver tabla 30)

Tabla 30.

Frecuencia del uso de servicios para el cabello

\begin{tabular}{lcc}
\hline Respuestas & Cantidad & Porcentaje \\
\hline 1 vez a la semana & 9 & $2.8 \%$ \\
Cada 2 semanas & 35 & $10.9 \%$ \\
Cada 3 semanas & 98 & $30.5 \%$ \\
Cada 4 semanas & 76 & $23.7 \%$ \\
Solo en caso de eventos especiales & 94 & $29.3 \%$ \\
Nunca & 9 & $2.8 \%$ \\
Total & $\mathbf{3 2 1}$ & $\mathbf{1 0 0 \%}$ \\
\hline
\end{tabular}

Con los datos de esta tabla se ha calculado frecuencia de visita mensual y semanal a salones de belleza para servicios para el cabello (ver tabla 31).

Tabla 31.

Frecuencia del uso del servicio para el cabello

\begin{tabular}{lccc}
\hline Respuestas & Cantidad & $\begin{array}{c}\text { Factor de visita } \\
\text { mensual }\end{array}$ & $\begin{array}{c}\text { Visitas } \\
\text { Mensuales }\end{array}$ \\
\hline 1 vez a la semana & 9 & 4.00 & 36.00 \\
Cada 2 semanas & 35 & 2.00 & 70.00 \\
Cada 3 semanas & 98 & 1.33 & 130.67 \\
Cada 4 semanas & 76 & 1.00 & 76.00 \\
Total & $\mathbf{2 1 8}$ & & $\mathbf{3 1 3}$ \\
\hline
\end{tabular}


Según la tabla de arriba podrían haber hasta 313 visitas para 218 encuestadas, lo que significa que en promedio dichas personas asistirían 1.4 veces al mes por servicios para el cabello.

- Pregunta 15.- ¿Cuánto es el costo promedio por servicio de cepillado o planchado? (ver tabla 32)

Tabla 32.

Costo promedio de los servicios para el cabello solicitado

\begin{tabular}{lcc}
\hline \multicolumn{1}{c}{ Respuestas } & Cantidad & Porcentaje \\
\hline Menos de S/20 & 12 & $3.7 \%$ \\
Entre S/20 y S/30 & 78 & $24.3 \%$ \\
Entre S/30 y S/40 & 202 & $62.9 \%$ \\
Más de S/40 & 29 & $9.0 \%$ \\
Total & $\mathbf{3 2 1}$ & $\mathbf{1 0 0 \%}$ \\
\hline
\end{tabular}

La mayor parte de encuestadas revela que paga en promedio entre S/ 30 y S/ 40, este dato se tendrá en cuenta al fijar los precios de los servicios que brindará el presente modelo de negocio. 
- $\quad$ Pregunta 16.- Si tuviera un salón que brinde los servicios de manicura, planchado y cepillado de cabello en las instalaciones de su centro de labores ¿se atendería? (ver tabla 33)

Tabla 33.

Propuesta del modelo de negocio

\begin{tabular}{lcc}
\hline Respuestas & Cantidad & Porcentaje \\
\hline 1 - Definitivamente No & 2 & $0.9 \%$ \\
2 - Probablemente No & 2 & $0.9 \%$ \\
3 - Indeciso & 12 & $5.1 \%$ \\
4 - Probablemente sí & 105 & $44.7 \%$ \\
5 - Definitivamente SÍ & 114 & $48.5 \%$ \\
Total & $\mathbf{2 3 5}$ & $\mathbf{1 0 0 \%}$ \\
\hline
\end{tabular}

El $92.5 \%$ de las encuestas aprueba el modelo de negocio propuesto dado que indican que si se atenderían en un salón de belleza dentro de las instalaciones de su empresa.

Si bien Mc Daniel y Gates indican que una estimación razonable pero conservadora sería considerar el $70 \%$ de los que "sin duda comprarían", $35 \%$ de los que “probablemente comprarían”, 10\% de los que "probablemente no comprarían" y cero por ciento de los que "sin duda no comprarían", esta recomendación no se ha tomado en cuenta para el presente proyecto dado que se ha realizado un muestreo por conveniencia, donde los encuestados han sido seleccionados por que forman parte de las sedes de las entidades bancarias que conforman nuestro mercado.

En el caso que la respuesta haya sido una de las 3 primeras opciones, se les preguntará la razón como se muestra en la siguiente pregunta. 
- Razones por las cuales no se atenderían.- ¿Por qué no se atendería en un salón de belleza dentro de las instalaciones de su centro de labores? (ver tabla 34)

Tabla 34.

Razón por la cual no aceptaría el modelo de negocio propuesto

\begin{tabular}{lcc}
\hline Respuestas & Cantidad & Porcentaje \\
\hline Prefiero no realizar actividades personales en el trabajo & 16 & $66.7 \%$ \\
Tendría que probar si es cómodo el sitio & 2 & $8.3 \%$ \\
Tengo un salón de confianza donde siempre me atiendo & 6 & $25.0 \%$ \\
Total & $\mathbf{2 4}$ & $\mathbf{1 0 0 \%}$ \\
\hline
\end{tabular}

Aun cuando el porcentaje de encuestadas que no aceptaría el modelo propuesto es muy bajo (7.5\%), la principal razón es porque prefieren realizar este tipo de actividades fuera del trabajo.

- Pregunta 17.- ¿Cuánto más estaría dispuesta a pagar por atenderse en un salón dentro de su centro laboral? (ver tabla 35)

Tabla 35 .

Incremental dispuesto a pagar en el modelo de negocio propuesto

\begin{tabular}{lcc}
\hline Respuestas & Cantidad & Porcentaje \\
\hline Ni un sol más & 28 & $9.4 \%$ \\
Entre S/1 y S/4 soles más & 110 & $37.0 \%$ \\
Entre S/5 y S/10 soles más & 149 & $50.2 \%$ \\
Más de S/10 soles & 10 & $3.4 \%$ \\
Total & $\mathbf{2 9 7}$ & $\mathbf{1 0 0 \%}$
\end{tabular}

Más del 90\% estaría dispuesta a pagar un adicional por recibir el servicio en su centro de labores. Es importante notar también que el 53.5\% está dispuesto a pagar más 
de S/5. Es importante señalar que esta pregunta servirá para establecer el precio más adelante.

- $\quad$ Pregunta 18.- ¿En qué horario le gustaría y podría atenderse? (ver tabla 36)

Tabla 36.

Horarios preferidos para atenderse en el modelo de negocio propuesto

Respuestas Cantidad Porcentaje

\begin{tabular}{lcc}
\hline Antes del ingreso al trabajo & 9 & $3.0 \%$ \\
Durante el refrigerio & 88 & $29.6 \%$ \\
En cualquier momento del día & 165 & $55.6 \%$ \\
Después de la hora de salida & 35 & $11.8 \%$ \\
Total & $\mathbf{2 9 7}$ & $\mathbf{1 0 0 \%}$ \\
\hline
\end{tabular}

Para la propuesta del modelo de negocio, no se debería considerar el rango de tiempo antes del inicio de las labores de las encuestadas dado que prácticamente no estaría dispuestas a ello.

Otro dato importante es que más de la mitad estaría dispuesta a atenderse en cualquier momento durante su horario laboral.

Desde la pregunta 19 comienza la sección de información general que aplica para todas las encuestadas. 
- Pregunta 19.- ¿Qué cargo tiene? (ver tabla 37)

Tabla 37.

Cargo de la encuestada

\begin{tabular}{lcc}
\hline Respuestas & Cantidad & Porcentaje \\
\hline Colaborador & 201 & $58.1 \%$ \\
Jefe-Supervisor & 90 & $26.0 \%$ \\
Manager-Gerente & 55 & $15.9 \%$ \\
Total & $\mathbf{3 4 6}$ & $\mathbf{1 0 0 \%}$ \\
\hline
\end{tabular}

- $\quad$ Pregunta 20.- ¿Qué edad tiene? (ver tabla 38)

Tabla 38.

Rango de edades de las encuestadas

Respuestas Cantidad Porcentaje

\begin{tabular}{lcc}
\hline Entre 20 y 30 años & 102 & $29.5 \%$ \\
Entre 30 y 40 años & 146 & $42.2 \%$ \\
Entre 40 y 50 años & 77 & $22.3 \%$ \\
50 a más años & 21 & $6.1 \%$ \\
Total & $\mathbf{3 4 6}$ & $\mathbf{1 0 0 \%}$ \\
\hline
\end{tabular}


- $\quad$ Pregunta 21.- ¿Cuál es su estado civil? (ver tabla 39)

Tabla 39.

Estado civil de las encuestadas

\begin{tabular}{lcc}
\hline Respuestas & Cantidad & Porcentaje \\
\hline Soltera & 116 & $33.5 \%$ \\
Casada & 131 & $37.9 \%$ \\
Convive con su pareja & 64 & $18.5 \%$ \\
Divorciada/Separada & 35 & $10.1 \%$ \\
Total & $\mathbf{3 4 6}$ & $\mathbf{1 0 0 \%}$ \\
\hline
\end{tabular}

- $\quad$ Pregunta 22.- ¿Tiene hijos?, ¿Cuántos? (ver tabla 40)

Tabla 40.

Cantidad de hijos de las encuestadas

\begin{tabular}{lcc}
\hline Respuestas & Cantidad & Porcentaje \\
\hline No tengo hijos & 142 & $41.0 \%$ \\
Si, 1 hijo(a) & 108 & $31.2 \%$ \\
Si, 2 hijos(as) & 73 & $21.1 \%$ \\
Si, 3 o más hijos(as) & 23 & $6.6 \%$ \\
Total & $\mathbf{3 4 6}$ & $\mathbf{1 0 0 \%}$ \\
\hline
\end{tabular}

Es importante notar que la mayoría de las encuestadas tiene hijos, más adelante se mostrará análisis cruzando esta respuesta con otras.

En la figura 4 se cruzan las respuestas de las preguntas referentes al cargo de las encuestadas y los horarios en los que se atenderían en el modelo de negocio propuesto. 


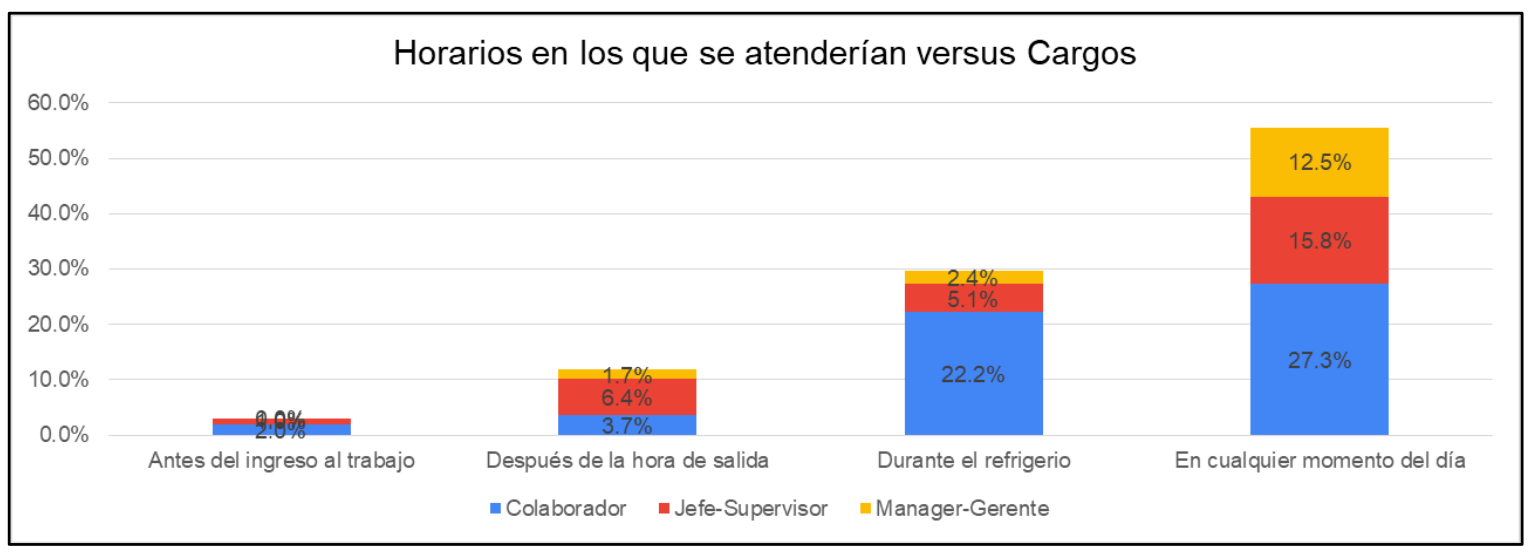

Figura 4 - Análisis de horarios de atención vs cargos de encuestadas

Se observa que no hay una preferencia muy marcada para ningún cargo respecto a los diferentes horarios propuestos.

Lo que se interpreta es que, independientemente del cargo, no necesariamente habría gran "congestión” en las atenciones.

En la figura 5 se cruzan las respuestas de las encuestadas acerca de la cercanía del salón de la belleza a sus casas o trabajos versus el horario en el que se atenderían en el modelo de negocio propuesto.

\section{Horarios en los que se atendería VS Cercanía}

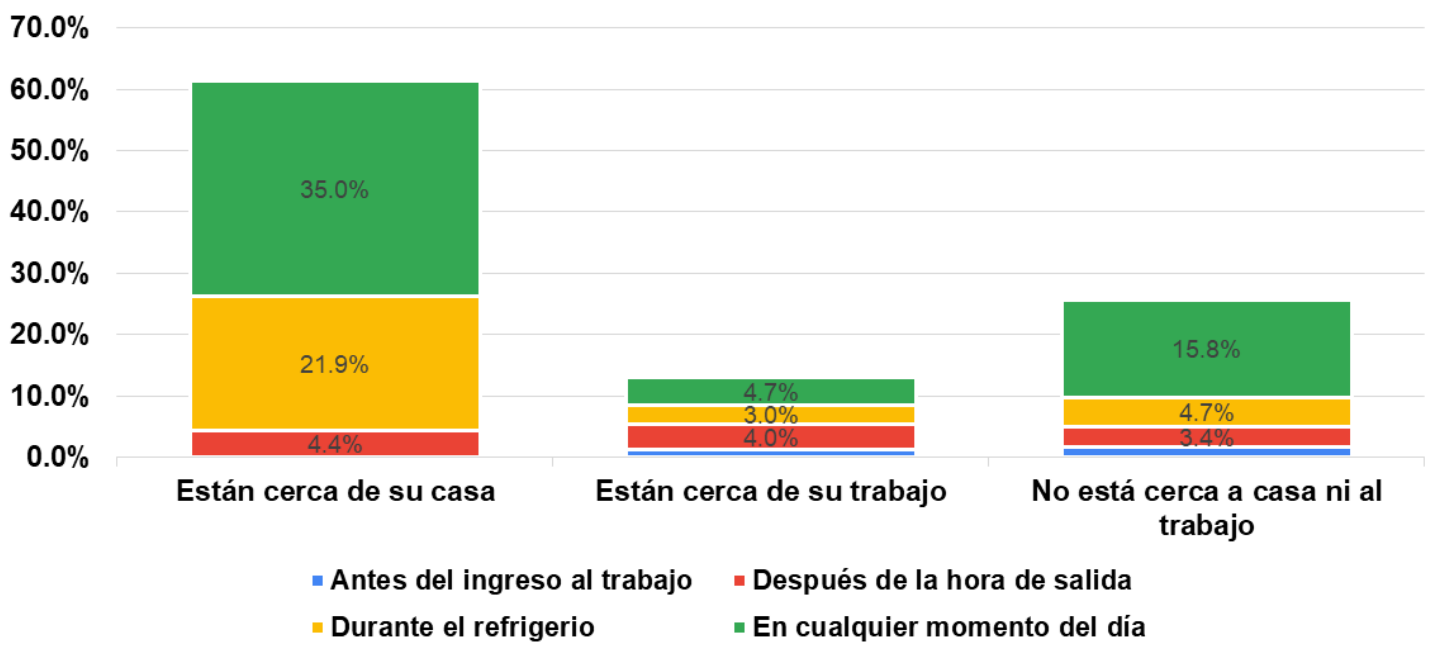

Figura 5 - Análisis de horarios de atención vs cercanía 
El análisis que se desprende de este cuadro, es que, aun cuando las encuestadas prefieren atenderse cerca de casa, aceptarían atenderse en el modelo de negocio propuesto, inclusive no tienen una preferencia de horario marcada.

En el gráfico 6 se cruzan las respuestas de las encuestadas que se atenderían en el modelo de negocio propuesto y en qué horario versus la cantidad de hijos que pudieran tener.

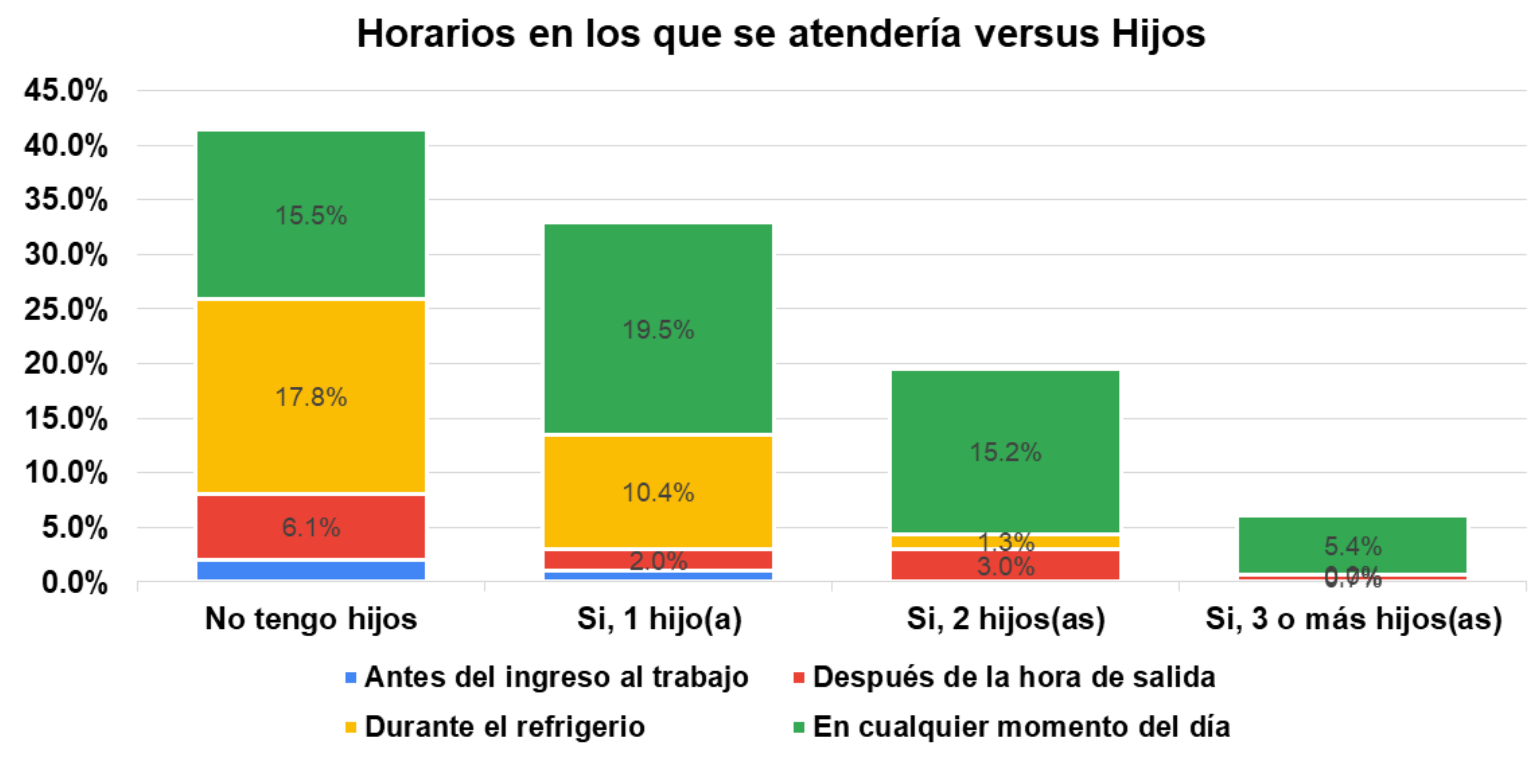

Figura 6 - Análisis de horarios de atención vs cantidad de hijos

El análisis que se desprende de este cuadro, es que, la mayoría de encuestadas que aceptaría en modelo de negocio y que no tiene hijos o tiene entre 1 y 2 se atenderían en diferentes horarios y no se concentra en ninguno en particular.

\subsection{Conclusiones del Estudio Cualitativo y Cuantitativo}

Luego de revisar los resultados del análisis cualitativo y cuantitativo-se tienen las siguientes conclusiones.

Sobre las conclusiones cualitativas: 
- Según los representantes del área de Recursos Humanos de las empresas, existen políticas para incrementar el clima laboral y la propuesta de negocio está alineada a dichas políticas.

- Las empresas del sector financiero contemplan la idea de concesionar ciertos servicios dentro de sus propias instalaciones.

- La limitación principal de las empresas es el espacio físico para brindar directamente beneficios a sus colaboradores.

- En cuanto al horario de funcionamiento del modelo de negocio propuesto deberá ser coordinado previamente con el empleador a través de un acuerdo de servicio.

- Existe predisposición para asignar espacios en sus estacionamientos para que las móviles del modelo de negocio propuesto operen en sus locales.

Sobre las conclusiones cuantitativas:

- Los resultados porcentuales de la encuesta realizada muestran que hay una gran cantidad de personas que el día de hoy asisten a salones de belleza (92.8\%).

- La encuesta también revela que el modelo de negocio propuesto tendría gran aceptación por parte de las encuestadas ( $92.5 \%$ del total de encuestadas).

- En promedio las encuestadas acuden al salón de belleza 1.6 veces al mes.

- $\quad$ El $61.4 \%$ de las encuestadas acude a salones de belleza cerca a sus hogares.

- $\quad$ El $83.5 \%$ de las encuestadas cree que es importante tener un salón de belleza cerca.

- En promedio las encuestadas acuden 1.6 veces al mes a realizarse algún servicio de manicura.

- La mayor parte de encuestadas (64.5\%) manifiestan que en promedio pagan entre S/ 20 y $S / 30$ por servicio de manicura.

- En promedio las encuestadas acuden 1.4 veces al mes a realizarse el planchado o cepillado de cabello. 
- La mayor parte de encuestadas (62.9\%) manifiestan que en promedio pagan entre S/ 30 y S/ 40 por servicio de planchado o cepillado de cabello.

- La mayor parte de encuestadas (54.5\%) manifiestan que están dispuestas a pagar un adicional mayor a S/ 5 por los servicios de manicura, planchado o cepillado de cabello con el modelo de negocio propuesto.

- Independientemente del cago de la encuestada, los horarios en los que se atenderían con el modelo propuesto no muestran una preferencia marcada en alguna opción en particular.

\subsection{Perfil del Consumidor Tipo y sus Variantes}

"El comportamiento de compra del consumidor se refiere a la conducta de compra de los consumidores finales, es decir, de los individuos y familias que compran bienes y servicios para consumo personal". "Las compras del consumidor reciben una gran influencia de las características culturales, sociales, personales y psicológicas”. (Kotler \& Armstrong, 2012)

Sobre las características culturales:

- La religión, la gran mayoría de personas en el país son católicos e incluso no practican la religión y en todo caso la religión católica no restringe el hecho de arreglarse las uñas o cabello.

- La cultura o incluso la subcultura de las organizaciones por lucir bien en el trabajo y más aún si se atiende a clientes externos.

Sobre las características sociales:

- La familia de donde se hereda la importancia de lucir siempre y más aún si se va a la calle o trabajo.

- Grupos de referencia que influyen en las personas y una forma es a través de la moda.

- El rol y/o estatus de las personas también las empujan en tomar estos servicios.

Sobre las características personales: 
- La edad de las personas del mercado meta, las cuales están entre 20 y 65 años de edad.

- La situación económica de las personas también puede ser muy determinante para asistir a estos locales.

- El estilo de vida también puede ser determinante para acudir a estos locales incluso sin tener una buena situación económica.

Sobre las características psicológicas:

- Motivación, las personas se sienten motivadas a asistir a estos locales si en su entorno muchas personas lo hacen.

- Percepción, podría haber asociación de belleza, lucir bien con trabajo. 


\section{Capítulo IV: Proyección del Mercado Objetivo}

\subsection{El Ámbito de la Proyección}

El éxito del plan de negocio radica en brindar a las trabajadoras de las entidades del sistema financiero la posibilidad de que cuenten con un Salón de belleza móvil dentro de las instalaciones de sus centros laborales, que ofrezca los servicios de manicura, cepillado y planchado de cabello. Esto implica saber determinar el ámbito de proyección de la demanda del servicio lo cual permitirá conocer el estado actual y el posible comportamiento del mercado en el futuro. El obtener indicadores de estos datos ayudará a formular estrategias que contribuyan con el posicionamiento del negocio dentro del público objetivo.

\subsection{Selección del Ámbito de la Proyección}

El modelo de negocio propuesto no cuenta con información histórica. Por otro lado, el público objetivo del presente trabajo son las trabajadoras de dos sedes bancarias principales pertenecientes a dos entidades del sistema financiero privado, Banco de Crédito del Perú Chorrilos e Interbank - La Victoria. Dado que las empresas no tienen un crecimiento en número de personas o nuevas contrataciones, no es posible definir un método de proyección, en todo caso, se mencionan otros indicadores indirectos que refuercen el presente modelo de negocio.

En febrero 2019 el BCR proyectó el crecimiento del PBI de 3.8\% a 3.9\% (Diario El Peruano, 2019), esto abona a favor del ya mencionado modelo de negocio.

\subsubsection{Mercado potencial.}

“Total de personas del segmento elegido que posiblemente consumirían el producto.” (Moyano Castillejo, 2015)

Para el cálculo del Mercado Potencial se incluyó en la encuesta la pregunta descritas en el punto 3.4.3: “¿Asiste Ud. A salones de belleza?”, la proporción de encuestadas que dijo que sí asiste a salones de belleza (92.8\%) se usó para determinar el 
mercado Potencial. En el punto 3.2 Selección de segmento del mercado se han mostrado los cálculos hechos para determinar el número total de colaboradoras mujeres el cual asciende a 2,578 como se ve en el la Tabla 10. Cantidad de colaboradores mujeres por entidad bancaria en sedes elegidas que asisten a salones de belleza. En ese sentido, el mercado potencial asciende a 2,391.

\subsubsection{Mercado disponible.}

“Total de personas del mercado potencial que están interesados en el nuevo producto o les llama la atención.” (Moyano Castillejo, 2015)

Cabe señalar que como se indicó anteriormente, en el presente trabajo se ha utilizado el método de muestreo no probabilístico por conveniencia.

Para el cálculo del mercado disponible se incluyó en la encuesta la siguiente pregunta descritas en el punto 3.4.3: "Si tuviera un salón que brinde los servicios de manicura, planchado y cepillado de cabello dentro de su centro de labores, ¿se atendería?", el resultado obtenido fue (ver tabla 41):

Tabla 41.

Determinación del Mercado disponible

Parámetro Cantidad

Mercado potencial 2,391

Porcentaje total de encuestas $297 / 321=92.5 \%$

Cálculo de Mercado disponible $2,391 \times 92.5 \%$

Mercado Disponible 2,212

De acuerdo a los resultados obtenidos se puede determinar que el Mercado Disponible es de 2,212 colaboradoras quienes normalmente acuden a locales que brindan este tipo de servicios y que además están interesados en hacer uso de los mismos si es 
local se encontrara ubicado dentro de su centro de labores. Se puede destacar que dentro de las personas que no consideran importante el cuidado de manos si estaría dispuesto a hacerlo si se brindara el servicio dentro de su centro de labores.

\subsubsection{Mercado efectivo.}

"Total de personas del mercado disponible que comprarían el nuevo producto." (Moyano Castillejo, 2015)

Para el cálculo del mercado disponible se considerarán la participación de las entidades financieras a las cuales se atenderán en la primera etapa de este proyecto. Los resultados se detallan en la tabla 42 :

Tabla 42.

Determinación del Mercado efectivo

\section{Parámetro}

Cantidad

Mercado disponible 2,212

Cantidad de encuestadas que están interesadas en el modelo de $269 / 297=90.6 \%$ negocio propuesto y que además pagarían un adicional por el mismo servicio

Cálculo de Mercado efectivo $2,212 \times 90.6 \%$

Mercado Efectivo 2,003

Como resultado de los cálculos realizados se obtuvo que el mercado efectivo es de 2,003 colaboradoras que se encuentran ya laborando dentro de las entidades financiaras a las cueles se les pretende prestar el servicio.

\subsubsection{Mercado objetivo.}

"Total de personas del mercado efectivo que el emprendedor puede atender." (Moyano Castillejo, 2015), en este caso el mercado objetivo son las colaboradoras del 
sistema financiero que usan los servicios propuestos y que a su vez se muestran interesadas en hacerlo dentro de su centro de labores y que de acuerdo a la capacidad instalada que maneja en plan de negocio, se pueden atender en un período determinado de tiempo.

Para determinar el mercado objetivo, primero se determinó la capacidad de atención máxima (ver tabla 43):

Tabla 43.

Determinación de la capacidad máxima instalada

\section{Parámetro}

Cantidad

Cantidad de trabajadoras por unidad 8

Promedio minutos por atención 35

Horas del día disponibles 9

Capacidad máxima de atención por día $8 \times(60 / 35) \times 9=123$

Días laborales por semana

Capacidad máxima de atenciones semanales $123 \times 5=615$

Cantidad de semanas al año

Capacidad máxima instalada de atenciones anual $615 \times 52=31,980$

Capacidad máxima instalada de atenciones mensual

$31,980 / 12=2,665$

El mercado objetivo antes calculado el cual asciende a 2003 (ver tabla 42) está expresado en personas y la capacidad máxima calculada está expresada en atenciones (ver tabla 43). Por otro lado según la encuesta realizada, como se muestra en la tabla 22, se ha calculado la frecuencia de visita promedio de las encuestadas la cual asciende a 1.6 veces al mes. Por los datos antes mencionados se estima que las 2,003 personas podrían 
ir 1.6 veces al mes. Entonces, las 2,003 personas podrían requerir hasta 2,804 atenciones cuya cantidad está por encima de nuestra capacidad máxima de atención.

Por todo lo antes mencionado, se concluye que el mercado objetivo expresada en atenciones asciende a 2,665.

\subsection{Pronóstico de la Venta.}

Para determinar el pronóstico de ventas se utilizó la capacidad instalada dado que no se tienen datos históricos de negocios similares o afines. Asimismo, se tomaron en cuenta las entrevistas realizadas a los expertos en el rubro.

Para este cálculo se establecieron los siguientes supuestos:

- Los horarios de atención serán entre las 10:00 y las 19:00 horas, es decir nueve horas por día.

- Las atenciones serán de lunes a viernes solamente.

- Las unidades móviles pueden atender a ocho personas a la vez cada 35 minutos aproximadamente, es decir hasta 108 clientes por día y hasta 540 clientes a la semana.

- Calculando una ocupación de 65\% el primer año el Mercado Objetivo semanal sería de 429 y mensual de 1,716 .

\subsection{Aspectos Críticos que Impactan en el Pronóstico de las Ventas}

Durante el análisis se identificó entre los siguientes aspectos críticos que pueden impactar en el pronóstico de la venta:

- La capacidad instalada debido a que el plan de negocio considera solo 8 estaciones de servicio por las dos unidades móviles, lo cual limita la oferta del negocio.

- El aumento en los precios de los insumos directos para la atención de los clientes (esmaltes, removedores, limpiadores, etc.) y los indirectos (gasolina, repuestos, etc.) lo cual podría impactar en los precios de los servicios. 
- Reducción del personal en las entidades financieras por la automatización de sus procesos internos o por coyuntura económica. 


\section{Capítulo V: Ingeniería del Proyecto}

Mediante el estudio de ingeniería se puede determinar cuáles serán las herramientas más adecuadas y necesarias para llevar a cabo un proyecto de este tipo, estas herramientas incluyen el tipo de vehículo y equipamiento del mismo, rutas hacia las ubicaciones donde se ofrecerá el servicio y lugar que se utilizará como base y resguardo de la unidad móvil durante la noche.

Dentro del equipamiento se tomarán en cuenta los insumos e implementos necesarios para brindar un servicio cómodo y de calidad.

En lo que a la unidad móvil se refiere se ha elegido un minibús de la marca JAC modelo HK 6750K año 2016, que por sus dimensiones se adecúa a los requerimientos de espacio y comodidad buscados. Este vehículo se puede solicitar con la menor cantidad de asientos posibles (16) debido a que serán retirados por no ser útiles para el servicio propuesto. El costo de la unidad móvil asciende aproximadamente S/98,000.00 soles, precio que puede variar de acuerdo a las promociones y descuentos que se obtengan al momento de la compra.

Luego de la compra del vehículo se contratarán los servicios de una empresa especializada en acondicionamiento a pedido para todo tipo de negocios. La empresa seleccionada deberá proveer de toda la logística y mano de obra para la implementación de cuatro estaciones de servicios ubicadas estratégicamente dentro de la unidad móvil, cada una de ellas deberá contar con las dimensiones adecuadas de tal manera que se tenga el espacio suficiente para almacenar productos, materiales y al mismo tiempo a 8 personas entre clientes y especialistas (ver tabla 44). 
Tabla 44.

Costos de vehículo y acondicionamiento

\begin{tabular}{lrr}
\hline \multicolumn{1}{c}{ Equipos } & \multicolumn{1}{c}{ Costos } & \% \\
\hline Camioneta & 98,000 & $83.33 \%$ \\
Acondicionamiento & 17,500 & $14.88 \%$ \\
Mesas & 1,400 & $1.19 \%$ \\
Sillas & 700 & $0.60 \%$ \\
Total & $\mathbf{1 1 7 , 6 0 0}$ & $\mathbf{1 0 0 . 0 0 \%}$ \\
Total unidades & & \\
Total inversión & 2 & \\
& & \\
\hline
\end{tabular}

\subsection{Estudio de Ingeniería}

\subsubsection{Selección del equipamiento.}

El vehículo elegido para la prestación del servicio de manicura, cepillado y planchado de cabello es de la marca JAC versión MINIBUS.

El vehículo será modificado para implementar en su interior 4 estaciones de servicios a fin de brindar un servicio de calidad y a la vez cómodo, tanto para el personal que lo brinda como para las clientes.

Cada estación constará de una mesita y dos asientos los cueles estarán empernados al piso del vehículo para evitar el desplazamiento del mobiliario. Se tomará en cuenta la altura tanto de la mesa como de las sillas para asegurar la comodidad de la clienta y de la especialista.

De la misma forma se ha de considerar las dimensiones de las mesas de trabajo a fin de que se tenga espacio suficiente para colocar o guardar los implementos necesarios para el servicio. 
Cada una de las estaciones contará con los siguientes elementos:

- Recipiente de forma redonda de metal para utilizar con jabón líquido y con dimensiones mínimas para poder remojar las uñas.

- Limas, deben ser descartables y de madera para no maltratar la capa de las uñas

- Pulidor o abrillantador de uñas.

- Removedor de cutícula, presentación en Gel.

- Empujador de cutícula, presentación en plástico y descartable con dos extremos diferentes uno redondo para recorrer la cutícula y el otro en punta para eliminar el exceso.

- Cortaúñas, presentación en acero inoxidable

- Algodón, necesario para el servicio y debe estar protegido de contaminación.

- Quita esmalte, para remover el esmalte de las uñas.

- Alicate corta cutícula, permite cortar el exceso de piel de las uñas.

- Aceite Hidratante de uñas, para mantener suave e hidratada las uñas.

- Base para uñas.

- Esmalte, en grandes cantidades y colores.

- Brillo Secante, para acelerar el secado de las uñas.

- Crema hidratante.

- Cepillos.

- Peines.

- Planchas de cabello.

- Capas de peluquería.

- Ganchos.

- Productos para controlar el frizz.

- Productos para fijar el planchado. 
Adicionalmente, cada una de las estaciones contará con un contenedor de agua ubicado en la parte superior de las estaciones de trabajo, para la utilización del agua corriente en el lavado de manos y limpieza de las consumidoras.

En la tabla 45, la lista de activos de Salón de belleza Express: 
Tabla 45.

Lista de activos del modelo propuesto

$\begin{array}{cccccccc}\text { PRODUCTO } & \text { CANTIDAD } & \text { FUENTE } & \text { MARCA } & \text { MODELO } & \text { CARACTERÍSTICA } & \begin{array}{c}\text { DIMENSIÓN/ } \\ \text { CAPACIDAD }\end{array} & \text { IMAGEN } \\ \text { ToTAL (S/) }\end{array}$




\begin{tabular}{|c|c|c|c|c|c|c|c|c|}
\hline PRODUCTO & CANTIDAD & FUENTE & MARCA & MODELO & CARACTERÍSTICA & $\begin{array}{l}\text { DIMENSIÓN/ } \\
\text { CAPACIDAD }\end{array}$ & IMAGEN & $\begin{array}{c}\text { PRECIO } \\
\text { TOTAL (S/) }\end{array}$ \\
\hline $\begin{array}{l}\text { Juego de } \\
\text { Limas }\end{array}$ & 90 & & Thuya & $10 / 150$ & $\begin{array}{l}\text { Limas descartables y } \\
\text { de colores doble uso }\end{array}$ & $10 / 150$ & & $\mathrm{~S} / 18,00$ \\
\hline $\begin{array}{l}\text { Set de } \\
\text { manicura }\end{array}$ & 16 & & Zacro & --- & $\begin{array}{l}\text { Set completo de } \\
\text { Acero. }\end{array}$ & $500 \mathrm{ml}$ & & $\mathrm{S} / 800,00$ \\
\hline $\begin{array}{l}\text { Peines y } \\
\text { cepillos }\end{array}$ & 60 & & & & Peines y cepillos & & & $\mathrm{S} / 300,00$ \\
\hline $\begin{array}{l}\text { Plancha para } \\
\text { cabello }\end{array}$ & 8 & & Oster & & $\begin{array}{l}\text { Plancha de cabello } \\
\text { nano titaniun }\end{array}$ & & & $\mathrm{S} / 800 ., 00$ \\
\hline $\begin{array}{l}\text { Maquina } \\
\text { secante }\end{array}$ & 2 & & & & $\begin{array}{l}\text { Alicate corta cutícula, } \\
\text { en acero de alta } \\
\text { calidad y esterilizable. }\end{array}$ & $10 \mathrm{~cm}$. & n & $\mathrm{S} / 3.400,00$ \\
\hline
\end{tabular}




\begin{tabular}{|c|c|c|c|c|c|c|c|c|}
\hline PRODUCTO & CANTIDAD & FUENTE & MARCA & MODELO & CARACTERÍSTICA & $\begin{array}{l}\text { DIMENSIÓN/ } \\
\text { CAPACIDAD }\end{array}$ & IMAGEN & $\begin{array}{c}\text { PRECIO } \\
\text { TOTAL }(\mathbf{S} /)\end{array}$ \\
\hline $\begin{array}{l}\text { Secadora de } \\
\text { cabelo }\end{array}$ & 4 & & & Oster & Secadora de cabello & $5 \mathrm{~cm}$ & & $\mathrm{~S} / 2.136,00$ \\
\hline Mandil & 100 & & & $\begin{array}{c}\text { vinilo } 91 x 137 \\
\text { para salón de } \\
\text { peluquería }\end{array}$ & $\begin{array}{l}\text { Capa mandil de } \\
\text { peluquería }\end{array}$ & & & $\mathrm{S} / 500,00$ \\
\hline Esterilizador & 2 & & & & $\begin{array}{l}\text { Esterilizador de set de } \\
\text { manicure }\end{array}$ & & & $\mathrm{S} / 800,00$ \\
\hline laptop & 3 & & $\mathrm{HP}$ & & Laptops & & & $\mathrm{S} / 7.500,00$ \\
\hline Celular & 3 & & Huawei & & celulares & & & $\mathrm{S} / 630,00$ \\
\hline
\end{tabular}


En la figura 7, la ficha técnica Bus JAC $6750 \mathrm{~K}$

\section{Especificaciones Técnicas}

\begin{tabular}{|c|c|c|}
\hline & & $\begin{array}{c}\text { ClTY } \\
\text { ADVANTAGE } 6750\end{array}$ \\
\hline Dimensiones & 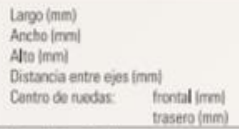 & $\begin{array}{l}7350 \\
2050 \\
2550 \\
3395 \\
1580 \\
1530\end{array}$ \\
\hline $\begin{array}{l}\text { Pesos y } \\
\text { Capacidades }\end{array}$ & $\begin{array}{l}\text { Peas bruto vehicallar } \\
\text { Tas } \\
\text { Ettangue } \\
\text { No de asientos }\end{array}$ & $\begin{array}{c}6000 \mathrm{Kg} \\
4900 \mathrm{~K}_{9} \\
90 \mathrm{ks} \\
21 \text { asientes }+69 \text { atontides }+1 \text { conductor }\end{array}$ \\
\hline Motor & 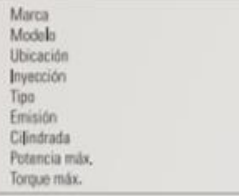 & 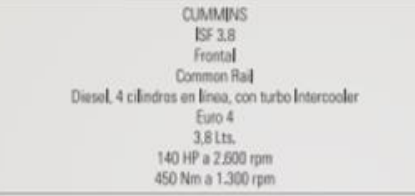 \\
\hline Transmisión & $\begin{array}{l}\text { Tipo } \\
\text { Modelo } \\
\text { Torpe max }\end{array}$ & $\begin{array}{l}\text { Menoul de } 6 \text { we boidades mas una revera } \\
\text { LC8151 } \\
560 \mathrm{Nm}\end{array}$ \\
\hline Embrague & $\begin{array}{l}\text { Tpo } \\
\text { Accionamiento }\end{array}$ & $\begin{array}{l}\text { Monodice seco } \\
\text { Por Giatragma con rodemiento emaje }\end{array}$ \\
\hline Ejes y suspensión & $\begin{array}{l}\text { Suspension dedantera } \\
\text { Suspensión trasera } \\
\text { Relución par cónico }\end{array}$ & 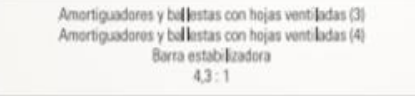 \\
\hline Freno & $\begin{array}{l}\text { De servicio } \\
\text { De motor } \\
\text { De estacionariento }\end{array}$ & 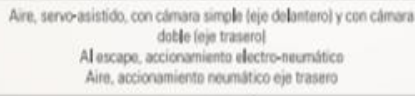 \\
\hline Dirección & & Asistencia hidridica \\
\hline Baterias & & 2 de 12 vels. conoctadas en serie $=24$ vats \\
\hline Neumáticos & & 8.5817 .5 \\
\hline Garantia & & $19 \mathrm{hlo} 6100.000 \mathrm{~km}$ \\
\hline Equipamiento interior & & 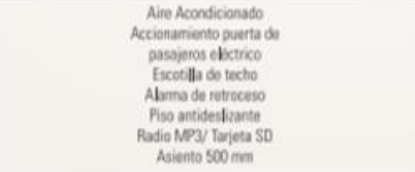 \\
\hline
\end{tabular}
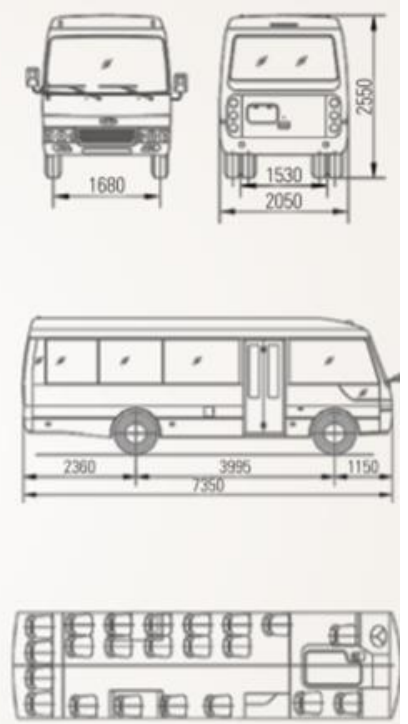

Espocicaciones neconcas supetas a canbio por di constuctoc.

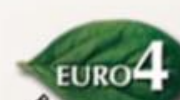

or un airems

www.camionesjac.cl 26006873787

Figura 7 - Ficha técnica Bus JAC 6750 K - Nota: Desco Maq [en línea] https://camionesjac.cl/

\subsubsection{Layout.}

El minibús elegido para ser transformado en la unidad móvil donde se brindará el servicio de manicura, cepillado y planchado de cabello (ver figura 8 y 9) tendrá las siguientes dimensiones (ver figura 10, 11, 12, 13, 14 y 15): 


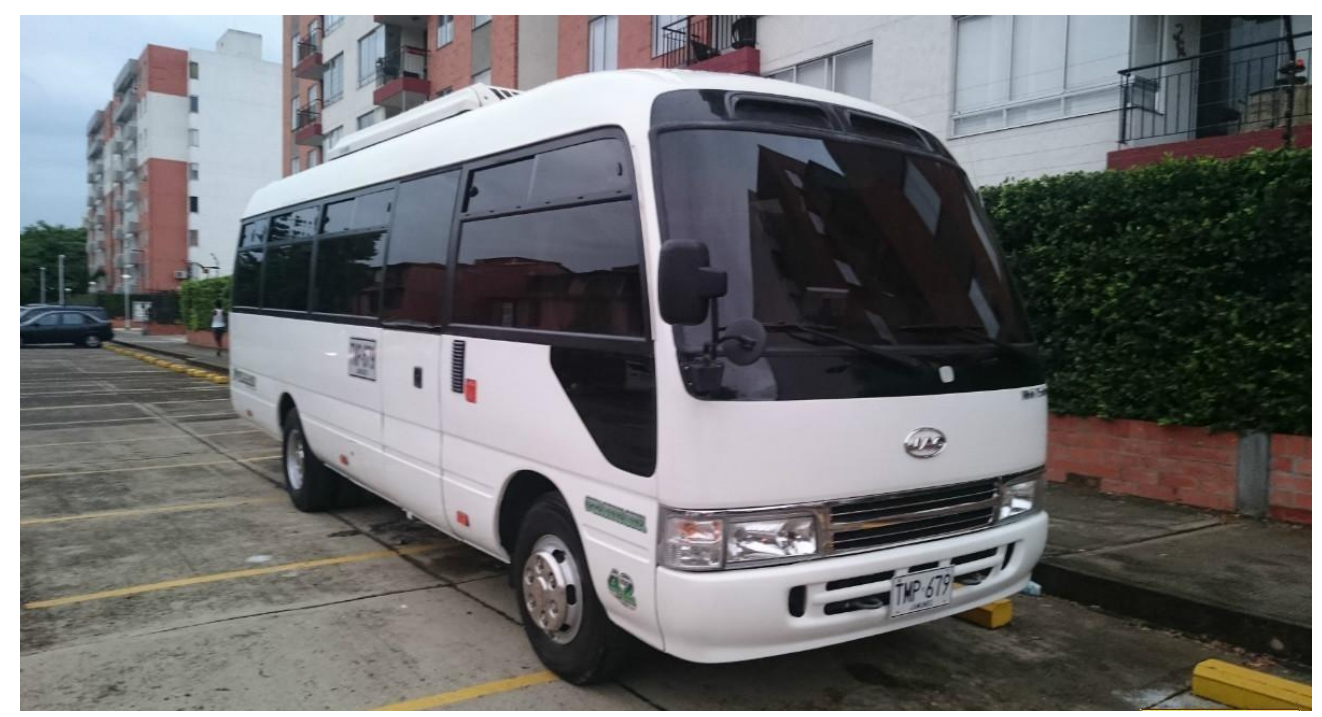

Figura 8 - Foto de la móvil - Nota: Suzuval [en línea] -

https://www.suzuval.cl/modelos/jac_camiones/city_advantage.html

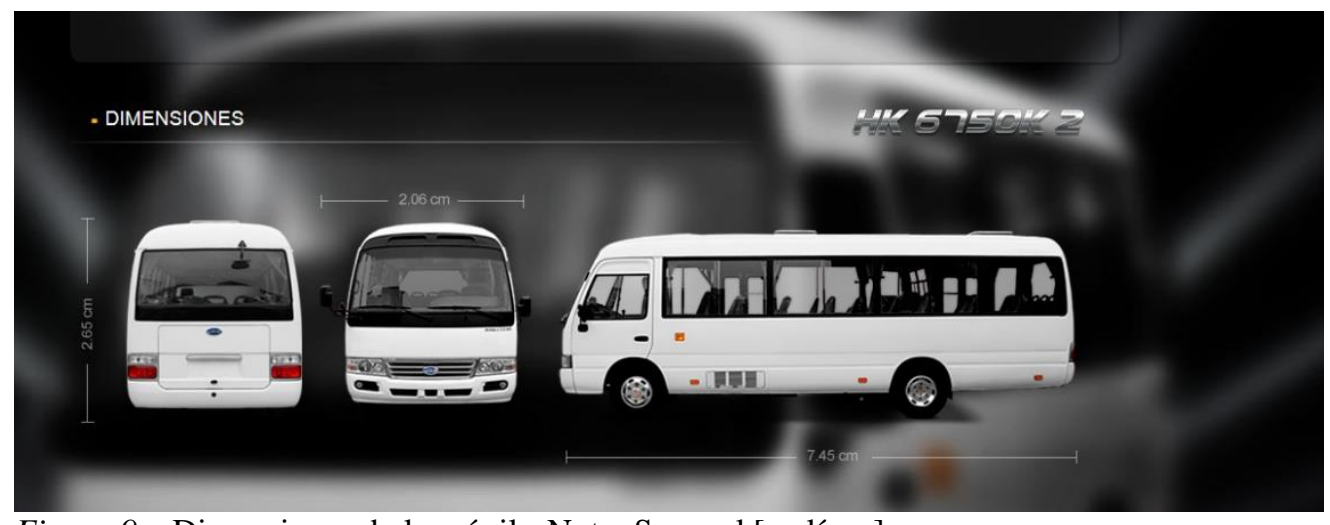

Figura 9 - Dimensiones de la móvil - Nota: Suzuval [en línea] -

https://www.suzuval.cl/modelos/jac_camiones/city advantage.html

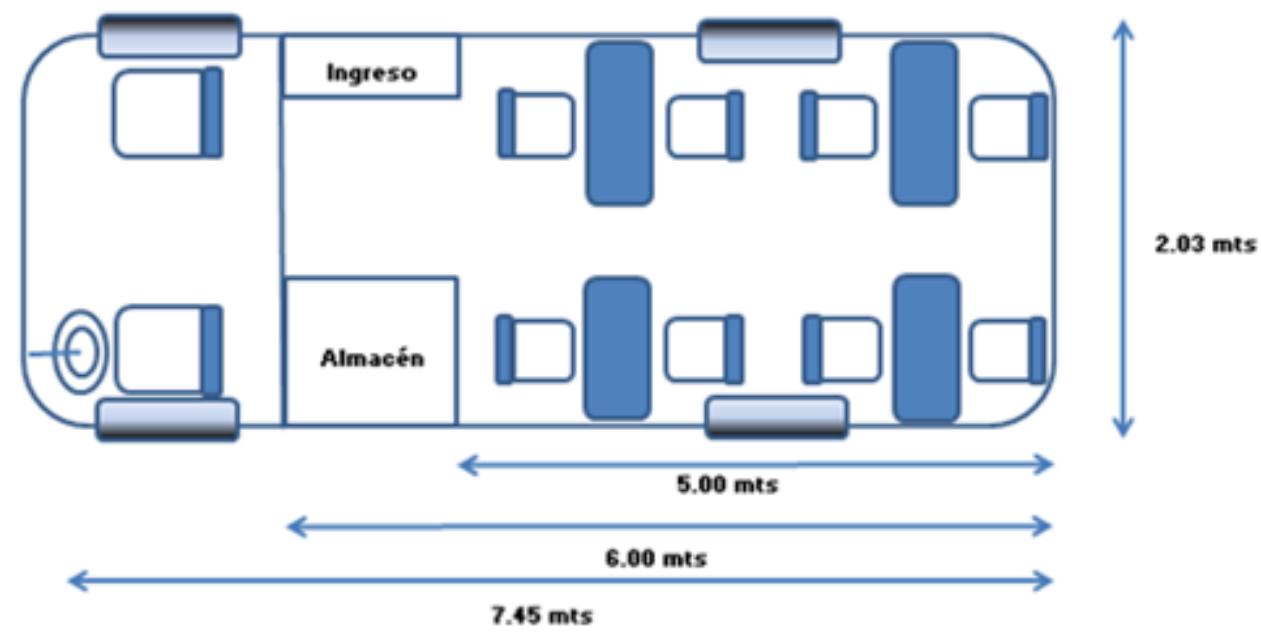

Figura 10 - Layout de la móvil vista superior 


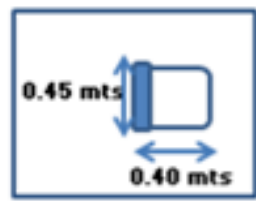

Silla

Figura 11 - Dimensiones de silla del layout de la móvil vista superior

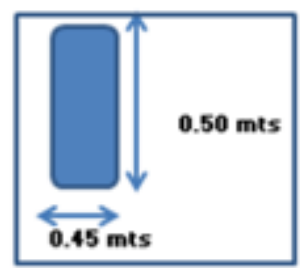

Mesa

Figura 12 - Dimensiones de mesa del layout de la móvil vista superior

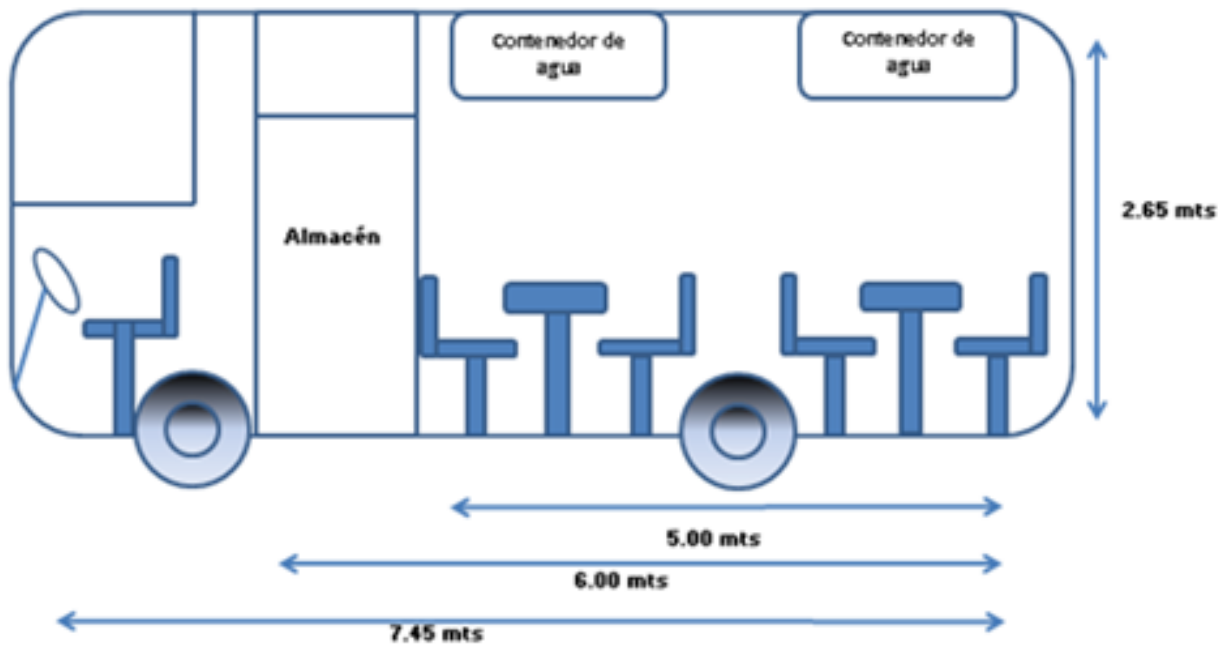

Figura 13 - Layout de la móvil vista lateral

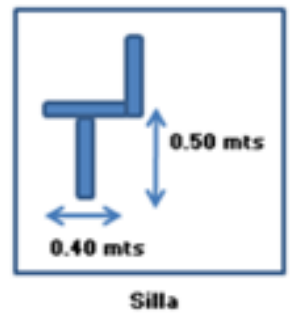

Figura 14 - Dimensiones de silla de layout de la móvil vista lateral 


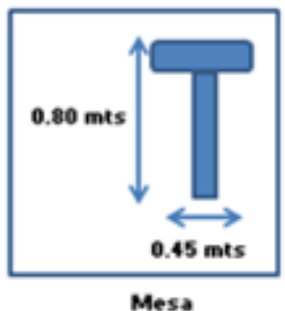

Figura 15 - Dimensiones de mesa de layout de la móvil vista lateral

Dimensiones de las estaciones:

Mesa de trabajo: las dimensiones de las mesitas serán de $80 \mathrm{~cm}$ de alto, $50 \mathrm{~cm}$ de ancho y $45 \mathrm{~cm}$ de profundidad (ver figura 16).

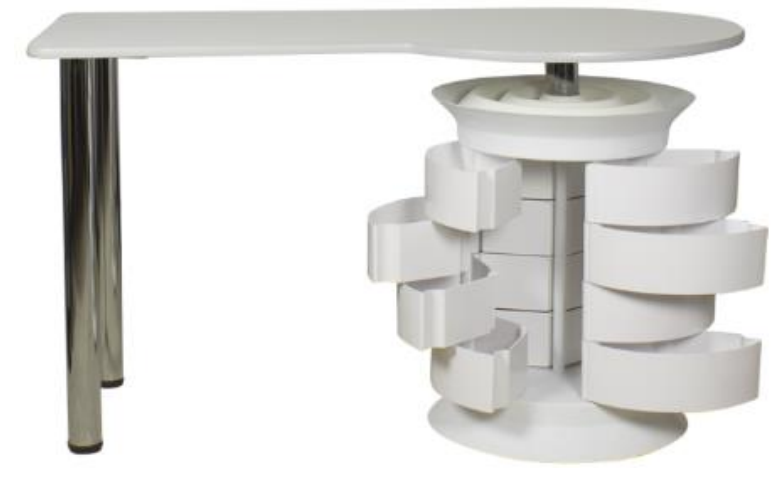

Figura 16 - Modelo de mesa de trabajo - Nota: EquipoBellaza [en línea] https://equipobelleza.com/muebles-para-manicura/mesa-manicura-lite-blanco-ms01b.html

Silla de trabajo: los asientos serán de $40 \mathrm{~cm}$ de profundidad x $45 \mathrm{~cm}$ de ancho y 50 $\mathrm{cm}$ de alto (ver figura 17).

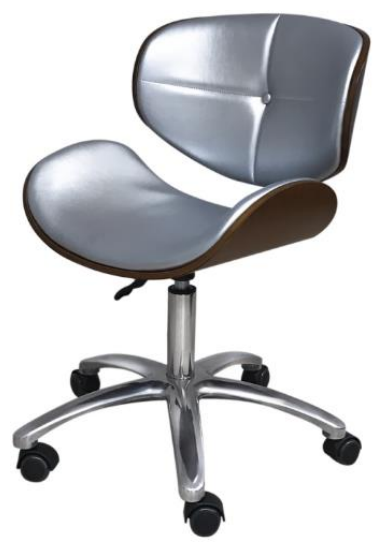

Figura 17 - Modelo de silla de trabajo - Nota: EquipoBelleza [en línea] https://equipobelleza.com/silla-de-manicura-hera-plata2131.html?keyword=silla\%20de\%20mani 


\subsubsection{Flujo de proceso}

Como se muestra en la figura 18, el flujo de procesos de atención de clientes.

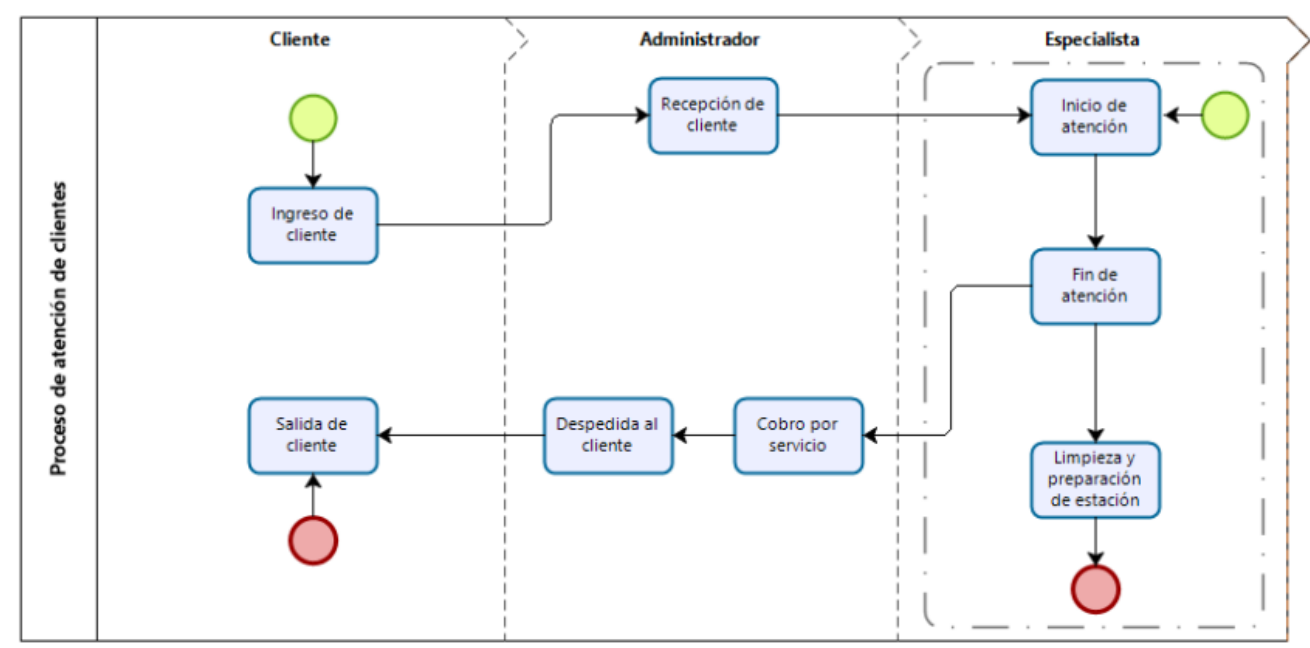

Figura 18 - Flujo de proceso de atención de clientes

Como se muestra en la tabla 46, se detallan los tiempos de atención del flujo de procesos.

Tabla 46.

Tiempos de atención del flujo de procesos

\begin{tabular}{llr}
\hline Nro & Proceso & Tiempo \\
\hline 1 & Ingreso de cliente & 0.5 minutos \\
2 & Recepción y ubicación de clientes & 1 minuto \\
3 & Inicio y proceso de atención & 32 minutos \\
4 & Fin de atención y preparación de estación & 3 minutos \\
5 & Cobro por servicio y despedida de cliente & 3 minutos \\
6 & Salida del cliente & 0.5 minutos \\
& Total & $\mathbf{4 0}$ minutos \\
\hline
\end{tabular}

Los procesos tres y cuatro de la tabla 46, corresponden al tiempo de atención de clientes, el cual se tomó en cuenta para los diferentes cálculos en los capítulos de Planificación Financiera y Evaluación Económica Financiera. 


\subsection{Determinación del Tamaño}

La determinación del tamaño en cualquier tipo de modelo de negocio es una variable importante para el éxito del mismo. En el modelo de negocio propuesto el servicio de manicura, cepillado y planchado de cabello se brindará dentro de 02 unidades móviles que contarán con espacio limitado donde en cada unidad se tendrán 4 posiciones ( 8 en total), sin embargo, se optimizará la distribución de los equipos y mobiliario para otorgar un servicio de calidad dentro de un ambiente acogedor con la finalidad de lograr la fidelización de las clientes y el crecimiento esperado.

Cabe indicar que esta determinación se logró en base al análisis realizado al tamaño del mercado objetivo y a las encuestas realizadas que arrojó que el $77.4 \%$ asiste a salones de belleza cada 4 semanas dando como resultado un promedio de 1.5 vistas al mes. En esta primera etapa estas 02 unidades estarán ubicadas estratégicamente en 02 entidades financieras para brindar el servicio determinándose un promedio de atención de 1,184 servicios por unidad al mes.

\subsubsection{Proyección de crecimiento.}

Este plan de negocio implementado a través de los aportes de los socios $50 \%$ y el otro $50 \%$ financiado, en su primera etapa brindará el servicio a través de dos unidades móviles ubicadas estratégicamente en las entidades financieras

El crecimiento del negocio se realizará básicamente con la adquisición de una tercera móvil proyectada para el tercer año donde se alcanzará el cumplimiento del pronóstico de ventas e ingresos debido al análisis financiero desarrollado.

Dentro de los factores limitantes, está el número de unidades con la que se iniciará el negocio y que incluirá solo 8 estaciones de servicio independientemente de la demanda que se pueda llegar a tener por parte de las clientes. Esto debido a que se priorizará la comodidad y espacio interno dejando de lado la colocación de estaciones de servicio adicionales. 
Otro de los factores a considerar son las condiciones existentes al inicio, como el hecho de que los contratos o acuerdos de servicio que se suscriban con las empresas en las que se ubicarán las unidades móviles detallarán los horarios de funcionamiento, los cuales serán de obligatorio cumplimiento. Esto se alinea a lo mencionado en la presentación del modelo de negocio donde se especifica que no se pretende afectar la productividad de los empleados, lo que podría traducirse en dejar de atender a clientes que lleguen con muy poco tiempo de antelación al término de los horarios que se manejaran.

\subsubsection{Recursos.}

En cuanto al recurso humano necesario para brindar el servicio se deben considerar los siguientes:

- 01 Gerente General, el cual estará encargado de planear y desarrollar las metas a corto y mediano plazo, así como de contactar y cerrar los contratos con las empresas que se visitarán.

- 02 Administradores, estarán encargados de la supervisión del personal y conducción de la unidad móvil. Un requisito indispensable para esta posición será el conocimiento o disposición a aprender y a realizar las labores de los especialistas en caso de ausencia de alguna de ellas, a manera de back up.

- 08 Especialistas, las cuales estarán encargadas de brindar el servicio de 10:00 a.m. a 7:00p.m.

- La asignación de turnos será la siguiente:

- 08 especialistas para el turno de 10:00 a.m. a 07:00 p.m., distribuidas en las 02 unidades móviles. 
Cabe mencionar que las especialistas deberán mantener su estación preparada para el servicio antes y después de finalizar su turno de trabajo, con lo que se puede asegurar que no habrá tiempos muertos.

\subsubsection{Flexibilidad.}

El administrador tendrá a su cargo la conducción de la unidad móvil y estará capacitado para atender a las clientes en caso de ausencia de alguna de las especialistas, con esto se cubre el $25 \%$ de inasistencias por parte del personal.

Cabe resaltar que, al momento de contactar y contratar a las especialistas, se les informará que, al contar con 02 unidades móviles con 8 módulos disponibles para la atención, las inasistencias no programadas o no comunicadas con la anticipación debida llevarán a reducir significativamente la cantidad de servicios prestados y, por consiguiente, una reducción en los ingresos. Adicionalmente, este hecho puede perjudicar la imagen de la empresa frente a las consumidoras.

\subsubsection{Selección del tamaño ideal.}

Durante esta parte del capítulo referido a la Ingeniería del Proyecto se hace énfasis, como en otras partes del proyecto, que tamaño inicial del modelo está directamente relacionado con el tamaño de la unidad móvil y de los implementos que se usarán. En base a ello se definió el tamaño ideal del vehículo y equipamiento según las características descritas en el punto 5.1.

\subsection{Determinación de la Localización Óptima}

La representación legal de la empresa estará ubicada en el domicilio de uno de los socios de la empresa, en el 2290 del Jirón Sinchi Roca, Dpto. 902 en Lince (referencia: altura Cdra. 11 de la Av. Canevaro). En esta ubicación permanecerán las unidades móviles fuera del horario de atención dado que cuenta con estacionamiento propio, no incurriendo en gastos de cochera. 


\section{Macrolocalización:}

Para determinar la macrolocalización y de acuerdo al modelo de negocio que se plantea no se tomaron en cuenta variables que quizás puedan afectar a un negocio con una ubicación fija. Como se mencionó anteriormente la unidad móvil se trasladará hacia los centros de trabajo, eliminando el traslado que realizan las clientes en busca de un servicio como el que se ofrece.

En un primer momento y tomando en cuenta el lugar de residencia de los socios, el modelo de negocio, la inversión realizada y el tipo de supervisión que se realizará la macrolocalización comprenderá la ciudad de Lima (ver figura 19).

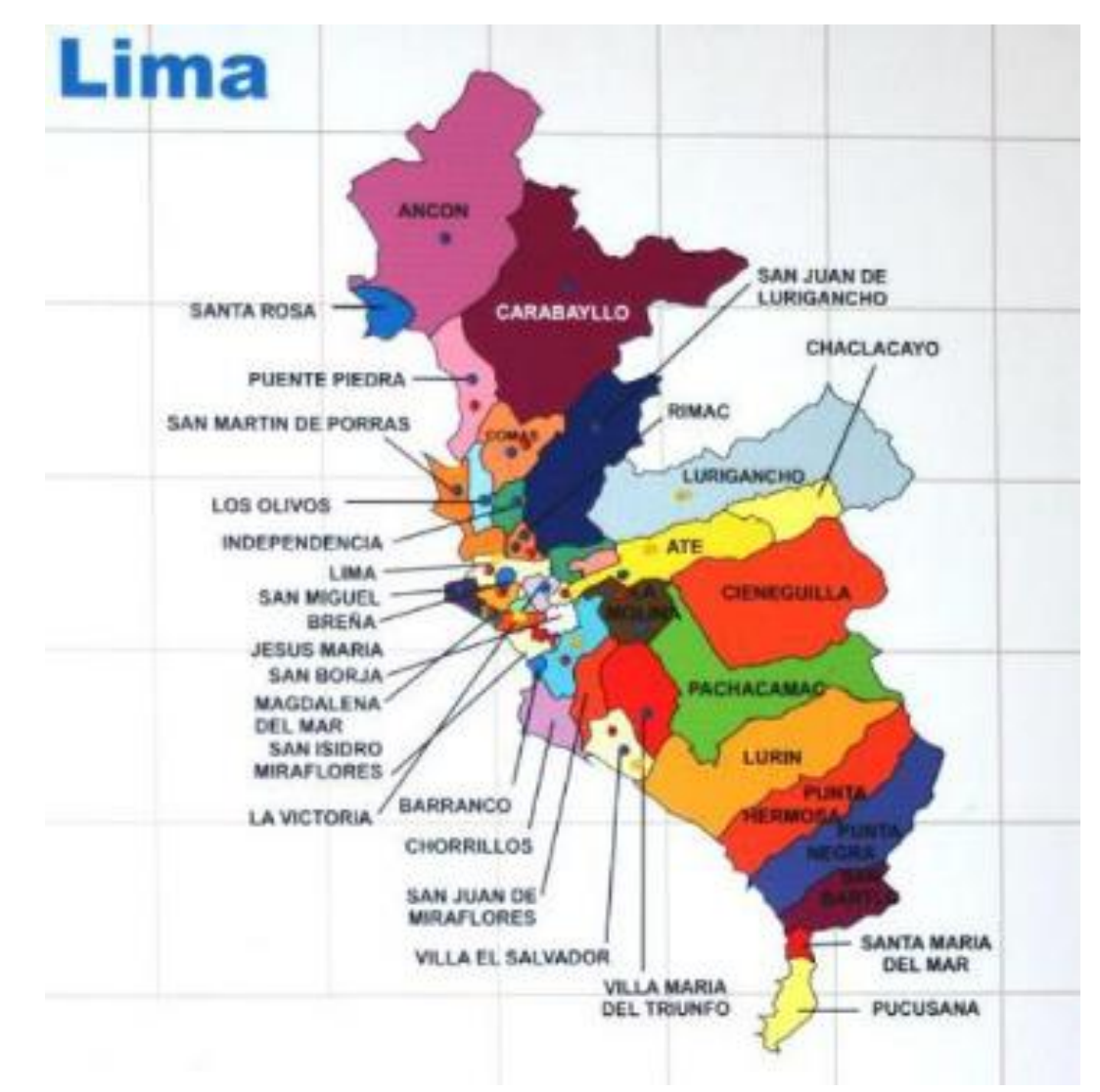

Figura 19 - Mapa de Lima metropolitana - Nota: Pinterest [en línea] https://www.pinterest.com/pin/622622717205793551/?1p=true

\section{Microlocalización:}

Para determinar la micro localización se tomó en cuenta los distritos en donde se ubican las dos sedes de las entidades financieras a las cuales se le brindará el servicio: Banco de Crédito - Chorrillos e Interbank - La Victoria. Asimismo, se tomó en cuenta la distancia de 
estas entidades entre sí porque la unidad móvil se desplazará en horas complicadas (hora punta).

Otra consideración fue la ubicación de la unidad móvil durante la noche y fines de semana, debido a que será el punto desde donde partirá a cumplir con el turno programado de $10 \mathrm{am}$ a $7 \mathrm{pm}$.

Como se puede apreciar el distrito más alejado en lo que a desplazamiento se refiere es Chorrillos, pero por la apertura de la entidad financiera al modelo y la concentración de trabajadores en un solo edificio compensa de cierta forma el recorrido de la unidad móvil hasta esa ubicación (ver figura 20).

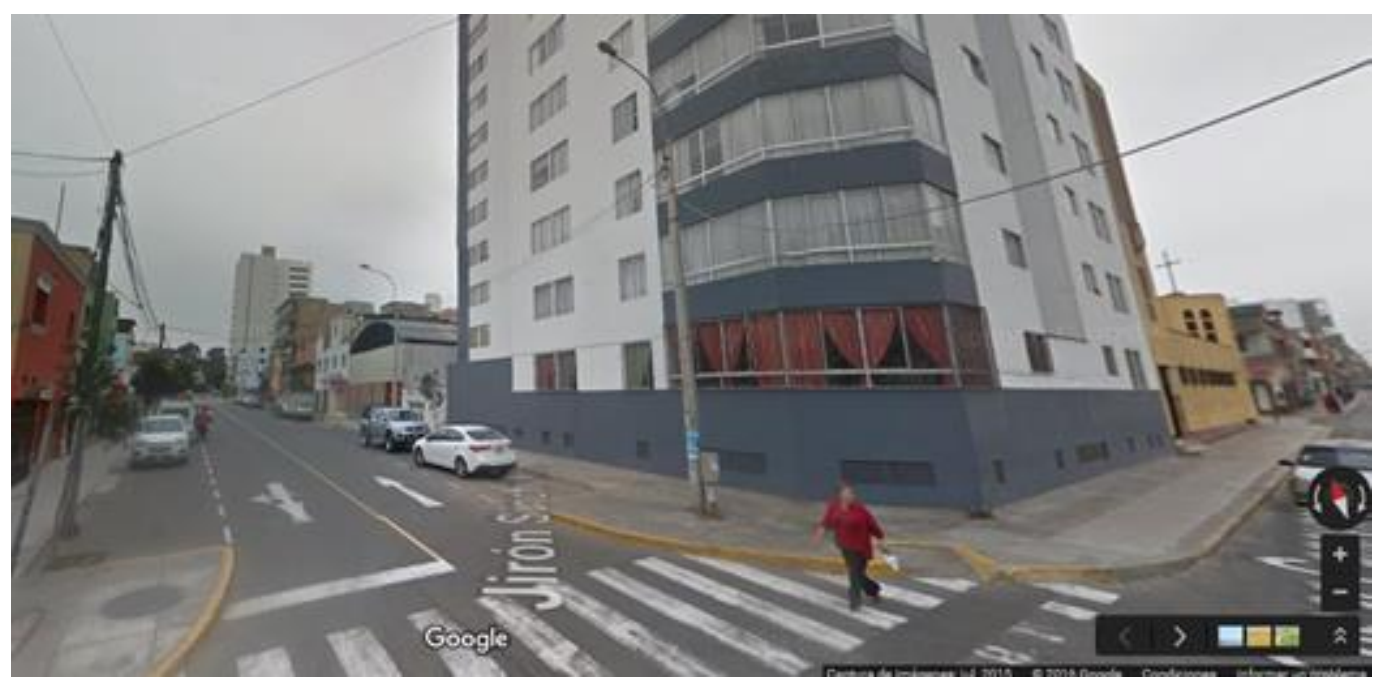

Figura 20 - Dirección legal - Nota: Google Maps [en línea] https://www.google.com/maps/@ 12.0848935,-77.044773,3a,75y,40.91h,94.85t/data=!3m6!1e1!3m4!1scYMkW2Bw9rNfyONNi7aYg!2e0!7i13312!8i6656https://www.pinterest.com/pin/622622717205793551/?lp=true 
En la figura 21 se aprecia que desde esta ubicación es factible acceder a las sedes de los bancos en los distritos de La Victoria y Chorrillos.

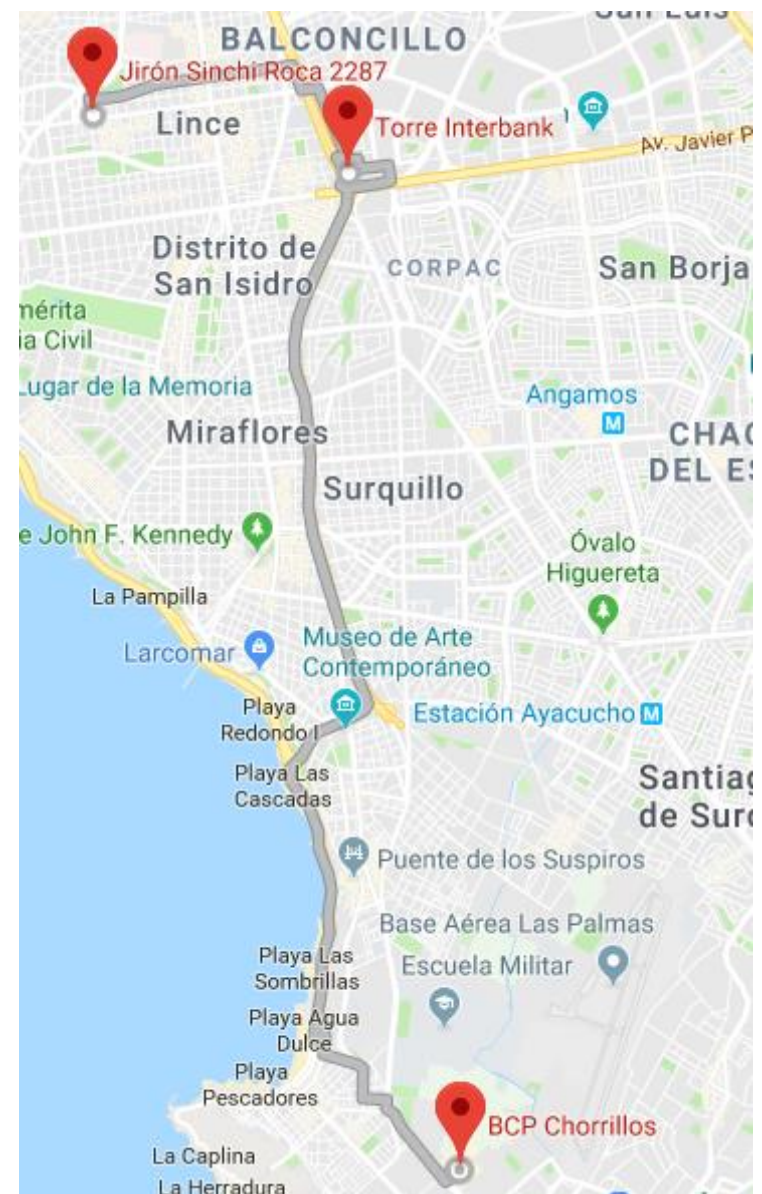

Figura 21 - Mapa de desplazamiento por distrito - Nota: Google Maps 


\section{Capítulo VI: Aspectos organizacionales}

\subsection{Caracterización de la Cultura Organizacional Deseada}

\subsubsection{Visión.}

La visión es el camino al cual se dirige la empresa a largo plazo y es la base para plantear las estrategias.

La empresa se orienta a ser la principal cadena de Salones de belleza rodantes o móviles, especializada a nivel nacional para lo cual se han considerado las tendencias tecnológicas, así como las necesidades y expectativas de los clientes.

\subsubsection{Misión.}

La misión determina el propósito o razón de ser de la existencia de la empresa.

Brindar a las colaboradoras de las entidades financieras los servicios de belleza de mayor demanda a través de un Salón de belleza móvil ubicado dentro de las instalaciones de su centro laboral; y a la vez mejorar los indicadores de clima laboral de estas entidades al contribuir con la calidad de vida e imagen de sus colaboradoras.

La misión se refuerza en las tendencias actuales donde se evidencia un claro interés de la mujer trabajadora por el cuidado de su imagen. Asimismo, existe un alto crecimiento a nivel global de tendencias que impulsan la búsqueda, casi imperante, del bienestar personal.

En síntesis, la misión está enfocada al cliente.

\subsubsection{Principios y valores.}

Los principios y valores se establecen para fomentar una buena comunicación y convivencia. Son el soporte de la misión, la visión y estrategias, y aplican para generar una buena imagen de la empresa y un entorno laboral positivo. 


\subsubsection{Misión, Visión, Principios y Valores.}

La Visión, Misión, Principios y Valores de la empresa se encuentran orientados al servicio y calidad hacia el cliente externo e interno.

Los principios y valores establecidos marcan la pauta para la correcta conducción de la empresa y al cumplimiento de los objetivos (ver tabla 47). 
Tabla 47.

Misión, Visión, Principios y Valores

\begin{tabular}{|c|c|c|c|}
\hline Visión & Misión & Principios & Valores \\
\hline $\begin{array}{l}\text { Ser la } \\
\text { principal } \\
\text { cadena de } \\
\text { Salones de } \\
\text { belleza } \\
\text { rodantes } \\
\text { especializad } \\
\text { os a nivel } \\
\text { nacional, } \\
\text { para lo cual } \\
\text { se han } \\
\text { considerado } \\
\text { las } \\
\text { tendencias } \\
\text { tecnológicas, } \\
\text { así como las } \\
\text { necesidades } \\
\text { y } \\
\text { expectativas } \\
\text { de los } \\
\text { clientes. }\end{array}$ & $\begin{array}{l}\text { Brindar a } \\
\text { las } \\
\text { colaborador } \\
\text { as de las } \\
\text { entidades } \\
\text { financieras } \\
\text { los } \\
\text { servicios de } \\
\text { belleza de } \\
\text { mayor } \\
\text { demanda a } \\
\text { través de un } \\
\text { Salón de } \\
\text { belleza } \\
\text { móvil } \\
\text { ubicado } \\
\text { dentro de } \\
\text { las } \\
\text { instalacione } \\
\text { s de su } \\
\text { centro } \\
\text { laboral; y a } \\
\text { la vez } \\
\text { mejorar los } \\
\text { indicadores } \\
\text { de clima } \\
\text { laboral de } \\
\text { estas } \\
\text { entidades al } \\
\text { contribuir } \\
\text { con la } \\
\text { calidad de } \\
\text { vida e } \\
\text { imagen de } \\
\text { sus } \\
\text { trabajadora } \\
\text { s. } \\
\text { abaid }\end{array}$ & $\begin{array}{l}\text { - Obtener la rentabilidad } \\
\text { y posicionamiento } \\
\text { dentro del sector } \\
\text { elegido que permita } \\
\text { crecimiento y } \\
\text { desarrollo. } \\
\text { - Destacar por el alto } \\
\text { nivel del servicio que } \\
\text { ofrece la empresa al } \\
\text { caracterizarnos por ser } \\
\text { competitivos, con } \\
\text { enfoque en la calidad e } \\
\text { innovación continua. } \\
\text { - Incluir la utilización de } \\
\text { productos naturales } \\
\text { para el cuidado de las } \\
\text { manos y cabello de las } \\
\text { clientes. } \\
\text { - Brindar calidad de vida } \\
\text { a los colaboradores, } \\
\text { velando por su } \\
\text { seguridad, desarrollo y } \\
\text { bienestar personal. } \\
\text { - Los colaboradores } \\
\text { deben tener un amplio } \\
\text { y profundo } \\
\text { conocimiento de las } \\
\text { normas de higiene } \\
\text { básicas, las cuales son } \\
\text { indispensables para el } \\
\text { buen desarrollo de las } \\
\text { actividades dentro y } \\
\text { fuera del Salón de } \\
\text { belleza. } \\
\text { - Atender las quejas y } \\
\text { sugerencias respecto } \\
\text { del servicio y del } \\
\text { personal con prontitud, } \\
\text { brindando siempre una } \\
\text { solución efectiva para } \\
\text { las clientes. }\end{array}$ & $\begin{array}{l}\text { Responsabilidad, Capacidad } \\
\text { para cumplir con los deberes } \\
\text { adquiridos, con puntualidad, } \\
\text { asistencia y productividad } \\
\text { Honestidad, los intereses } \\
\text { colectivos deben prevalecer al } \\
\text { interés particular y que el actuar } \\
\text { se realice con la debida } \\
\text { transparencia, enfocados a } \\
\text { alcanzar la misión de la empresa. } \\
\text { Lealtad, guardar } \\
\text { confidencialidad sobre la } \\
\text { información de la empresa y en } \\
\text { caso de conflicto de intereses } \\
\text { abstenerse de opinar de los } \\
\text { asuntos. } \\
\text { Respeto, implica la comprensión } \\
\text { y la aceptación de la condición } \\
\text { inherente a las personas como } \\
\text { seres humanos con derechos y } \\
\text { deberes en un constante proceso } \\
\text { de mejora espiritual y material. } \\
\text { Justicia, dar a cada quien lo que } \\
\text { le corresponde de conformidad } \\
\text { con sus méritos y los derechos } \\
\text { que le asisten. } \\
\text { Tolerancia, valorar a los demás } \\
\text { por lo que son y aceptar con } \\
\text { respeto lo distinto, lo diferente y } \\
\text { lo que no es igual a nosotros. } \\
\text { Imparcialidad, actuar con } \\
\text { legalidad, justicia e } \\
\text { imparcialidad tanto en la } \\
\text { prestación de servicios como en } \\
\text { las relaciones laborales sin tratar } \\
\text { con privilegio o discriminación, } \\
\text { sin tener en cuenta su condición } \\
\text { económica, social, ideológica, } \\
\text { política, sexual, racial, religiosa } \\
\text { Compromisor voluntad para } \\
\text { afro de un bien } \\
\text { antar reto en }\end{array}$ \\
\hline
\end{tabular}




\subsubsection{Formulación de Estrategias del Negocio}

El establecimiento de los principios y valores de la empresa tienen como objetivo alcanzar, en el mediano plazo, ser una de las mejoras empresas donde trabajar dentro del sector Salones de Belleza.

Al culminar el análisis interno y externo de la empresa se han identificado aquellas fortalezas, oportunidades, debilidades y amenazas con las cuales se ha construido la matriz AODF, a partir de la cual se desarrollan estrategias.

Se puede concluir que la empresa se encuentra en etapa de desarrollo la cual le permite crear servicios alternativos, difundir las características exclusivas de la empresa y buscar la consolidación en el sector (ver tabla 48). 
Tabla 48.

\section{Matriz AODF}

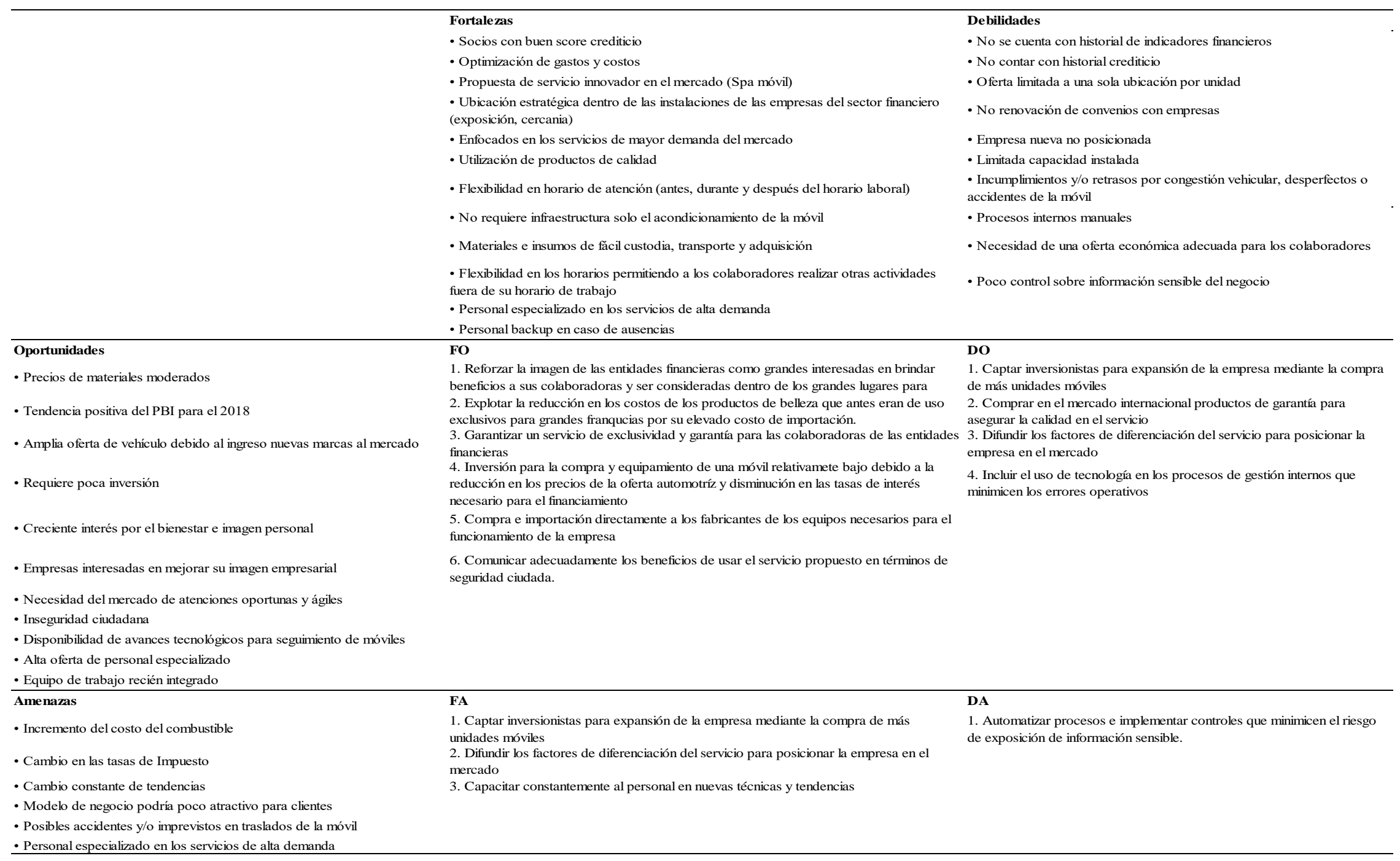




\subsection{Determinación de las Ventajas Competitivas}

La determinación de las ventajas competitivas en el presente plan de negocio está basada en los factores de diferenciación y en este proyecto se ha buscado obtener la preferencia de los clientes, estos factores se deben encontrar directamente relacionando el servicio o producto que se ofrece y debe ser fácil de recordar.

En el caso de este proyecto se pueden identificar 3 factores:

Servicio Móvil: Al ser un servicio móvil las colaboradoras de las empresas no tienen que preocuparse el tiempo que les tomará trasladarse hacia el local que les brinde el servicio, por el contrario, lo tendrán a su disposición en los horarios ya establecidos.

Seguridad: Con la creciente inseguridad que se vive en el país, el hecho de brindar el servicio en la misma ubicación donde ya se encuentran las colaboradas de las diferentes empresas evita que se expongan, por lo menos durante este proceso, a los peligros que actualmente se viven por solo hecho de transitar por la vía pública.

Agilidad en la atención: Al brindar servicios de relativamente corta duración (express), se asegura de que la percepción de las clientas sea que no necesitan invertir mucho tiempo en su cuidado personal. Además, de que los servicios que se brindarán aseguran una rápida rotación de clientes en las estaciones especialmente acondicionadas.

La identificación de estos tres criterios da como resultado el Factor de Diferenciación:

\section{“Salón de belleza Express, vamos a ti."}

De acuerdo a los resultados obtenidos mediante las entrevistas, Focus Group y encuestas realizadas se identificaron las preferencias de los participantes, las cuales junto con los factores de diferenciación mencionados permiten elaborar las ventajas competitivas lo cuales a su vez representan los factores de posicionamiento de la empresa.

- Atención exclusiva para colaboradoras del sector financiero dentro de las instalaciones de sus centros de labores. 
- Cero inversiones de tiempo por traslados.

- $\quad$ Agilidad y calidad en el servicio.

\subsection{Diseño de la Estructura Organizacional Deseada}

El diseño de la estructura organizacional deseada, se basa en una estructura formal que tiene como objetivo gestionar de forma eficiente la empresa. Entre las gestiones propias de la empresa destacan la generación de convenios, la eficiencia, la productividad y el clima laboral.

La estructura formal de la empresa busca alcanzar la eficiencia a partir de la adecuada división del trabajo y la especialización en las funciones.

La organización lineal de estructura sencilla permitirá a la empresa precisión en las gestiones, controlar las operaciones y delimitar las responsabilidades dentro de la organización. Asimismo, la departamentalización por funciones generará eficiencia en la utilización del recurso humano.

La empresa presenta un organigrama lineal en donde se grafican las relaciones de autoridad y comunicación. Funciona bajo una unidad de mando a fin de garantizar la coordinación (ver figura 22).

La estructura irá creciendo de forma piramidal en relación al crecimiento de la empresa. 


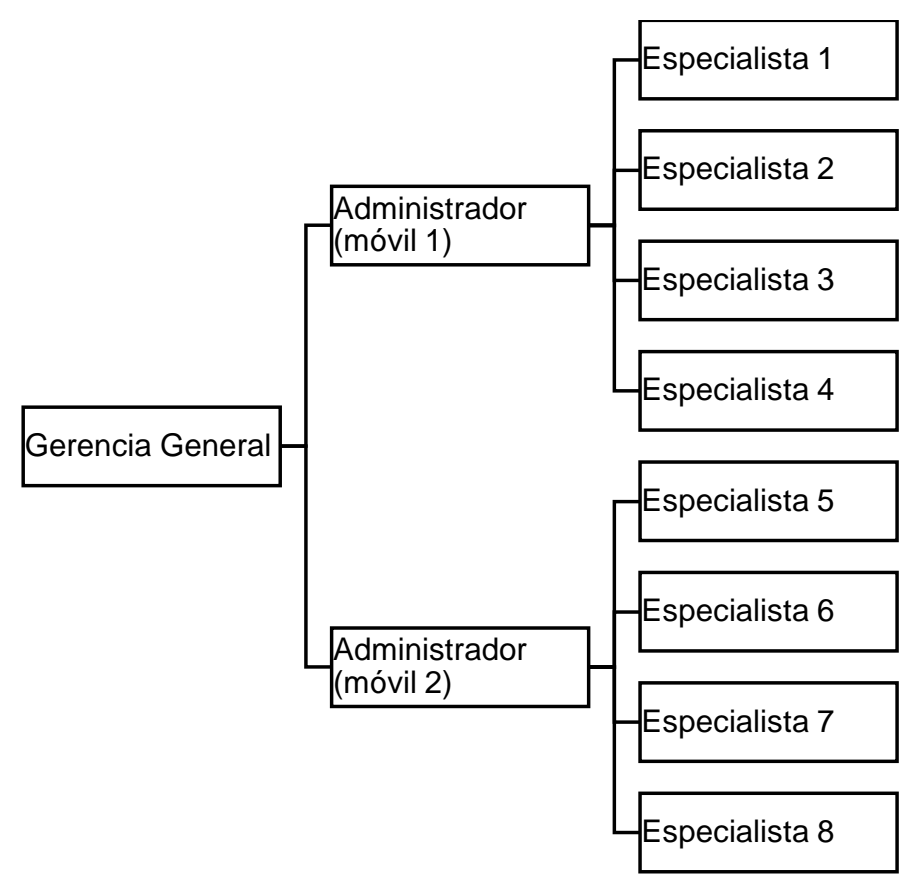

Figura 22 - Estructura organizacional

\subsection{Diseño de los Perfiles de Puestos Clave}

La adecuada distribución del trabajo facilita el cumplimiento de los objetivos de forma eficaz y eficiente. Por tal motivo, se asignan roles y funciones a cada miembro de la empresa.

Se busca consolidar una empresa conformada por personal especializado y capacitado que aseguraran el cumplimiento de los objetivos y compromisos internos y externos.

\section{Gerencia General:}

Personal con estudios de Administración, Ingeniería Industrial o Ingeniería Comercial. Además, deberá contar con las siguientes capacidades personales: experiencia en el manejo de relaciones sociales, capacidad de liderazgo y comunicación, alto desempeño bajo presión.

El Gerente tiene como función asegurar que las operaciones diarias del negocio fluyan correctamente. Es el encargado de tomar las decisiones en cuanto a nuevos convenios, contrataciones, facturación, entre otros.

Tendrá como función principal generar nuevos convenios con las empresas del sector financiero y realizar la modificación y/o renovación de los acuerdos existentes. 
Asimismo, sus funciones abarcan el desarrollo de políticas y procedimientos, manejo de los recursos humanos, análisis y equilibrio del presupuesto, desarrollo de una exitosa campaña de marketing, además de la supervisión de las unidades móviles.

Tendrá como función principal generar nuevos convenios con las empresas del sector financiero y realizar la modificación y/o renovación de los acuerdos existentes.

Asimismo, sus funciones abarcan el desarrollo de políticas y procedimientos, manejo de los recursos humanos, análisis y equilibrio del presupuesto, desarrollo de una exitosa campaña de marketing, además de la supervisión de las unidades móviles (ver figura 23).

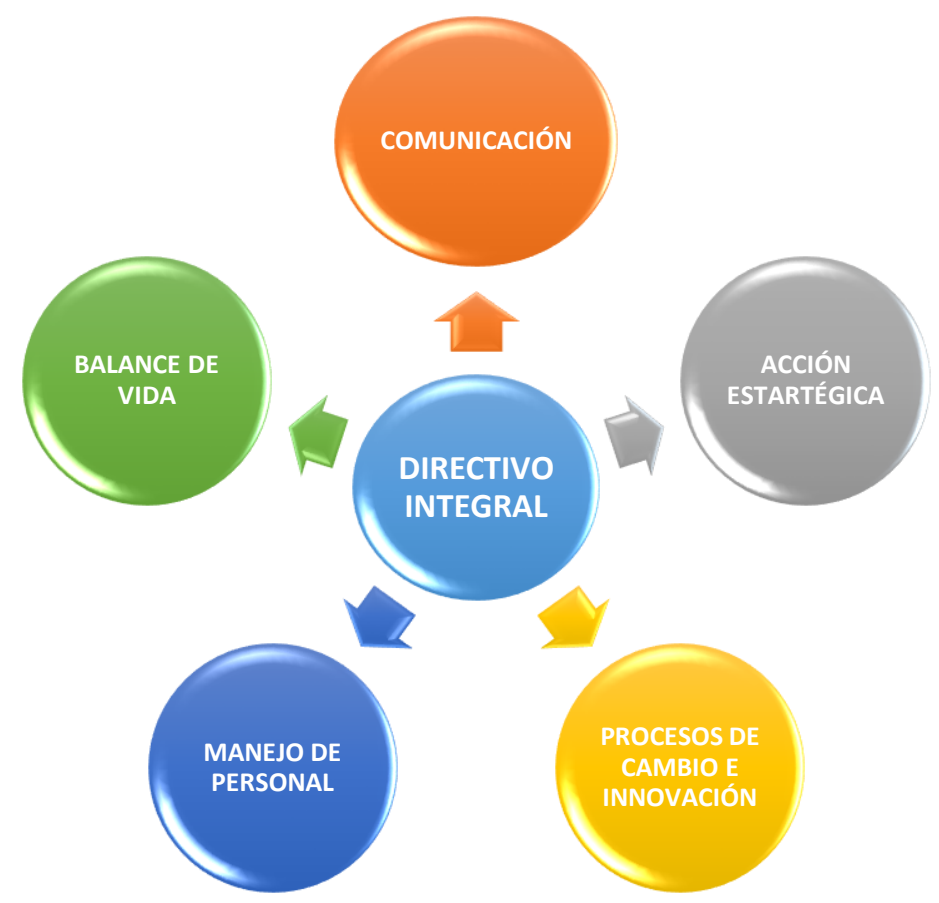

Figura 23 - Propuesta de valor del modelo de negocio

\section{Administradores:}

Personal con experiencia en el manejo de personal y con estudios especializados en el cuidado de las manos y cabello. Cordial y con enfoque de servicio. Además, deberá contar con licencia de conducir vigente y autorizada para el tipo de unidad móvil del negocio.

Entre sus funciones destacan:

- Supervisar el control de caja. 
- Coordinar trámites, documentación y/o pagos con entidades financieras.

- Responsable de la facturación de las atenciones a las clientes.

- Verificar el cumplimiento de las normas y reglamento de la empresa en cuanto a control y cumplimiento de horarios de trabajo, elaboración, delegación y programación de actividades de los colaboradores semanalmente.

- Ser el responsable de la atención a los clientes en: Dar información, resolver dudas, quejas, solución de problemas, etc. propias del Salón de belleza móvil.

- Atender al cliente en caso de ausencia del personal especialista.

- Apoyar al Gerente en la logística de la empresa, coordinación con proveedores, elaboración de inventarios y verificación del stock de productos del Salón de belleza móvil.

- Apoyar al Gerente en la promoción y publicidad de la imagen del Salón a través de campañas, eventos de la empresa en la atracción de clientes y ventas de productos propios del negocio

- Elaborar informes sobre los indicadores de gestión. Semanal, quincenal y mensual sobre la productividad del Salón de belleza móvil.

- Verificar que se cumplan los estándares de calidad en la atención de clientes del Salón de belleza móvil.

- Promover un óptimo clima laboral en el Salón de belleza móvil.

- Conducir la unidad móvil correctamente a fin de trasladar de forma segura al personal de la organización. Asimismo, informar sobre las fechas de mantenimiento de la unidad y de los desperfectos que se pudieran presentar.

\section{Especialistas:}

Conformado por el personal especializado y certificado en el cuidado de las manos y cabello que tiene como función principal atender a las clientes. Entre sus deberes se destaca la 
búsqueda de actualización constante, correcta utilización de insumos/maquinaria y brindar una excelente calidad de atención al cliente.

Los especialistas tendrán la responsabilidad de dejar al cierre de las operaciones diarias, sus ubicaciones de trabajo en perfecto estado (limpias).

\subsection{Remuneraciones, Compensaciones e Incentivos}

El sistema de remuneración de la empresa cumplirá con 3 variables: competitiva, atractiva y motivadora.

La estructura salarial será simple y equitativa a fin de evitar complejidades.

La remuneración estará compuesta por un salario base y por pagos variables según la posición y funciones, lo cual se detalla en la tabla 49.

Tabla 49.

Remuneraciones del personal

\begin{tabular}{llll}
\hline Puesto & Cantidad & Costo Unitario S/ & Costo Total S/ \\
\hline Gerente & 1 & S/ 4,000 & S/ 4,000 \\
Administrador & 2 & S/ 2,000 & S/ 4,000 \\
Especialista & 8 & S/ 1,400 & S/ 11,200 \\
Total & & S/ 7,400 & S/ 19,200 \\
\hline
\end{tabular}

Asimismo, la organización es consciente de que los incentivos son una herramienta poderosa para alcanzar el buen clima laboral dentro de la empresa y mejorar los índices de productividad.

Los incentivos que se brindarán serán de carácter monetario y no monetario:

\section{Monetario:}

La empresa entregará bonificaciones por superar el promedio de atenciones diarias. 
Se entregará una bonificación fija S/ 200.00 al final de cada mes al especialista que supere el promedio de atenciones diarias. Para determinar el promedio de atenciones se tomarán en cuenta el total de atenciones diarias en un mes y se encontrará el promedio. Aquel especialista (solo uno) que obtenga un promedio mensual de atenciones mayor al determinado recibirá la bonificación (ver tabla 50). Es importante aclarar es que esta bonificación y su cálculo será hecho para cada móvil.

Tabla 50.

Bonificaciones al personal

Mecánica Bonificación

Superar el promedio de atenciones $\quad$ Bonificación: S/ 200.00

diarias

\section{No monetario:}

Establecer un programa de beneficios que fomente la motivación y el buen clima laboral de la empresa. El programa contará con lo siguiente:

- Horario Flexible, administrar correctamente los horarios con la finalidad de cubrir la demanda esperada y contribuir con la calidad de vida de los colaboradores. Intensificar el horario de lunes a jueves con la finalidad de brindar tiempo libre los viernes por la tarde.

- Reconocimiento de logros, felicitar el esfuerzo y los logros obtenidos por parte del personal, considerando los logros internos, felicitaciones recibidas por parte de los clientes y también los logros que a nivel personal cumplan los colaboradores.

\subsection{Política de Recursos Humanos}

Las políticas de recursos humanos se basan en la misión, principios y valores de la organización. 
El objetivo de las políticas es asegurar una gestión eficaz del recurso humano, entre ellas se tiene:

- Asegurar la interiorización y cumplimiento de los valores de la organización.

- Trabajar con los mejores, lo cual implica contratar al personal calificado e incentivar el desarrollo profesional constante.

- Comunicación eficaz, a fin de que interioricen la cultura organizacional.

- Velar por la salud y seguridad de los colaboradores, alineados a las regulaciones laborales se promueve una cultura de prevención dentro de la organización.

- Fidelizar al personal alineado con los objetivos de la empresa.

- Mantener bajo nivel de ausentismo y evitar la rotación del personal especializado.

- Mejorar la comunicación interna de la empresa.

- Fomentar el bienestar personal a través de la búsqueda del equilibrio personal/profesional de los colaboradores, lo cual no solo se traduce en eficiencia, sino que también genera buena reputación, mantiene motivado al personal y atrae al talento humano. 


\section{Capítulo VII: Plan de Marketing}

En este capítulo se detallan las estrategias de marketing que se desplegarán las cuales se basan en la fortaleza innovadora del plan de negocio sobre la puesta en marcha de un Salón de belleza móvil.

El objetivo principal es posicionar la marca dentro del mercado, inicialmente dentro del sector financiero, teniendo como premisa principal la satisfacción del cliente.

\subsection{Estrategias de Marketing}

Para poder lograr el posicionamiento de la marca en el mercado se requiere planificar las estrategias y concretar la implementación de las mismas, con la finalidad de asegurar el éxito.

La principal estrategia se basa en el servicio innovador que se describe en el presente plan de negocios, salón de belleza que va hacia el cliente, el cual no cuenta con competencia directa en el mercado.

Las estrategias que se describan en cada uno de las variables están alienadas con el objetivo de lograr el posicionamiento y tienen como base resaltar el modelo innovador.

La estrategia de cara a las clientes es la de resaltar la conveniencia del servicio, el cual se basa en la cercanía, agilidad y calidad.

Asimismo, es importante contar con el apoyo de las entidades financieras para que efectúen la difusión y comunicación del servicio a sus colaboradoras a través de su sistema de comunicación interno.

Por otro lado, la estrategia estará acompañada de la difusión de los beneficios de la propuesta a las entidades financieras, tales como alinearse a las tendencias actuales de las grandes empresas de incluir servicios dentro de sus instalaciones. 


\subsubsection{Estrategias de producto.}

La propuesta de negocio les ofrece a las trabajadoras del sector financiero un servicio estético especializado en el cuidado de las manos o manicura, cepillado y planchado de cabello que les permita recibir un tratamiento ágil, oportuno y de calidad en un ambiente agradable dentro de las instalaciones de su centro de labores, con el fin de impactar favorablemente en la salud e imagen de las personas, así como en su bienestar personal.

En cuanto a las entidades financieras, les ofrece la posibilidad de facilitar a sus colaboradoras un servicio de salón de belleza dentro de las instalaciones de la empresa, el cual será captado como un beneficio adicional. Las entidades financieras no tendrán que invertir en la construcción de instalaciones ni tampoco destinar un espacio permanente dedicado a este fin.

Para buscar marcar la diferencia en cuanto al servicio, será imprescindible considerar los factores más valorados por el público objetivo según los datos recogidos en la investigación cualitativa y cuantitativa, los cuales son: agilidad en la atención y calidad del servicio.

- Agilidad: cumplimiento de los tiempos de atención con la finalidad de no perjudicar otras actividades del cliente.

- Calidad: capacidad de mantener un estándar de atención de acuerdo a los atributos valorados por el cliente, lo cual incluye el ambiente, servicio, productos, entre otros.

En cuanto a la marca, esta engloba no solo el nombre y el logo de la empresa, sino también la esencia de la propuesta de negocio para los clientes. El nombre, logo y eslogan serán el distintivo que representará a la empresa dentro del mercado.

- Nombre: la creación del nombre se basó en la agilidad del servicio. Este se conforma por las palabras "Salón de belleza", las cuales hacen referencia a un lugar donde se 
ofrecen tratamientos que buscan resaltar la belleza además de brindar un tiempo de relajación y disfrute; y por la palabra "Express" que se refiere a rapidez.

También se consideró que, según la investigación cuantitativa, el 60\% de las encuestadas no asiste a un salón de belleza por falta de tiempo.

Como resultado se obtuvo el nombre: "Salón de belleza Express"

- Eslogan: corresponde a la frase corta y de fácil recordación que expresa el concepto de la propuesta de negocio. Asimismo, diferencia a la empresa de la competencia.

"Vamos a ti"

- Logo: es la herramienta para el reconocimiento visual dentro del mercado. La utilización de los colores, fuente de letra y formas simbolizan el concepto de la propuesta de negocio.

\subsubsection{Estrategias de precio.}

Según Kotler (Kotler \& Armstrong), la fijación de precio por valor agregado, esta referenciado a ofrecer características y servicios de valor agregado para diferenciar las ofertas de una compañía y poder cobrar precios más elevados.

Adicionalmente como resultado de la encuesta realizada en el presente plan de negocio específicamente en el capítulo III.4.2. Diseño de instrumento en la pregunta 17, el $90.6 \%$ de las clientes estarán dispuestas a pagar un valor adicional al precio actual y el 53.6\% estarán dispuestas a pagar un adicional de S/ 5 hasta a más del precio de lista por los servicios que recibirán.

Bajo estos puntos se ha considerado por la característica innovadora de este servicio que va hacia el cliente, aplicar los precios según la tabla 51. 
Tabla 51.

Precios propuestos

Servicio

Precio

Manicura un solo color

S/ 20.00

Manicura Francesa

S/ 23.00

Manicura con Gel

S/ 65.00

Manicura con Diseño

S/ 23.00

Cepillado de cabello

S/ 40.00

Planchado de cabello

S/ 40.00

Para las entidades financieras en donde se tendrá presencia, se determinó que no se les cobrará importe alguno.

Dado que el servicio ofrecido tiene cierta exclusividad en virtud a los convenios establecidos con las entidades financieras en las cuales se brindará el servicio, la propuesta es ingresar al mercado con una estrategia de precios diferenciados dada la inexistencia de un modelo de servicio similar en el mercado.

La base de la estrategia de precio son los costos de servicios y gastos de operación, precios de la competencia y los resultados de las encuestas y focus groups.

\subsubsection{Estrategias de distribución.}

Se utilizará una estrategia de distribución exclusiva y directa dado que el servicio se brindará en las entidades financieras seleccionadas, las cuales cuentan con espacio en sus instalaciones para la ubicación de la móvil. Asimismo, estas sedes son las que concentran la mayor cantidad de trabajadoras debido a que albergan a las áreas administrativas. Según información de la Asociación de Bancos del Perú, al cierre del 
2018 la participación de las mujeres en la fuerza laboral del sector bancario alcanzó el 53\% (Diario La República, 2019).

Según se ha analizado, la demanda estimada para las dos entidades financieras seleccionadas supera la capacidad instalada mensual de las móviles (una móvil versus una entidad financiera). En ese sentido, las móviles permanecerán cada una en una entidad financieras seleccionadas. En otras palabras, no habrá mayor movimiento de las móviles en esta primera etapa.

\subsubsection{Estrategias de promoción y publicidad (comunicación).}

"Las ventas personales y la publicidad suelen trabajar muy cerca con otra herramienta, la promoción de ventas. La promoción de ventas consiste en incentivos a corto plazo para fomentar la compra o venta de un producto o servicio. Mientras que la publicidad ofrece razones para comprar un producto o servicio, la promoción de ventas ofrece razones para comprar en el momento" (Kotler \& Armstrong, 2012).

Las estrategias de promoción y publicidad son valiosas para cualquier empresa dado a que colaboran con el incremento de las ventas y posicionamiento de la marca en el mercado.

El plan de promoción tiene como fin atraer clientes. Como estrategia de promoción inicial se lanzará la campaña "Tu primer express gratis" en donde el cliente podrá solicitar un servicio gratuito durante el primer mes de ejecución del Salón de belleza móvil en su centro de labores.

La campaña tiene la siguiente estructura:

- Vigencia: durante el primer mes de ejecución en la entidad financiera

- Aplica: solo podrá elegir un servicio

- Restricciones: no aplica para manicura gel o manicura con diseño 
El objetivo de la publicidad es difundir la marca, resaltando el factor diferenciador de la propuesta de negocio.

La publicidad principal se realizará a través de los portales/páginas internas de las dos entidades financieras en donde se brindará el servicio. Es de conocimiento que las empresas del sector financiero cuentan con una intranet en donde se comunica de forma oportuna información relevante a todos los colaboradores de le empresa. Asimismo, se publicitarán los servicios en los murales internos que puedan encontrarse dentro de las empresas.

A pesar de que la propuesta de negocio inicia con un mercado acotado, dos sedes de entidades financieras, contará con los siguientes canales:

- Página web: se creará un sitio web que tendrá información de la empresa, la visión, misión y el detalle de los servicios que se brindan. Se resaltará la esencia de la propuesta innovadora que es la de trasladar el salón de belleza a las empresas para la atención de sus trabajadoras.

La página contará con un formulario de contacto en donde las empresas interesadas podrán solicitar la visita de un representante para conocer a detalle la propuesta de negocio.

La web se actualizará según se determinen cambios o lanzamientos que requieran comunicarse al público.

- Redes sociales: la empresa contará con Facebook e Instagram, plataformas que permitirán conectar con un mayor número de personas, lo cual facilitará la difusión de la marca.

En ambos casos, los costos de esta comunicación serán mínimos y no significarán mayores inversiones. 
Cabe señalar que el Gerente General tendrá a su cargo el cierre de acuerdos con las entidades financieras, por lo que contactará a las áreas de recursos humanos de estas empresas con el fin de mostrar el modelo de negocio con todos los beneficios asociados. Este contacto será a través de visitas físicas y/o llamadas telefónicas principalmente.

\subsubsection{Estrategias de personas.}

Con la finalidad de brindar un servicio de la más alta calidad es vital la contratación de personas con experiencia suficiente y comprobada en el rubro al cual se apunta, el contexto actual en el país permite que existan innumerables lugares de formación lo que amplía la oferta; sin embargo, no basta con tener los estudios sino la experiencia. Se sabe que la percepción que se lleve el cliente al recibir su primer servicio es determinante para que este transmita la información de boca a boca que a fin de cuentas es uno de los medios más útiles para la promoción de cualquier negocio. Lo antes mencionado se puede traducir en una ventaja diferencial sobre competidores directos (aunque no brinden un servicio exactamente igual al propuesto).

Un negocio no puede evolucionar o proyectar una imagen que llame la atención de los clientes si no se encuentra a la vanguardia de las tendencias técnicas actuales, por lo que la capacitación constante es de suma importancia.

Todo lo antes mencionado se debe traducir en una atención que permita que el cliente vuelva no solo por la cercanía del servicio sino por la calidad ofrecida no solo en el resultado final sino también en el trato.

\subsubsection{Estrategias de procesos.}

La mejora en los procesos va de la mano con la atención que percibe el cliente en cada una de sus visitas por lo que se desarrollarán encuestas anónimas físicas o virtuales que permitan conocer que tareas se deben afinar a fin de evolucionar en el mercado, toda 
la información que se pueda recabar se debe reflejar en acciones que impacten directamente en el negocio. Un punto fundamental es que el cliente debe notar que todo lo relacionado y utilizado para su atención está organizado por lo que las estrategias a seguir serán:

- Automatizar el sistema de cobranza y facturación.

- Gestión eficiente de reposición de materiales para optimizar el tiempo entre servicio y servicio.

- Medición correcta de tiempo de atención con la finalidad de cumplir los horarios y rotación optima de clientes en las estaciones de servicio implementadas.

\subsubsection{Estrategias de posicionamiento (ambiente).}

El presente modelo de negocio tiene como fin posicionar la marca en las trabajadoras de las sedes administrativas de las entidades financieras que no disponen de mucho tiempo para acudir a salones de belleza o cuya frecuencia es limitada, eliminando el traslado al salón además de brindar un servicio oportuno, ágil y de calidad.

Al tratarse de una nueva propuesta el posicionamiento se dará solo con un buen servicio y lógicamente a través del tiempo. Si bien el servicio se brindará dentro de la entidad financiera y el tema del traslado de los clientes no será un problema, el riesgo nace en el hecho de que si la percepción inicial no es buena esto sería muy difícil de revertir en el corto plazo afectando el flujo de efectivo.

Las estrategias que se usarán se basarán en reforzar el hecho de la cercanía y familiaridad con la que se brindarán los servicios, el ambiente estará diseñado de tal forma que se disimule la sensación de estar dentro de una móvil. Si bien se realizarán servicios express, esto no debe reflejarse en el equipamiento y en la sensación que se trata de transmitir al cliente. 
Finalmente, de acuerdo a la cantidad de ventas se realizarán promociones que afiancen el vínculo entre el negocio y las clientas, de esta forma y tomando en cuenta que el tamaño del mercado al cual se apunta es bastante especifico, el nombre de la empresa trascenderá entre las instituciones que apuesten por el servicio. 


\section{Capítulo VIII: Planificación Financiera}

\subsection{La Inversión}

Luego de identificar el mercado objetivo y el tipo de estructura organizacional de la empresa se determina el importe requerido para la ejecución y financiamiento del proyecto.

La inversión consiste en adquirir bienes a fin de obtener rentabilidad en el tiempo.

\subsubsection{Inversión pre-operativa.}

La inversión necesaria para iniciar la puesta en marcha del proyecto asciende a S/ 253,284 (ver tabla 52). El activo fijo consta de la inversión en dos vehículos, los muebles correspondientes y los utensilios necesarios para realizar el servicio. En esta primera etapa del proyecto se atenderán en dos establecimientos bancarios. 
Tabla 52.

Inversión Pre-operativa (CAPEX)

\begin{tabular}{|c|c|c|c|c|}
\hline Descripción Ítems & Área & Unid. & Costo & Total \\
\hline Camioneta & Producción & 2 & 98,000 & 196,000 \\
\hline Acondicionamiento & Producción & 2 & 17,500 & 35,000 \\
\hline Mesas & Producción & 8 & 350 & 2,800 \\
\hline Sillas & Producción & 8 & 175 & 1,400 \\
\hline Maquina Secante & Producción & 2 & 1,700 & 3,400 \\
\hline Recipiente remojador uñas & Producción & 24 & 50 & 1,200 \\
\hline Juego de Limas & Producción & 90 & 0.20 & 18 \\
\hline Set de Manicura & Producción & 16 & 50.00 & 800 \\
\hline Peines y Cepillos & Producción & 60 & 5 & 300 \\
\hline Plancha para cabello & Producción & 8 & 100 & 800 \\
\hline Esterilizador & Producción & 2 & 400 & 800 \\
\hline Secadora de cabello & Producción & 4 & 534 & 2,136 \\
\hline Mandiles & Producción & 100 & 5 & 500 \\
\hline Laptops - Gerente General & Administración & 1 & 2,500 & 2,500 \\
\hline Laptops & Administración & 2 & 2,500 & 5,000 \\
\hline Celulares & Administración & 3 & 210 & 630 \\
\hline Total & & & & 253,284 \\
\hline
\end{tabular}

El $93 \%$ de este importe estará destinado a la compra de los vehículos y su acondicionamiento para realizar los servicios. Asimismo, se ha contemplado un aproximado de 7\% de la inversión para la compra de equipos de cómputo necesarias para 
el proceso y todos los utensilios requeridos de acuerdo a los servicios planteados y que la empresa ofrece.

\subsubsection{Inversión en capital de trabajo.}

El capital de trabajo es la inversión que se requiere para iniciar el servicio y ayudará a sostenerlo hasta lograr el nivel adecuado de ingresos que permita pagar los compromisos básicos (Punto de Equilibrio). Se ha estimado que a los tres meses se debe lograr esta meta.

La inversión en capital de trabajo está compuesta por los insumos, salarios y permisos requeridos para el funcionamiento de la empresa. Como se muestra en la tabla 53, el capital de trabajo será de S/ 111,406:

Tabla 53.

Presupuesto de Fondos (1 Trimestre)

\begin{tabular}{lrr}
\hline Capital de trabajo & Total & $\%$ \\
& & \\
\hline Mercadería & 28,576 & $21.0 \%$ \\
Personal Producción & 42,493 & $40.5 \%$ \\
Gastos Operativos & 40,338 & $38.5 \%$ \\
Sub Total OPEX & 111,406 & $100.0 \%$ \\
\hline
\end{tabular}

El capital de trabajo incluye mercadería a utilizarse en los primeros tres meses de acuerdo a las proyecciones efectuadas, el salario total de 8 especialistas por tres meses, los gastos operativos y administrativos, así como el sueldo de tres meses del personal administrativo. Esta parte está incluida en la partida de "Gastos Operativos". En el caso de las planillas (producción y administración), el valor considerado incluye los beneficios 
laborales de ley bajo el régimen de Mype laboral y Tributario. El flujo operativo demuestra que con el nivel de capital de trabajo planteado y asumiendo que las ventas acompañarán al modelo de negocio propuesto, se tiene el flujo operativo para el primer año como se muestra en

la tabla 54:

Tabla 54.

Flujo neto de caja proyectado

\begin{tabular}{|c|c|c|c|c|c|c|c|c|c|c|c|c|c|}
\hline Per & Mes 1 & Mes 2 & Mes 3 & Mes 4 & Mes 5 & Mes 6 & Mes 7 & Mes 8 & Mes 9 & Mes 10 & Mes & Mes & $\begin{array}{l}\text { Total } \\
\text { Año } 1\end{array}$ \\
\hline Inver & - & - & - & - & - & - & - & - & - & - & - & - & - \\
\hline Tota & & & & & & 1 &, 435 & & & & & & $60 s$ \\
\hline Total Costo de Ventas & $-17,914$ & $-18,937$ & $-21,222$ & $-22,346$ & $-25,414$ & $-23,469$ & $-24,184$ & 928 & $-25,414$ & $-26,162$ & -25 & $-27,666$ & $-284,276$ \\
\hline Total gastos Fijos sin Dep. & $-25,589$ & $-20,289$ & $-19,789$ & $-20,789$ & $-19,789$ & $-19,789$ & $-19,789$ & $-20,789$ & $-19,789$ & $-19,789$ & $-19,789$ & $-20,789$ & $-246,763$ \\
\hline Total Gastos Financieros & $-2,279$ & $-2,279$ & $-2,279$ & $-2,279$ & $-2,279$ & $-2,279$ & $-2,279$ & $-2,279$ & $-2,279$ & $-2,279$ & $-2,279$ & $-2,279$ & $-27,352$ \\
\hline Saldo (Ingresos - Egresos) & $-25,785$ & $-25,785$ & $-5,650$ & $-1,783$ & 12,510 & 4,084 & & & 12,510 & 15,755 & 13,406 & 21,269 & 41,453 \\
\hline Saldo Acumulado & $-25,785$ & $-51,569$ & $-57,220$ & $-59,003$ & $-46,492$ & $-42,408$ & $-35,225$ & $-21,487$ & $-8,977$ & 6,778 & 20,185 & 41,453 & \\
\hline
\end{tabular}

\subsubsection{Ingresos del proyecto.}

Los Ingresos del proyecto se sustentan en los servicios a brindar y estos se enfocan principalmente en Planchado, Cepillado y Manicura.

Este proyecto buscar ser prudente en los cálculos y estimaciones de la demanda de los servicios, pero apoyados en una buena comunicación y estrategia de marketing para llegar al público objetivo. Se ha planteado la meta de lograr ser un negocio auto sostenible a partir del cuarto mes de funcionamiento. Se ha estimado un margen unitario promedio de $50.7 \%$ el cual se obtuvo de la información recabada del mercado y cálculos propios tal como se muestra en la tabla 55: 
Tabla 55.

Ingresos del proyecto

\begin{tabular}{|c|c|c|c|c|c|c|c|}
\hline Servicios & Planchado & Cepillado & $\begin{array}{l}\text { Manicura Un } \\
\text { color }\end{array}$ & $\begin{array}{c}\text { Manicura } \\
\text { Francesa }\end{array}$ & $\begin{array}{c}\text { Manicura } \\
\text { Gel }\end{array}$ & $\begin{array}{l}\text { Manicura } \\
\text { Diseño }\end{array}$ & Promedio \\
\hline Precio & 40.00 & 40.00 & 20.00 & 23.00 & 65.00 & 23.00 & 35.17 \\
\hline Valor de Venta & 33.90 & 33.90 & 16.95 & 19.49 & 55.08 & 19.49 & 29.80 \\
\hline Costo Servicio & -12.83 & -11.83 & -12.08 & -12.23 & -14.33 & -12.23 & -12.59 \\
\hline Margen & 21.07 & 22.07 & 4.87 & 7.26 & 40.75 & 7.26 & 7.21 \\
\hline$\%$ Margen & $62.2 \%$ & $65.1 \%$ & $28.7 \%$ & $37.3 \%$ & $74.0 \%$ & $37.3 \%$ & $50.7 \%$ \\
\hline Tiempo Utiliz (min) & 30.00 & 30.00 & 30.00 & 30.00 & 60.00 & 30.00 & 35.00 \\
\hline Margen $*$ Min & 0.70 & 0.74 & 0.16 & 0.24 & .68 & 0.24 & \\
\hline
\end{tabular}

Un dato relevante a tomar en cuenta es el Margen por Minuto. Este indicador permitirá enfocar el negocio a los servicios más eficientes y rentables combinado con campañas promocionales que apunten a este objetivo financiero en la medida que sea necesario o posible. 
Por otro lado, se ha calculado la capacidad del negocio. Se calculó la cantidad de servicios que se puede brindar en cada uno de los establecimientos teniendo en cuenta el tiempo que toma cada servicio (ver tabla 56), con lo cual se ha dimensionado que el número de servicios que se puede brindar en un año por cada móvil es de 15,799 servicios (ver tabla 57).

Tabla 56.

Capacidad de producción diaria por vehículo

\begin{tabular}{|c|c|c|c|c|c|c|c|c|}
\hline Turnos & Banda Hor. & $\begin{array}{c}\text { Q } \\
\text { horas }\end{array}$ & Q Minutos & Minutos * Serv & $\begin{array}{c}\mathbf{Q} \\
\text { Servicios }\end{array}$ & Q Sillas & Q Servicios & Obs. \\
\hline Mañana & 7:00 a 9:00 & & & 35.00 & & 4.00 & & Descartado \\
\hline Medio día & $10: 00$ a $15: 00$ & 5.00 & 300.00 & 35.00 & 8.75 & 4.00 & 34.00 & \\
\hline Tarde & $15: 01$ a 19:00 & 4.00 & 240.00 & 35.00 & 6.86 & 4.00 & 27.00 & \\
\hline \multicolumn{2}{|c|}{ Capacidad disponible diaria: } & 9.00 & 540.00 & & 15.43 & & 61.00 & \\
\hline
\end{tabular}


Tabla 57.

Capacidad de producción anualizada

\begin{tabular}{|c|c|c|c|c|c|c|}
\hline Meses & Días mes & Feriados & Sáb y Dom & Días Efectivos & Atenciones & Ingresos \\
\hline Enero & 31 & 1 & 8 & 22 & $1,342.00$ & 39,995 \\
\hline Febrero & 28 & & 8 & 20 & $1,220.00$ & 36,359 \\
\hline Marzo & 31 & & 8 & 23 & $1,403.00$ & 41,813 \\
\hline Abril & 30 & 2 & 8 & 20 & $1,220.00$ & 36,359 \\
\hline Mayo & 31 & 1 & 8 & 22 & $1,342.00$ & 39,995 \\
\hline Junio & 30 & 1 & 8 & 21 & $1,281.00$ & 38,177 \\
\hline Julio & 31 & 2 & 8 & 21 & $1,281.00$ & 38,177 \\
\hline Agosto & 31 & & 8 & 23 & $1,403.00$ & 41,813 \\
\hline Setiembre & 30 & & 8 & 22 & $1,342.00$ & 39,995 \\
\hline Octubre & 31 & 1 & 8 & 22 & $1,342.00$ & 39,995 \\
\hline Noviembre & 30 & 1 & 8 & 21 & $1,281.00$ & 38,177 \\
\hline Diciembre & 31 & 1 & 8 & 22 & $1,342.00$ & 39,995 \\
\hline Total año & & 10 & & 22 & $15,799.00$ & 470,846 \\
\hline Total unidades & & 2 & & & $31,598.00$ & 941,692 \\
\hline
\end{tabular}

*El importe mostrado es a máxima capacidad en un primer año

Respecto a la demanda, para el primer año se está considerando alcanzar 65\% de uso de la capacidad de servicios que se puede brindar con las dos unidades habilitadas (ver tabla 58): 
Tabla 58.

Capacidad de servicio (nuevos soles)

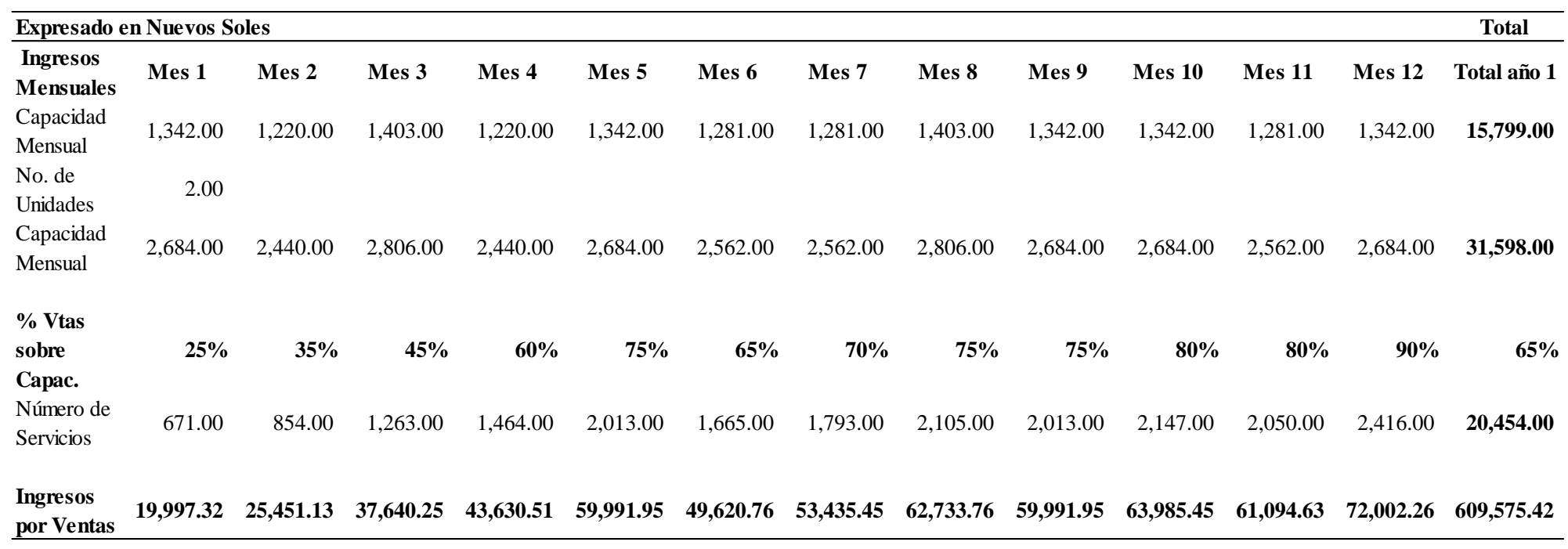

Por principio de prudencia y con el objetivo de no generar falsas expectativas entre los inversionistas u socios y de acuerdo a las experiencias y/o data de negocio recopilado de estudios efectuados para proyecto de tesis consultadas, se ha estimado un nivel de uso del $85 \%$ para el primer año de funcionamiento del negocio.

\subsubsection{Costos del proyecto}

\section{Costos Variables}

- Especialistas: Costos correspondientes a las remuneraciones del personal contratado.

- Producción: Constituido por el costo de los insumos. 
El incremento de costos se calcula de acuerdo al crecimiento estimado de las ventas ajustados por la inflación (BCRP, Reporte de inflación, 2016). Se ha considerado una tasa anual del 2.2\% anual año por año. En ese sentido la estimación de costos variables para el primer año se muestra en la tabla 59:

Tabla 59.

Costos variables

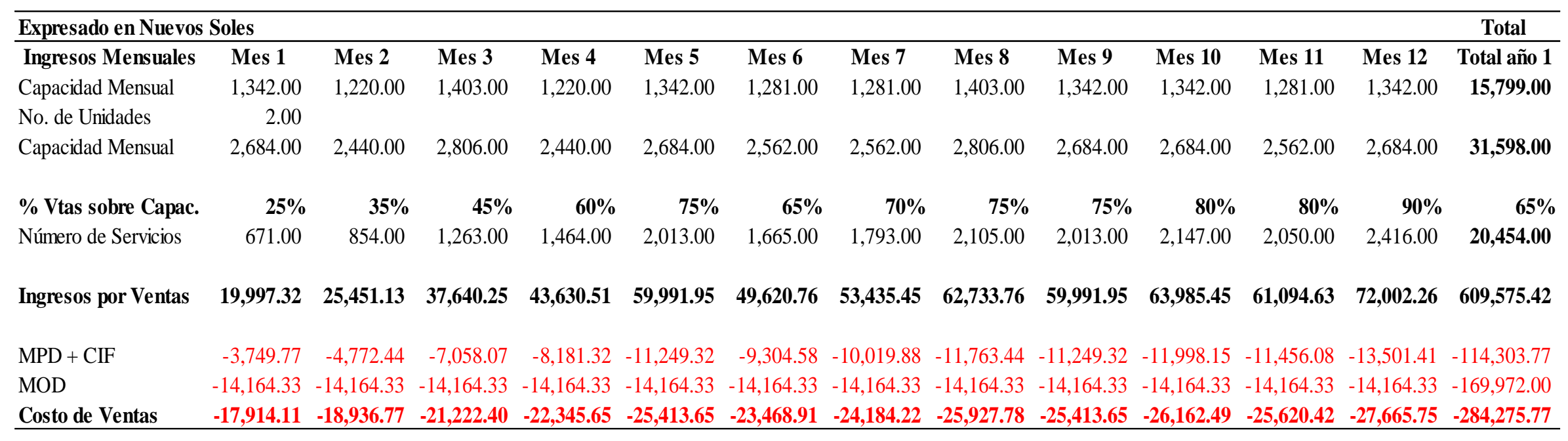




\section{Costos fijos}

Los costos fijos constan del pago de los salarios, publicidad, entre otros. El incremento de costos también se calcula de acuerdo al crecimiento estimado de la inflación $2.2 \%$ anual cada año. El requerimiento de fondos para el primer año de acuerdo a lo presupuestado asciende a la suma de S/ 196,107 (ver tabla 60): 
Tabla 60.

Costos fijos

Nuevos Soles

\begin{tabular}{|c|c|c|c|c|c|c|c|c|c|c|c|c|c|}
\hline Gastos Administrativos & ENE & FEB & MAR & ABR & MAY & JUN & JUL & AGT & SET & OCT & NOV & DIC & Año 1 \\
\hline Planilla Adm & 9,780 & 9,780 & 9,780 & 9,780 & 9,780 & 9,780 & 9,780 & 9,780 & 9,780 & 9,780 & 9,780 & 9,780 & 117,360 \\
\hline Servicio de Contador & 600 & 600 & 600 & 600 & 600 & 600 & 600 & 600 & 600 & 600 & 600 & 600 & 7,200 \\
\hline Serv. Publicos (Luz/Agua/Tel & & & & & & & & & & & & & \\
\hline fija/Internet) & 500 & 500 & 500 & 500 & 500 & 500 & 500 & 500 & 500 & 500 & 500 & 500 & 6,000 \\
\hline Facturación Electronica & 266 & 266 & 266 & 266 & 266 & 266 & 266 & 266 & 266 & 266 & 266 & 266 & 3,190 \\
\hline Comidas fuera de horario & & & & & & & & & & & & & - \\
\hline Señalectica & 800 & & & & & & & & & & & & 800 \\
\hline Permisos y Licencias & 2,500 & & & & & & & & & & & & 2,500 \\
\hline Depreciación & 4,086 & 4,086 & 4,086 & 4,086 & 4,086 & 4,086 & 4,086 & 4,086 & 4,086 & 4,086 & 4,086 & 4,086 & 49,031 \\
\hline Total S/- & $\mathbf{1 8 , 5 3 2}$ & 15,232 & 15,232 & 15,232 & $\mathbf{1 5 , 2 3 2}$ & 15,232 & 15,232 & 15,232 & 15,232 & 15,232 & 15,232 & 15,232 & 186,081 \\
\hline Gastos Comerciales & ENE & FEB & MAR & ABR & MAY & JUN & JUL & AGT & SET & OCT & NOV & DIC & Año 1 \\
\hline Depreciación & 136 & 136 & 136 & 136 & 136 & 136 & 136 & 136 & 136 & 136 & 136 & 136 & 1,626 \\
\hline Total S/- & 136 & 136 & 136 & 136 & 136 & 136 & 136 & 136 & 136 & 136 & 136 & 136 & 1,626 \\
\hline
\end{tabular}

\begin{tabular}{|c|c|c|c|c|c|c|c|c|c|c|c|c|c|}
\hline Gastos de Marketing & ENE & FEB & MAR & ABR & MAY & JUN & JUL & AGT & SET & OCT & NOV & DIC & Año 1 \\
\hline Facebook & 500 & 500 & & & & & & & & & & & 1,000 \\
\hline Materiales de visibilidad & 500 & & & & & & & & & & & & 500 \\
\hline Evento de lanzamiento & 1,500 & & & & & & & & & & & & 1,500 \\
\hline Total S/- & 2,500 & 500 & - & - & - & - & - & - & - & - & - & - & $\mathbf{3 , 0 0 0}$ \\
\hline
\end{tabular}

\begin{tabular}{|c|c|c|c|c|c|c|c|c|c|c|c|c|c|}
\hline Otros gastos & ENE & FEB & MAR & ABR & MAY & JUN & JUL & AGT & SET & OCT & NOV & DIC & Año 1 \\
\hline Distribución y transporte & 150 & 150 & 150 & 1,150 & 150 & 150 & 150 & 1,150 & 150 & 150 & 150 & 1,150 & 4,800 \\
\hline Otros gastos financieros (comision & & & & & & & & & & & & & \\
\hline banco) & 50 & 50 & 50 & 50 & 50 & 50 & 50 & 50 & 50 & 50 & 50 & 50 & 600 \\
\hline Imprevistos & & & & & & & & & & & & & - \\
\hline TOTAL OTROS GASTOS & 200 & 200 & 200 & 1,200 & 200 & 200 & 200 & $\mathbf{1 , 2 0 0}$ & 200 & 200 & 200 & $\mathbf{1 , 2 0 0}$ & 5,400 \\
\hline $\begin{array}{l}\text { Total Gtos Adm/Vta/Mkt/Otros } \\
\text { Gastos }\end{array}$ & 21,367 & 16,067 & 15,567 & 16,567 & 15,567 & 15,567 & 15,567 & 16,567 & 15,567 & 15,567 & 15,567 & 16,567 & 196,107 \\
\hline
\end{tabular}




\subsection{Financiamiento}

\subsubsection{Endeudamiento y condiciones.}

Según lo explicado, se requiere alrededor de 365 mil soles (S/ 364,690) como Inversión para cubrir la compra de maquinaria y equipos y para Capital de Trabajo que sostendrá el negocio en su etapa inicial. Este importe representa aproximadamente 109 mil dólares americanos. Los socios no cuentan con la totalidad del dinero y se requerirá financiamiento por el cincuenta por ciento de la inversión inicial.

Para financiar el capital de trabajo se recopiló información sobre tasas, tiempos y diferentes condiciones comerciales de algunas entidades financieras. Se muestran algunos ejemplos:

- Banco de Crédito del Perú (BCP) (ver tabla 61)

Tabla 61.

Costos de capital de trabajo del BCP

Capital de trabajo TEA

De 13,000 a 20,000 (USD) $\quad 38 \%$

De 20,000 a 30,000 (USD) $\quad 36 \%$

De 30,000 a 40,000 (USD) $\quad 33 \%$

En moneda nacional, la TEA va desde $25 \%$ hasta $60 \%$, este banco no presta a nuevas empresas o recién constituidas, requiere que la empresa tenga al menos 2 años en el mercado.

- Banco de Continental del Perú, el cual solo otorga préstamos para Mypes hasta 12 meses (ver tabla 62). 
Tabla 62.

Costos de capital de trabajo del Banco Continental

Capital de trabajo TEA

Hasta 100,000 (Soles) $18.0 \%$

De 100,000 a 150,000 (Soles) $\quad 17.5 \%$

- Banco Interbank, en moneda nacional, la TCEA va desde $30 \%$ hasta 55\%, en moneda extranjera (USD) va de $28 \%$ a $45 \%$.

- Banco Financiero, presta para Mypes hasta S/ 60,000 por primera vez sin garantía hipotecaria y si se cumple más de 12 meses laborando con ello, se puede acceder hasta S/ 80,000 de financiamiento.

Para todos los casos, como requisito indispensable es que la empresa tenga al menos 2 años de funcionamiento para que la entidad financiera haga el desembolso del crédito.

Por lo mencionado, se decidió financiar a la empresa con el aporte personal de cada uno de los cuatro socios, completando hasta el $50 \%$ y por la diferencia se tomará un crédito personal o se buscará un financiamiento paralelo al sistema financiero. Se ha decidido solicitar un préstamo a un familiar para completar lo requerido a una tasa de $15 \%$ de interés anual.

\subsubsection{Capital y costo de oportunidad.}

Con las restricciones que se han mencionado en el anterior punto y teniendo en cuenta la necesidad de obtener capital, se determinó obtener un préstamo paralelo al sistema financiero, para lo cual los socios aportaran el otro 50\% con capital propio. Esta situación obliga a determinar la tasa de costo de oportunidad del dinero para los 
accionistas y la tasa de costo promedio ponderado de la inversión en el negocio en mención.

Los dos conceptos mencionados miden el riesgo de un negocio. Como inversionista, es necesario tener claridad sobre cuáles son los riesgos inherentes al negocio y asociados a la industria en general a la cual se pretende ingresar. El valor que tenga esta tasa indicará el nivel de riesgo al cual se enfrenta y estos valores son los que ayudarán a medir la fortaleza del proyecto a través del Flujo de Caja Neto Descontado.

La metodología para el cálculo y determinación del Costo de Oportunidad se sustenta en base a criterios estadísticos o en función al requerimiento de retornos que tengan los inversionistas en particular. Es decir, si la expectativa del inversionista es obtener un nivel de rentabilidad por su dinero, entonces el inversionista esperaría obtener esa misma tasa o un valor mayor por su dinero al colocarlo en un nuevo negocio, caso contrario, no tendría incentivo para canalizar sus recursos en este proyecto.

En finanzas existe la metodología necesaria para comparar negocios. Se toma como referencia los resultados de otras latitudes y se extrapolan a la realidad de nuestro mercado. Para ello, un mercado referente es el mercado norteamericano en donde existe un reconocido científico - estadístico, el Sr. Damodaran, quien ha trabajado por muchos años información estadísticas de negocios y ha obtenido parámetros confiables sobre cuál es la rentabilidad y el riesgo asociado de cada tipo de negocio en el mercado estadounidense. Tomando esta información como base para el análisis, se ha seleccionado los valores del Costo de Capital de algunas industrias similares al negocio que se tienen entre manos obteniendo los siguientes resultados que al promediarlos da una tasa del costo de capital promedio de $8.2 \%$ en USA (ver tabla 63): 
Tabla 63.

Industrias comparables

Entertainment

$8.4 \%$

Healthcare Products

$8.7 \%$

Healthcare Support Services

$7.9 \%$

Heathcare Information and Technology

$8.7 \%$

Recreation

$7.5 \%$

Tasa Promedio

$8.2 \%$

Adicionalmente a este valor se le debe incorporar el efecto riesgo país de nuestro país con la finalidad de adaptar/extrapolar estos valores a la realidad o mercado peruano y con ello obtener una tasa de costo de capital del inversionista en Perú. El riesgo país a la fecha es de $1.7 \%$. Es decir, al valor o tasa del costo de capital de Estados Unidos para los negocios similares al proyecto presentado, $8.2 \%$, se le agregará el valor de $1.7 \%$ con lo cual se obtendrá una tasa del costo de capital para un negocio de salón de belleza en el Perú de 9.9\%. Este es el valor mínimo de rentabilidad que deberían esperar los inversionistas del salón de belleza propuesto por el dinero que inviertan en el presente proyecto.

\subsubsection{Costo de Capital Promedio Ponderado (WACC por sus siglas en ingles).}

Este concepto es importante para el análisis del proyecto. El nivel de inversión se considera importante para los socios y como se analizó anteriormente, será necesario conseguir financiamiento para el inicio de este proyecto. El financiamiento requerido asciende al 50\% del total de inversión en maquinaria e inversión en Capital de Trabajo demandado el presente proyecto. Este importe sería de S/ 182,345 (50\% de S/. 364,690). 
Conceptualmente, el financiamiento o apalancamiento, es una herramienta financiera apropiada para lograr reducir el riesgo del inversionista dado que no tiene que colocar todo el dinero necesario en un proyecto nuevo y del cual no se cuenta con la seguridad si funcionará (Facto Riesgo), en otras palabras, el prestamista también comparte el riesgo en el presente proyecto dado que el proyecto podría no tener éxito y el prestamista correría el riesgo de no recuperar el dinero prestado. El costo de oportunidad del prestamista es la tasa de interés por el monto prestado.

El efecto del apalancamiento financiero se puede demostrar a través de un sencillo ejemplo basado en cuatro escenarios en donde el nivel de deuda aumenta gradualmente (ver tabla 64):

Tabla 64.

Estructura de financiamiento.

Estructura de financiamiento de una inversión

\begin{tabular}{lcccc}
\hline Deuda @ 10\% & - & 200.00 & 500.00 & 900.00 \\
Capital & $1,000.00$ & 800.00 & 500.00 & 100.00 \\
Inversión & $\mathbf{1 , 0 0 0 . 0 0}$ & $\mathbf{1 , 0 0 0 . 0 0}$ & $\mathbf{1 , 0 0 0 . 0 0}$ & $\mathbf{1 , 0 0 0 . 0 0}$
\end{tabular}

\section{Estado de Ganancias y Pérdidas}

\begin{tabular}{|c|c|c|c|c|}
\hline Utilidad operativa & 277.78 & 277.78 & 277.78 & 277.78 \\
\hline Intereses & - & 20.00 & 50.00 & 90.00 \\
\hline \multicolumn{5}{|l|}{ Utilidad antes de } \\
\hline impuestos & 277.78 & 257.78 & 227.78 & 187.78 \\
\hline Impuesto $(28 \%)$ & -77.78 & -72.18 & -63.78 & -52.58 \\
\hline Utilidad Neta & 200.00 & 185.60 & 164.00 & 135.20 \\
\hline \multirow{2}{*}{ Rentab. Accionista } & $20.0 \%$ & $23.2 \%$ & $32.8 \%$ & $135.2 \%$ \\
\hline & Económica & & Financiera & \\
\hline
\end{tabular}

Aquí se refleja que conforme en un proyecto se incorpore más deuda, la rentabilidad por el dinero invertido (cada vez menor) es mayor. ¿Cómo ocurre esto? En 
buena cuenta el inversionista invierte menos en cada oportunidad, sin embargo, la rentabilidad del proyecto es similar, descontando los gastos por interés, con lo cual, el inversionista tiene una rentabilidad mayor por el dinero invertido.

El proyecto necesita de deuda para completar el capital inicial requerido y en los párrafos anteriores se demuestra que el financiamiento es una herramienta para obtener capital y sobre todo permite disminuir el riesgo del inversionista y por ende generar en el futuro mayor rentabilidad. Lo importante es tener claro cuál es el nivel óptimo de deuda para el negocio.

Para el proyecto se ha logrado conseguir financiamiento a una tasa de $15 \%$. Se tiene un costo de oportunidad del dinero que es del $9.9 \%$ de acuerdo al cálculo del costo de oportunidad en base a la estadística de negocios similares en el mercado estadounidense.

Con esta información se aplica la metodología de cálculo para obtener la Tasa de Costo Promedio Ponderado de Capital (CPPC) o WACC y que se resume en la aplicación de la siguiente fórmula:

$$
C P P C=[k D * D(1-t)+k E * E]
$$

En donde:

D: $\quad$ Proporción de la Deuda. En el proyecto el 50\% del capital requerido.

KD: $\quad$ Costo de la Deuda. Para el proyecto 15\% que ofrece un familiar.

E: Proporción del Capital Propio. 50\% aporte de los accionistas.

KE: $\quad$ Costo del Capital Propio. 9.9\% como costo de Oportunidad

T: Tasa de impuesto aplicable. Tasa promedio Régimen Mype Tributario

$\mathrm{CPPC}=[15 \% * 50 \%(1-16.3 \%)+9.9 \% * 50 \%=11.23 \%$

CPPC $=\mathbf{1 1 . 2 3 \%}$. Esta tasa servirá para hallar el Valor Presente Neto de los flujos futuros del proyecto. 


\subsection{Presupuesto base}

El presupuesto base para este plan de negocios está conformado por todos los ingresos y egresos que conlleva el proyecto.

\subsubsection{Presupuesto de ventas.}

En la tabla 65 se presentará el presupuesto de ventas estimado del proyecto:

Tabla 65 .

Presupuestos de venta estimados.

\begin{tabular}{crrr}
\hline Años & \% Uso & Atenciones & \multicolumn{1}{l}{ Ingresos } \\
\hline 1ero & $65 \%$ & $20,454.00$ & $609,575.42$ \\
2do & $70 \%$ & $22,119.00$ & $659,196.19$ \\
3ero & $75 \%$ & $23,699.00$ & $706,283.76$ \\
4to & $80 \%$ & $25,278.00$ & $753,341.53$ \\
5to & $85 \%$ & $26,858.00$ & $800,429.10$ \\
\hline
\end{tabular}

En la tabla 65 se presenta la proyección estimada por servicios de planchado y cepillado de cabello además del servicio de manicura para los siguientes 5 años. Cabe indicar que del análisis realizado la capacidad de atención semanal es de 304 servicios en promedio y por ser una empresa nueva en este rubro la capacidad de atención para el primer año se estima que alcanzara el $65 \%$ del total de la capacidad, es decir se atenderá 20,454 servicios. Para el segundo año se estima atender al $70 \%$ de la capacidad el cual asciende a 22,119 servicios y así sucesivamente. El Precio considerado según la investigación dependerá del tipo de servicio. El precio promedio es de S/ 35.17 soles para cada servicio (incluye IGV). 
Como política de aumento en el precio para los servicios se establece un incremento anual del 2.2\% según el crecimiento de inflación estimada para los siguientes 5 años (BCRP, Reporte de inflación, 2016).

\subsubsection{Presupuesto de compras.}

Para el presupuesto de compras se ha calculado el material necesario a utilizar en forma anual como se muestra en la tabla 66 :

Tabla 66.

Presupuesto de Compras estimado

\begin{tabular}{llrl}
\hline Años & \% Uso & Atenciones & Compras \\
\hline 1ero & $65 \%$ & $20,454.00$ & $114,303.77$ \\
2do & $70 \%$ & $22,119.00$ & $123,608.35$ \\
3ero & $75 \%$ & $23,699.00$ & $132,437.91$ \\
4to & $80 \%$ & $25,278.00$ & $141,261.89$ \\
5to & $85 \%$ & $26,858.00$ & $150,091.46$ \\
\hline
\end{tabular}

La estimación de compra anual de materiales se detalla en tabla 66 para la atención durante el primer año. El incremento de compras de materiales para el segundo año será del $8.1 \%$ según el crecimiento de la demanda (ventas) y así sucesivamente hasta el 5to año.

El incremento de precios de los insumos se calcula de acuerdo al crecimiento estimado de la inflación (BCRP, Reporte de inflación, 2016) de 2.2\% anual cada año. Sin embargo, los precios se subirán 4\% cada dos años.

\subsubsection{Presupuesto de gastos financieros.}

Como se ha señalado en el punto VIII.2, la inversión inicial será financiada, en un $50 \%$ a un costo del dinero (interés por préstamo) del 15\%. El importe de gastos 
financieros a pagar el primer año asciende a S/ 27,952 que debería disminuir conforme se pague la deuda.

\subsection{Presupuesto de Resultados}

Los presupuestos son cálculos que se realizan por anticipado dentro de un determinado lapso de tiempo, el cual es elegido por el que los realiza con la finalidad de saber con qué condiciones se podrían contar bajo determinados escenarios, de esta forma se pueden tomar decisiones basados en indicadores tangibles y no solo en corazonadas por partes de los empresarios.

A continuación, se presentan los instrumentos que permitirán saber bajo que supuestos se deben realizar los ajustes en la parte económica de la empresa:

\subsubsection{Estado de ganancias y pérdidas proyectado.}

Como se nuestra en la tabla 67, se puede observar el comportamiento de la empresa a través del tiempo en términos de rentabilidad, en otras palabras, se puede conocer las ganancias o pérdidas que se esperaría tener en un período determinado. Se ha realizado este análisis utilizando una proyección a 5 años de la utilidad Operativa. Es decir, esta información servirá para efectos de realizar el Presupuesto y Flujo de Caja Operativo del negocio cuando se ponga en marcha.

El Flujo de Caja descontado y el análisis de sensibilidad se verán en el siguiente capítulo: 
Tabla 67.

Estado de ganancias y pérdidas proyectadas

Ganancias y Pérdidas

Expresado en Soles

\begin{tabular}{lccccc}
\hline & Año 1 & Año 2 & Año 3 & Año 4 & Año 5 \\
Ingresos & 609,575 & 659,196 & 706,284 & 753,342 & 800,429 \\
Costos Variables & $-284,276$ & $-278,441$ & $-298,331$ & $-318,208$ & $-338,097$ \\
Margen Contrib & $\mathbf{3 2 5 , 3 0 0}$ & $\mathbf{3 8 0 , 7 5 5}$ & $\mathbf{4 0 7 , 9 5 3}$ & $\mathbf{4 3 5 , 1 3 4}$ & $\mathbf{4 6 2 , 3 3 2}$ \\
Gastos de Ventas & - & - & - & - & - \\
Gastos Fijos + Dep & $-196,107$ & $-196,107$ & $-196,107$ & $-196,107$ & $-196,107$ \\
Utilidad Bruta & $\mathbf{1 2 9 , 1 9 3}$ & $\mathbf{1 8 4 , 6 4 8}$ & $\mathbf{2 1 1 , 8 4 6}$ & $\mathbf{2 3 9 , 0 2 7}$ & $\mathbf{2 6 6 , 2 2 5}$ \\
\end{tabular}

*No se considera los gastos financieros en este cálculo.

\subsubsection{Balance proyectado.}

Este informe muestra con claridad la situación económica y financiera de la empresa para un determinado período. Para ello se ha calculado cuáles serían los resultados para los próximos 5 años tomando en cuenta los activos, pasivo y el patrimonio que se espera conseguir en un determinado plazo (5 años). También se ha considerado el pago de las deudas asumidas en la etapa pre operativa para capital de trabajo y posteriormente el pago de dividendos a los accionistas para cumplir con la meta de PayBack considerada en el proyecto (ver tablas 68, 69, 70, 71 y 72). 
Tabla 68.

Balance general del año 1

\begin{tabular}{|c|c|c|c|}
\hline \multicolumn{4}{|c|}{ BALANCE GENERAL DEL AÑO 1} \\
\hline \multicolumn{2}{|l|}{ ACTIVO } & \multicolumn{2}{|l|}{ PASIVO } \\
\hline Activo Corriente & & Pasivo Corriente & \\
\hline Caja y bancos & S/. 233,652 & Impuestos por Pagar & S/. 17,020 \\
\hline Inventarios a corto plazo & S/. 28,576 & Remuneraciones por Pagar & S/. 1,600 \\
\hline \multirow{2}{*}{ Cuentas por cobrar } & S/. 0 & Cuentas por Pagar & S/. 0 \\
\hline & & Otras cuentas por pagar & S/. 0 \\
\hline Inventarios & S/. 0 & & \\
\hline Pagos por anticipado & S/. 0 & & \\
\hline Total Activo Corriente & S/. 262,228 & Total Pasivo Corriente & S/. 18,620 \\
\hline Activo No Corriente & & Pasivo No Corriente & \\
\hline Inmuebles, maquinaria y equipo & S/. 253,284 & Deuda a largo plazo & S/. 182,345 \\
\hline \multirow[t]{6}{*}{ Depreciación } & $-S / .50,657$ & & \\
\hline & & Total Pasivo No Corriente & S/. 182,345 \\
\hline & & Patrimonio & \\
\hline & & Capital social & S/. 182,345 \\
\hline & & Resultados Acumulados & $\mathrm{S} / .0$ \\
\hline & & Resultados del Ejercicio & S/. 81,545 \\
\hline Total Activo No Corriente & S/. 202,627 & Total Patrimonio & S/. 263,890 \\
\hline TOTAL ACTIVO & S/. $464,855^{\circ}$ & OTAL PASIVO + PATRIMONIO & S/. 464,855 \\
\hline
\end{tabular}

Tabla 69.

Balance general del año 2

\begin{tabular}{|c|c|c|c|}
\hline \multicolumn{4}{|c|}{ BALANCE GENERAL DEL AÑO 2} \\
\hline \multicolumn{2}{|l|}{ ACTIVO } & \multicolumn{2}{|l|}{ PASIVO } \\
\hline Activo Corriente & & Pasivo Corriente & \\
\hline Caja y bancos & S/. 413,351 & Impuestos por Pagar & S/. 31,901 \\
\hline Inventarios a corto plazo & S/. 28,576 & Remuneraciones por Pagar & S/. 1,600 \\
\hline \multirow{2}{*}{ Cuentas por cobrar } & S/. 0 & Cuentas por Pagar & $\mathrm{S} / .0$ \\
\hline & & Otras cuentas por pagar & S/. 0 \\
\hline Inventarios & $\mathrm{S} / .0$ & & \\
\hline Pagos por anticipado & S/. 0 & & \\
\hline Total Activo Corriente & S/. 441,927 & Total Pasivo Corriente & S/. 33,501 \\
\hline Activo No Corriente & & Pasivo No Corriente & \\
\hline Inmuebles, maquinaria y equipo & S/. 253,284 & Deuda a largo plazo & S/. 182,345 \\
\hline \multirow[t]{6}{*}{ Depreciación } & $-\mathrm{S} / .101,313$ & & \\
\hline & & Total Pasivo No Corriente & S/. 182,345 \\
\hline & & Patrimonio & \\
\hline & & Capital social & S/. 182,345 \\
\hline & & Resultados Acumulados & S/. 81,545 \\
\hline & & Resultados del Ejercicio & S/. 114,161 \\
\hline Total Activo No Corriente & S/. 151,970 & Total Patrimonio & S/. 378,051 \\
\hline TOTAL ACTIVO & \multicolumn{2}{|c|}{ S/. 593,897 TOTAL PASIVO + PATRIMONIO } & S/. 593,897 \\
\hline
\end{tabular}


Tabla 70.

Balance general del año 3

\begin{tabular}{|c|c|c|c|}
\hline \multicolumn{4}{|c|}{ BALANCE GENERAL DEL AÑO 3} \\
\hline \multicolumn{2}{|l|}{ ACTIVO } & \multicolumn{2}{|l|}{ PASIVO } \\
\hline Activo Corriente & & Pasivo Corriente & \\
\hline Caja y bancos & S/. 621,107 & Impuestos por Pagar & S/. 44,421 \\
\hline Inventarios a corto plazo & S/. 28,576 & Remuneraciones por Pagar & S/. 1,600 \\
\hline \multirow[t]{2}{*}{ Cuentas por cobrar } & S/. 0 & Cuentas por Pagar & $\mathrm{S} / .0$ \\
\hline & & Otras cuentas por pagar & S/. 0 \\
\hline Inventarios & S/. 0 & & \\
\hline Pagos por anticipado & $\mathrm{S} / .0$ & & \\
\hline Total Activo Corriente & S/. 649,683 & Total Pasivo Corriente & $\mathrm{S} / . \mathbf{4 6 , 0 2 1}$ \\
\hline Activo No Corriente & & Pasivo No Corriente & \\
\hline Inmuebles, maquinaria y equipo & S/. 253,284 & Deuda a largo plazo & S/. 182,345 \\
\hline \multirow[t]{6}{*}{ Depreciación } & $-S / .151,970$ & & \\
\hline & & Total Pasivo No Corriente & S/. 182,345 \\
\hline & & Patrimonio & \\
\hline & & Capital social & S/. 182,345 \\
\hline & & Estado de resultados & S/. 195,706 \\
\hline & & Resultados del Ejercicio & S/. 144,579 \\
\hline Total Activo No Corriente & S/. 101,313 & Total Patrimonio & $\mathrm{S} / . \mathbf{5 2 2 , 6 3 0}$ \\
\hline TOTAL ACTIVO & S/. $750,996^{\prime}$ & DTAL PASIVO + PATRIMONIO & S/. 750,996 \\
\hline
\end{tabular}

Tabla 71.

Balance general del año 4

\begin{tabular}{|c|c|c|c|}
\hline \multicolumn{4}{|c|}{ BALANCE GENERAL DEL AÑO 4} \\
\hline \multicolumn{2}{|l|}{ ACTIVO } & \multicolumn{2}{|l|}{ PASIVO } \\
\hline Activo Corriente & & Pasivo Corriente & \\
\hline Caja y bancos & S/. 833,814 & Impuestos por Pagar & S/. 49,429 \\
\hline Inventarios a corto plazo & S/. 28,576 & Remuneraciones por Pagar & S/. 1,600 \\
\hline \multirow{2}{*}{ Cuentas por cobrar } & $\mathrm{S} / .0$ & Cuentas por Pagar & S/. 0 \\
\hline & & Otras cuentas por pagar & S/. 0 \\
\hline Inventarios & S/. 0 & & \\
\hline Pagos por anticipado & $\mathrm{S} / .0$ & & \\
\hline Total Activo Corriente & S/. 862,390 & Total Pasivo Corriente & S/. 51,029 \\
\hline Activo No Corriente & & Pasivo No Corriente & \\
\hline Inmuebles, maquinaria y equipo & S/. 253,284 & Deuda a largo plazo & S/. 182,345 \\
\hline \multirow[t]{6}{*}{ Depreciación } & $-S / .202,627$ & & \\
\hline & & Total Pasivo No Corriente & S/. 182,345 \\
\hline & & Patrimonio & \\
\hline & & Capital social & S/. 182,345 \\
\hline & & Estado de resultados & S/. 340,285 \\
\hline & & Resultados del Ejercicio & S/. 157,043 \\
\hline Total Activo No Corriente & S/. 50,657 & Total Patrimonio & S/. 679,673 \\
\hline TOTAL ACTIVO & S/. 913,047 & OTAL PASIVO + PATRIMONIO & S/. 913,047 \\
\hline
\end{tabular}


Tabla 72.

Balance general del año 5

\begin{tabular}{|c|c|c|c|}
\hline \multicolumn{4}{|c|}{ BALANCE GENERAL DEL AÑO 5} \\
\hline \multicolumn{2}{|l|}{ ACTIVO } & \multicolumn{2}{|l|}{ PASIVO } \\
\hline Activo Corriente & & Pasivo Corriente & \\
\hline Caja y bancos & S/. 906,671 & Impuestos por Pagar & S/. 63,296 \\
\hline Inventarios a corto plazo & S/. 28,576 & Remuneraciones por Pagar & S/. 1,600 \\
\hline \multirow[t]{2}{*}{ Cuentas por cobrar } & $\mathrm{S} / .0$ & Cuentas por Pagar & S/. 0 \\
\hline & & Otras cuentas por pagar & S/. 0 \\
\hline Inventarios & S/. 0 & & \\
\hline Pagos por anticipado & S/. 0 & & \\
\hline Total Activo Corriente & S/. 935,247 & Total Pasivo Corriente & S/. 64,896 \\
\hline Activo No Corriente & & Pasivo No Corriente & \\
\hline Inmuebles, maquinaria y equipo & S/. 253,284 & Deuda a largo plazo & S/. 0 \\
\hline \multirow[t]{6}{*}{ Depreciación } & $-S / .253,284$ & & \\
\hline & & Total Pasivo No Corriente & S/. 0 \\
\hline & & Patrimonio & \\
\hline & & Capital social & S/. 182,345 \\
\hline & & Estado de resultados & S/. 497,328 \\
\hline & & Estado de resultados & S/. 190,678 \\
\hline Total Activo No Corriente & $\mathrm{S} / .0$ & Total Patrimonio & S/. 870,351 \\
\hline TOTAL ACTIVO & \multicolumn{2}{|c|}{ S/. 935,247 TOTAL PASIVO + PATRIMONIO } & S/. 935,247 \\
\hline
\end{tabular}

\subsubsection{Flujo de caja del proyecto.}

Para la realización del flujo de caja se tomó en cuenta tanto los ingresos totales, como los egresos totales, de esta forma se podrá observar tanto el flujo obtenido a lo largo de cada uno de los 5 próximos años, como el acumulado durante este mismo período de tiempo (ver tabla 73). 
Tabla 73.

Flujo de caja proyectado

\begin{tabular}{|c|c|c|c|c|c|c|}
\hline \multicolumn{7}{|c|}{ FLUJO NETO DE CAJA PROYECTADO } \\
\hline Descripción & Año 0 & Año 1 & Año 2 & Año 3 & Año 4 & Año 5 \\
\hline Inversión & 364,690 & & & & & \\
\hline Total Ingresos & & 609,575 & 659,184 & 734,520 & 783,488 & 865,754 \\
\hline TotalEgresos & & $-477,374$ & $-494,366$ & $-537,258$ & $-573,762$ & $-1,027,780$ \\
\hline Saldo (Ingresos - Egresos) & 364,690 & 132,202 & 164,818 & 197,262 & 209,726 & $-162,026$ \\
\hline Saldo Acumulado & 364,690 & 496,892 & 661,710 & 858,972 & $1,068,697$ & 906,671 \\
\hline
\end{tabular}

Nota. El monto indicado como inversión en el Año 0 corresponde a los aportes de capital de los accionistas y al préstamo recibido para financiar el proyecto. $\mathrm{La}$ inversión de los accionistas se devuelve vía el pago de dividendos. 


\section{Capítulo IX: Evaluación Económica Financiera}

\subsection{Evaluación Financiera}

En el presente capítulo se presenta la evaluación económica financiera de la empresa en base a las proyecciones colocadas en el balance general, flujo de caja y estado de pérdidas y ganancias. Para ello se utilizaron los siguientes métodos de valoración: TIR, VAN, ROE y Ratios.

\subsubsection{PAYBACK (Período de Recuperación del Capital).}

El PAYBACK es un indicador importante para los inversionistas. Generalmente el inversionista busca reducir sus riesgos y una manera de asegurarse que un negocio es viable es su capacidad de devolverle su inversión. En ese sentido, generalmente los inversionistas se sienten más tranquilos cuando un negocio te devuelve tu inversión en un máximo de tres (03) años. En este caso, este modelo de negocio apunta a devolver la totalidad de la inversión a los dos años y cinco meses, es decir, está dentro de los parámetros o estándares aceptados en el mercado peruano.

\subsubsection{TIR.}

El TIR (Tasa Interna de Retorno) mide la rentabilidad de los cobros sobre los pagos en base a una inversión generada. Se tiene el TIR Económico (TIRE) y el TIR Financiero (TIRF) que es el que todos conocen por TIR. Finalmente, el que debe salir siempre positivo es el financiero. Sin embargo, para tener claro cuál es el efecto financiamiento / apalancamiento en los flujos se comparan ambos y se espera que salgan positivos con lo cual se tendría una manera adicional de demostrar que el proyecto va por buen camino en su factibilidad.

En base a los flujos económicos se obtiene en el Flujo de Caja sin deuda (Económico) como se muestra en la tabla 74: 


\section{Tabla 74.}

TIR por año

\begin{tabular}{lr}
\hline Período & \multicolumn{1}{l}{ Importe } \\
\hline Año 0 & $-364,690.0$ \\
Año 1 & $151,907.7$ \\
Año 2 & $184,524.0$ \\
Año 3 & $216,967.8$ \\
Año 4 & $229,431.6$ \\
Año 5 & $629,864.5$ \\
\hline
\end{tabular}

Con estas cifras el cálculo de la TIRE sale $51.6 \%$ a un período de 5 años, esto significa que la rentabilidad del proyecto es mayor que la rentabilidad del mercado, lo cual lleva a pensar que si es viable el llevar a cabo el modelo de negocio.

También es importante obtener el TIRF de acuerdo a lo descrito anteriormente, el cual proviene del flujo financiero (ver tabla 75):

Tabla 75 .

Flujo por año

\begin{tabular}{cc}
\hline Período & Importe \\
\hline AÑO 0 & $-364,690.0$ \\
AÑO 1 & $132,201.8$ \\
AÑO 2 & $164,818.0$ \\
AÑO 3 & $197,261.8$ \\
AÑO 4 & $209,725.6$ \\
AÑNO 5 & $610,158.5$ \\
\hline
\end{tabular}


El valor del TIR Financiero es de 46.6\%, disminuyendo en 5 puntos porcentuales por el efecto de los intereses financieros. Sin embargo, este valor garantiza que el proyecto podrá asumir sus propios costos financieros.

\subsubsection{VAN.}

Para el cálculo del VAN se utiliza la tasa de $11.23 \%$ de acuerdo a los cálculos realizados previamente en donde se combinó el costo del dinero del accionista y la tasa de interés del préstamo de un familiar, con esa tasa respecto al TIR obtenido se puede afirmar que el proyecto es viable logrando un VAN atractivo de S/ '`710,885 para el proyecto.

Estos cálculos se han podido obtener al realizar el flujo de caja descontado del negocio. Con esta metodología y en función a los a los siguientes supuestos considerados:

- Capacidad instalada utilizada a un $65 \%$ finalizando en $85 \%$.

- Crecimiento de los ingresos de $8.1 \%$ el primer año y posteriormente a una tasa promedio anual de $6.7 \%$.

- Crecimiento de la inflación del 2.2\% anual.

- Incremento de precios cada dos años del 4\% para recuperar el efecto inflación.

- Costos asociados al negocio de acuerdo a data estadística recopilada del mercado.

- Costo financiero del $15 \%$

- $\quad$ Tasa de costo de Capital del $11.23 \%$

- $\quad$ Riesgo País de $1.67 \%$

Se logró el flujo del negocio que obtuvo los valores antes mencionados que se muestran en la tabla 76: 
Tabla 76.

VAN

\begin{tabular}{|c|c|c|c|c|c|c|c|}
\hline Expresado en Soles & & & & & & & \\
\hline Ganancias y Perdidas & Año 0 & Año 1 & Año 2 & Año 3 & Año 4 & Año 5 & Total \\
\hline Número de Servicios & & 20,454 & 22,119 & 23,699 & 25,278 & 26,858 & 118,408 \\
\hline Ventas Brutas & & 609,575 & 659,184 & 734,520 & 783,488 & 865,754 & $3,652,521$ \\
\hline Descuentos & & - & - & - & - & - & - \\
\hline Ventas Netas & - & 609,575 & 659,184 & 734,520 & 783,488 & 865,754 & $3,652,521$ \\
\hline Costo de Ventas & - & $-284,276$ & $-284,562$ & $-311,595$ & $-339,680$ & $-368,850$ & $-1,588,964$ \\
\hline Margen Bruto & - & 325,300 & 374,622 & 422,924 & 443,807 & 496,903 & $2,063,557$ \\
\hline Gastos de Marketing y Ventas & - & $-3,000$ & $-3,066$ & $-3,133$ & $-3,202$ & $-3,273$ & $-15,675$ \\
\hline Margen Neto & - & 322,300 & 371,556 & 419,791 & 440,605 & 493,630 & $2,047,882$ \\
\hline Gastos Fijos & - & $-145,450$ & $-148,650$ & $-151,920$ & $-155,262$ & $-158,678$ & $-759,961$ \\
\hline Miscelaneos Incomes & - & - & - & - & - & - & - \\
\hline Miscelaneos Expenses & - & - & - & - & - & - & - \\
\hline Ebita & - & 176,850 & 222,906 & 267,871 & 285,342 & 334,952 & $1,287,921$ \\
\hline Amortization & - & - & - & - & - & - & - \\
\hline Depreciacion & - & $-50,657$ & $-50,657$ & $-52,683$ & $-52,683$ & $-54,790$ & $-261,470$ \\
\hline Margen Operativo & - & 126,193 & 172,250 & 215,188 & 232,659 & 280,162 & $1,026,452$ \\
\hline Costos Financieros & - & $-27,952$ & $-27,952$ & $-27,952$ & $-27,952$ & $-27,952$ & $-139,759$ \\
\hline Utilidad antes de Impuestos & - & 98,241 & 144,298 & 187,236 & 204,708 & 252,210 & 886,693 \\
\hline Impuesto a la Renta (Tasa $10 \%$ \& $29.5 \%$ ) & - & $-16,696$ & $-30,137$ & $-42,657$ & $-47,665$ & $-61,532$ & $-198,687$ \\
\hline Utilidad despues de Impuestos & - & 81,545 & 114,161 & 144,579 & 157,043 & 190,678 & 688,006 \\
\hline \multicolumn{8}{|l|}{ Flujo de Caja Operativo } \\
\hline Utilidad despues de Impuestos & - & 81,545 & 114,161 & 144,579 & 157,043 & 190,678 & 688,006 \\
\hline Depreciación & - & 50,657 & 50,657 & 52,683 & 52,683 & 54,790 & 261,470 \\
\hline Total Flujo de Caja Operativo & - & 132,202 & 164,818 & 197,262 & 209,726 & 245,468 & 949,476 \\
\hline \multicolumn{8}{|l|}{ Flujo Financiero } \\
\hline Inversión en Activos & $-253,284$ & - & - & - & - & 253,284 & - \\
\hline Inversión en Capital de Trabajo & $-111,406$ & - & - & - & - & 111,406 & - \\
\hline Investment - CAPEX & - & - & - & - & - & - & - \\
\hline Investment - Bonds & - & - & - & - & - & - & - \\
\hline Total Flujo de Caja Financiero & $-364,690$ & - & - & - & - & 364,690 & - \\
\hline Total Flujo de Caja & $-364,690$ & 132,202 & 164,818 & 197,262 & 209,726 & 610,159 & 949,476 \\
\hline Cost of Capital & $11.23 \%$ & & & & & & \\
\hline VAN (5 años) & 525,976 & & & & & & \\
\hline VAN + Perpetuity & $\mathbf{2 , 7 1 0 , 8 8 5}$ & & & & & & \\
\hline Payback & 2 & \multirow{2}{*}{\multicolumn{6}{|c|}{ (2 años y 5 meses aprox.) }} \\
\hline TIR & $46.6 \%$ & & & & & & \\
\hline
\end{tabular}

\subsubsection{Flujo Económico.}

También es importante saber cuál es el efecto en el flujo de caja si no se considera impuestos por financiamiento como se muestra la tabla 77: 
Tabla 77.

Flujo económico

\begin{tabular}{cc}
\hline Período & Importe \\
\hline AÑO 0 & $-364,690.0$ \\
AÑO 1 & $151,907.7$ \\
AÑO 2 & $184,524.0$ \\
AÑO 3 & $216,967.8$ \\
AÑO 4 & $229,431.6$ \\
AÑO 5 & $629,864.5$ \\
\hline
\end{tabular}

\subsubsection{ROE.}

El retorno sobre la inversión ayuda a medir la capacidad de generar rentabilidad utilizando el valor invertido por los accionistas en esta etapa inicial (ver tabla 78).

Tabla 78.

\begin{tabular}{|c|c|c|c|c|c|}
\hline Conceptos & AÑO 1 & AÑO 2 & $\overline{\text { AÑO } 3}$ & AÑN 4 & AÑNO 5 \\
\hline Utilidad & $81,545.0$ & $114,161.3$ & $144,578.8$ & $157,042.6$ & $190,678.2$ \\
\hline Inversión & $182,345.0$ & $182,345.0$ & $182,345.0$ & $182,345.0$ & $182,345.0$ \\
\hline ROE & $44.7 \%$ & $62.6 \%$ & $79.3 \%$ & $86.1 \%$ & $104.6 \%$ \\
\hline
\end{tabular}

Con los resultados obtenidos se puede concluir que a medida que pasan los años, hay una mayor contribución de las utilidades sobre el patrimonio. Otra forma de ver este indicador, es que, por cada S/ 100 invertido se obtiene S/ 44.7 para el año 1 y así sucesivamente de acuerdo al cuadro de arriba. 


\subsubsection{Ratios.}

Estas razones financieras son indicadores que permiten conocer el estado de la empresa haciendo uso de los resultados obtenidos con anterioridad (ver tabla 79).

Tabla 79.

Rentabilidad bruta sobre ventas

\begin{tabular}{lrrrrr}
\hline Conceptos & Año 1 & Año 2 & Año 3 & Año 4 & Año 5 \\
\hline Utilidad Bruta & $325,299.7$ & $374,622.4$ & $422,924.3$ & $443,807.2$ & $496,903.3$ \\
Ventas Netas & $609,575.4$ & $659,184.3$ & $734,519.6$ & $783,487.6$ & $865,753.8$ \\
Rentabilidad Bruta & $53.4 \%$ & $56.8 \%$ & $57.6 \%$ & $56.6 \%$ & $57.4 \%$ \\
& & & & & \\
\hline
\end{tabular}

Como se puede apreciar se obtienen valores altos, los cuales dejan un panorama muy positivo de cara al futuro, ya que a pesar de que entre el primer y segundo año el crecimiento es de $8.1 \%$ y luego este crecimiento se reduce a $6 \%$ en promedio los siguientes años, el crecimiento es sostenido en los resultados del negocio (ver tabla 80).

Tabla 80 .

Rentabilidad neta sobre ventas

\begin{tabular}{lrrrrr}
\hline Conceptos & Año 1 & Año 2 & Año 3 & Año 4 & Año 5 \\
& & & & & \\
\hline Utilidad Neta & $81,545.0$ & $114,161.3$ & $144,578.8$ & $157,042.6$ & $190,678.2$ \\
Ventas Netas & $609,575.4$ & $659,184.3$ & $734,519.6$ & $783,487.6$ & $865,753.8$ \\
Rentabilidad Neta & $13.4 \%$ & $17.3 \%$ & $19.7 \%$ & $20.0 \%$ & $22.0 \%$ \\
& & & & & \\
\hline
\end{tabular}

Los resultados obtenidos mediante este indicador afinan en gran medida la perspectiva de las utilidades que se puede obtener en un período de 5 años. Refiriéndose exclusivamente a este último ratio, se puede apreciar que la rentabilidad se presenta 
positiva y robusta en el tiempo. Estos resultados mejoraran en la medida que se logre lo siguiente:

- Incrementando el número de servicios utilizados. De acuerdo a los cálculos se alcanzará el 85\% de utilización al final del quinto año.

- Invertir en nuevas unidades para atender nuevos puntos de venta en la medida que las primeras dos unidades confirmen la hipótesis inicial del negocio.

\subsubsection{ROA:}

Como se muestra en la tabla 81, el cálculo del ROA por año.

Tabla 81.

$R O A$

\begin{tabular}{llllll}
\hline Conceptos & Año 1 & Año 2 & Año 3 & Año 4 & Año 5
\end{tabular}

$\begin{array}{llllll}\text { Utilidad Neta } & 81,545.0 & 114,161.3 & 144,578.8 & 157,042.6 & 190,678.2\end{array}$

Activos

(CAPEX)

$253,283.6 \quad 253,283.6 \quad 253,283.6 \quad 253,283.6 \quad 253,283.6$

$\begin{array}{llllll}\text { ROA } & 32.2 \% & 45.1 \% & 57.1 \% & 62.0 \% & 75.3 \%\end{array}$

El ROA muestra la relación entre el beneficio logrado en un determinado período y los activos totales de la empresa. En este caso, se puede apreciar en la tabla 80 que la eficiencia para generar utilidades es buena después del primer año, alcanzando un ROA de alrededor de $75.3 \%$ para el año cinco.

\subsection{Análisis de Riesgos}

Los riesgos durante la creación de un proyecto son inherentes al mismo, ya que se trabaja en base a supuestos y estimaciones que pueden cambiar sin previo aviso, en este caso se analizan los posibles riesgos que podrían afectar: 


\section{Riesgos Operativos:}

Dentro de los riesgos operativos se tienen:

Renuncias: Si bien es cierto legalmente las renuncias deberían anunciarse con un cierto tiempo te anticipación, se debe tomar en cuenta el pedido de exoneración de este plazo legal que se pueda hacer llegar en cualquier momento, para este tipo de casos se decidió que el chofer de la unidad móvil tenga los conocimientos necesarios para brindar el servicio sin sacrificar la calidad ofrecida. De esta forma se puede tener el tiempo suficiente para la contratación de un nuevo colaborador.

Comportamiento Ilícito: Para minimizar este escenario se realizará un continuo control (auditorías) a los materiales utilizados diariamente, así como al dinero registrado como ingreso, esto en el caso de los colaboradores. Para el caso del personal administrativo se realizarán controles sobre los fondos registrados en los diferentes instrumentos financieros y se realizará un reporte mensual, el cual deberá ser aprobado por cada uno de los socios en las reuniones mensuales.

Rotación del Personal: La rotación se debe en gran medida al alto grado de insatisfacción de los trabajadores, para ellos se realizarán diferentes actividades, así como continuos feedbacks con la finalidad de monitorear el estado anímico de cada uno de los colaboradores.

Despidos masivos del personal al cual se brinda el servicio (clientes): Debido a que el modelo de negocio apunta a un público muy específico, los despidos masivos en las empresas donde se brindarán servicios afectarían el proyecto directamente. Para ello se debe conocer bien el ambiente en el que se desarrolla el negocio y buscar un acercamiento con la empresa tratando de conseguir algún tipo de subsidio por parte de ellos para poder continuar con operando, resaltando la calidad y beneficios que representas frente a sus colaboradores. 


\section{Riesgos Financieros:}

Subida del dólar: Una medida eficaz para contrarrestar esto es restringir el endeudamiento en moneda extranjera, es decir, comprar los equipos a plazo, de ser necesario, en moneda local debido a que los ingresos de la empresa son en soles.

Altas tasas de interés: Como se ha indicado a lo largo del trabajo el financiamiento para la implementación del modelo de negocio ha corrido por cuenta de los accionistas, pero no se descarta que en un futuro se tenga que solicitar financiamiento a entidades bancarias, las cuales mantienen tasas de interés altas, las cuales afectarían en gran medida. Este riesgo se puede minimizar realizando un análisis exhaustivo de las ofertas ofrecidas por los bancos y financieras.

\section{Riesgos Políticos:}

Incremento en los impuestos: Este es un riesgo que no es posible de controlar, así que cualquier cambio en este escenario deberá ser analizado con la finalidad de determinar si el traslado de este aumento será asumido por la empresa o será trasladado de alguna forma y en algún porcentaje al consumidor final.

\subsection{Análisis de punto de Equilibrio}

Después del análisis realizado, el Punto de Equilibrio se muestra en la tabla 82: 
Tabla 82.

Análisis de punto de equilibrio

\begin{tabular}{lrrr}
\hline Período & Costo Fijo Anual & Margen Unitario & Punto de Equilibrio \\
\hline Año 1 & 148,450 & 15.90 & 9,334 \\
Año 2 & 151,716 & 16.94 & 8,958 \\
Año 3 & 155,054 & 17.85 & 8,688 \\
Año 4 & 158,465 & 17.56 & 9,026 \\
Año 5 & 161,951 & 18.50 & 8,754 \\
& & Promedio & $\mathbf{8 , 9 5 2}$ \\
& & Capacidad & $\mathbf{3 1 , 5 9 8}$ \\
& & Uso Mínimo & $\mathbf{2 8 \%}$ \\
& & & \\
& & &
\end{tabular}

De aquí se concluye que el Punto de Equilibrio está alrededor de $28 \%$ de atenciones posibles en la infraestructura para cada año (Atenciones anuales estimadas / Punto de equilibrio atenciones) en el horizonte de evaluación de este proyecto.

\subsection{Análisis de Sensibilidad}

En la revisión de los drivers de ingresos y costos del negocio bajo la perspectiva de su importancia dentro de la estructura financiera, se encuentran los principales factores de riesgo. Desde el punto de vista empresarial se encuentran la tarifa, el número de servicios disponibles y los costos de producción del servicio (materia prima y mano de obra).

Al revisar estas variables se identifica que los competidores podrían impactar desde dos frentes: Estrategia de guerra de precios en las tarifas y/o pagando alquiler en los espacios asignados por las empresas para el servicio con lo cual se afectaría lo costos. 
En ese sentido, con el flujo financiero se puede modelar situaciones extremas para entender cómo se comportarían los resultados ante cambios drásticos en los ingresos y/o costos. En el análisis de sensibilidades, llevando el Valor Presente Neto a cero, sobre estos factores más relevantes se muestran en la tabla 83:

Tabla 83.

Análisis de puntos críticos

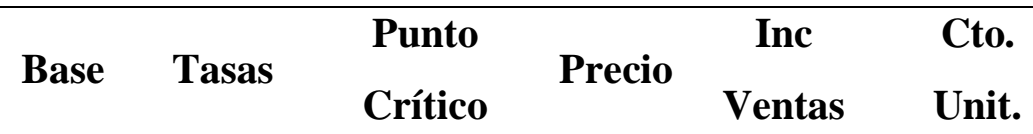

\begin{tabular}{lllll}
\hline Var. Promedio Valor & $0.00 \%$ & 29.8 & $-35.00 \%$ & 19.37 \\
Venta/Servicio (Precio) & & & &
\end{tabular}

Var. \% Incremento en las

Ventas

$\begin{array}{llll}0.00 \% & 8.1 \% & -40.00 \% & 4.9 \%\end{array}$

Var. Costo Unitario

$0.00 \% \quad 12.6 \quad 40.00 \%$

\begin{tabular}{|r|r|r|r|}
\hline \multicolumn{5}{|c|}{ VALOR PRESENTE NETO } \\
\hline \% Variación & \multicolumn{1}{|c|}{ Precio } & \% var Vtas & \multicolumn{1}{c|}{ Costo } \\
\hline$-40.00 \%$ & $-422,092$ & $2,614,582$ & $3,889,075$ \\
\hline$-35.00 \%$ & 18,576 & $2,628,206$ & $3,741,801$ \\
\hline$-30.00 \%$ & 459,245 & $2,641,831$ & $3,594,527$ \\
\hline$-25.00 \%$ & 899,914 & $2,655,456$ & $3,447,253$ \\
\hline$-20.00 \%$ & $1,316,420$ & $2,668,194$ & $3,299,980$ \\
\hline$-15.00 \%$ & $1,672,424$ & $2,678,867$ & $3,152,706$ \\
\hline$-10.00 \%$ & $2,020,504$ & $2,689,539$ & $3,005,432$ \\
\hline$-5.00 \%$ & $2,365,694$ & $2,700,212$ & $2,858,158$ \\
\hline $\mathbf{. 0 0 0 \%}$ & $\mathbf{2 , 7 1 0 , 8 8 5}$ & $\mathbf{2 , 7 1 0 , 8 8 5}$ & $\mathbf{2 , 7 1 0 , 8 8 5}$ \\
\hline $5.00 \%$ & $3,056,075$ & $2,721,557$ & $2,563,611$ \\
\hline $10.00 \%$ & $3,401,265$ & $2,732,230$ & $2,416,337$ \\
\hline $15.00 \%$ & $3,746,456$ & $2,742,903$ & $2,269,063$ \\
\hline $20.00 \%$ & $4,091,646$ & $2,753,575$ & $2,121,790$ \\
\hline $25.00 \%$ & $4,436,837$ & $2,764,248$ & $1,974,516$ \\
\hline $30.00 \%$ & $4,782,027$ & $2,774,920$ & $1,826,482$ \\
\hline $35.00 \%$ & $5,127,218$ & $2,785,593$ & $1,676,966$ \\
\hline $40.00 \%$ & $5,472,408$ & $2,796,266$ & $1,527,181$ \\
\hline & & & \\
\hline
\end{tabular}

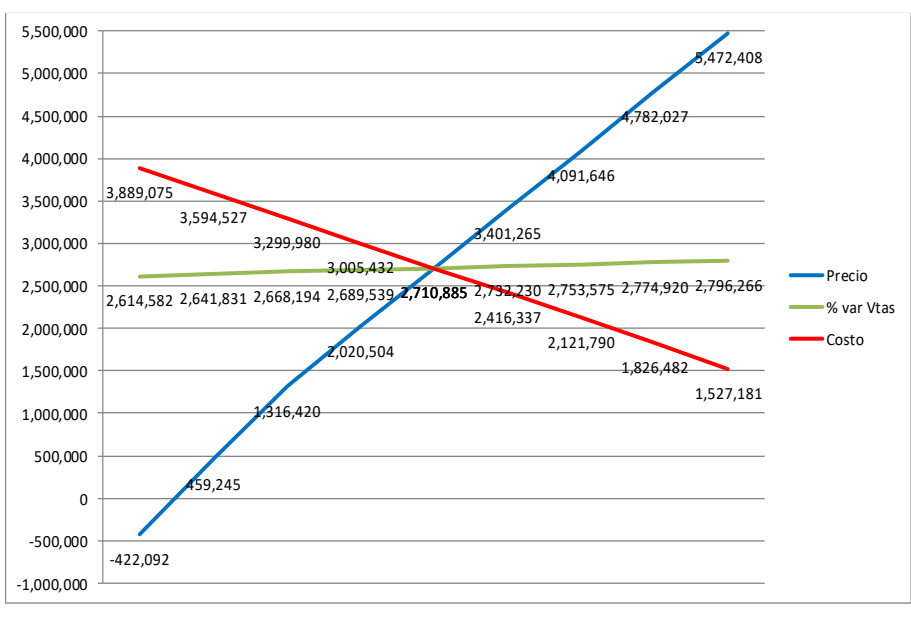

Del cuadro y gráfico se describe que las variables críticas son Precio y Costo de producción del servicio, en ese orden de importancia. Esta información es relevante para entender que rangos de manejo económico y financiero tendrá la empresa para contrarrestar cualquier situación o imponderable que se presente. También se deberá realizar ajustes al plan 
de Marketing para identificar oportunidades de mejora y de mitigación de riesgos que gatillen estas variables relevantes.

Del cuadro se desprenden algunas inferencias a tener en cuenta (céteris páribus):

- Máximo se puede bajar el valor de venta de cada servicio a S/ 19.37 (Precio = S/ 22.86); es decir un menor ingreso hasta 35\% por cada uno, llevando el VPN a S/ 18,576. El factor precio es el más sensible o relevante para este negocio.

- El Costo del alquiler, de ocurrir, o cualquier costo que se incremente es una variable a monitorear, pero aparentemente no tendría un impacto extremo que ponga en riesgo al negocio. Se tiene bastante flexibilidad en los costos puesto que pueden incrementar hasta un $40 \%$ a nivel unitario y se tendría aun un valor presente positivo atractivo.

- Se analizó también la variable de incremento de las ventas y al tener la posibilidad de uso alto, no es relevante para el análisis. Obviamente se está considerando un potencial público cautivo atractivo.

Continuando con el análisis de riesgos y para dimensionar adecuadamente los efectos de los entornos cambiantes y/o buscando tener una idea de cómo se afecta el proyecto ante diferentes contextos se generaron 3 escenarios posibles para el proyecto con la siguiente definición (ver tabla 84): 
Tabla 84.

Análisis de escenarios

\section{Escenarios}

Precio por Servicio

$\%$ Uso

$\%$ Cto. Unit. Materiales
29.80

$8.1 \%$

$12.6 \%$

\section{Pesimista Esperado Optimista}

\begin{tabular}{lr|r|r|}
\hline Variación \% promedio del Precio & $-10.00 \%$ & $0.00 \%$ & $10.00 \%$ \\
\hline Variación \% Cantidad de Spots & $-10.00 \%$ & $0.00 \%$ & $10.00 \%$ \\
\hline Variación \% promedio del Cto.Unit.MP & $10.00 \%$ & $0.00 \%$ & $-10.00 \%$ \\
\hline
\end{tabular}

Los resultados observados son los siguientes y teniendo en cuenta las dos principales variables se tiene a nivel de Valor Presente (ver tabla 85):

Tabla 85.

$V P N$

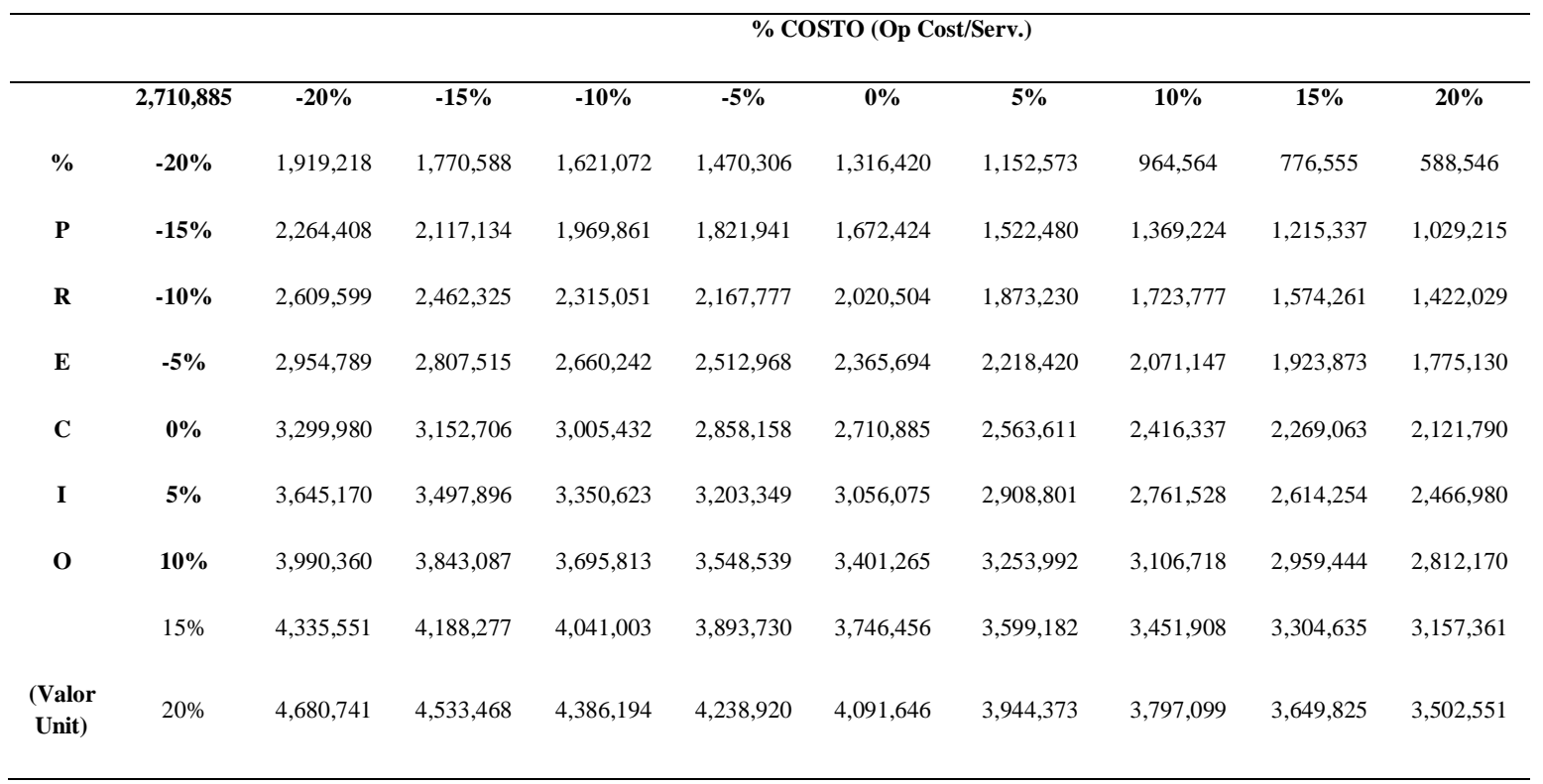

Y analizando los efectos en la TIR se tiene (ver tabla 86): 
Tabla 86.

$T I R$

\begin{tabular}{crrrrrrrrrr}
\hline & & \multicolumn{7}{c}{$\% \mathbf{C ~ O ~ S ~ T ~ O ~ ( O p ~ C o s t / S e r v . ) ~}$} \\
\hline & $\mathbf{4 6 . 6 \%}$ & $\mathbf{- 2 0 \%}$ & $\mathbf{- 1 5 \%}$ & $\mathbf{- 1 0 \%}$ & $\mathbf{- 5 \%}$ & $\mathbf{0 \%}$ & $\mathbf{5 \%}$ & $\mathbf{1 0 \%}$ & $\mathbf{1 5 \%}$ & $\mathbf{2 0 \%}$ \\
$\mathbf{\%}$ & $\mathbf{- 2 0 \%}$ & $36.8 \%$ & $34.8 \%$ & $32.6 \%$ & $30.2 \%$ & $27.6 \%$ & $24.9 \%$ & $22.0 \%$ & $19.0 \%$ & $15.9 \%$ \\
$\mathbf{P}$ & $\mathbf{- 1 5 \%}$ & $41.3 \%$ & $39.4 \%$ & $37.5 \%$ & $35.5 \%$ & $33.3 \%$ & $31.0 \%$ & $28.5 \%$ & $25.8 \%$ & $23.0 \%$ \\
$\mathbf{R}$ & $\mathbf{- 1 0 \%}$ & $45.5 \%$ & $43.7 \%$ & $41.9 \%$ & $40.0 \%$ & $38.1 \%$ & $36.2 \%$ & $34.0 \%$ & $31.8 \%$ & $29.3 \%$ \\
$\mathbf{E}$ & $\mathbf{- 5 \%}$ & $49.5 \%$ & $47.8 \%$ & $46.1 \%$ & $44.3 \%$ & $42.5 \%$ & $40.6 \%$ & $38.7 \%$ & $36.8 \%$ & $34.7 \%$ \\
$\mathbf{C}$ & $\mathbf{0 \%}$ & $53.4 \%$ & $51.7 \%$ & $50.1 \%$ & $48.4 \%$ & $46.6 \%$ & $44.9 \%$ & $43.1 \%$ & $41.2 \%$ & $39.4 \%$ \\
$\mathbf{I}$ & $\mathbf{5 \%}$ & $57.1 \%$ & $55.5 \%$ & $53.9 \%$ & $52.3 \%$ & $50.6 \%$ & $48.9 \%$ & $47.2 \%$ & $45.5 \%$ & $43.7 \%$ \\
$\mathbf{O}$ & $\mathbf{1 0 \%}$ & $60.7 \%$ & $59.2 \%$ & $57.6 \%$ & $56.0 \%$ & $54.5 \%$ & $52.8 \%$ & $51.2 \%$ & $49.5 \%$ & $47.8 \%$ \\
& $\mathbf{1 5 \%}$ & $64.2 \%$ & $62.7 \%$ & $61.2 \%$ & $59.7 \%$ & $58.1 \%$ & $56.6 \%$ & $55.0 \%$ & $53.4 \%$ & $51.7 \%$ \\
$($ Valor & $\mathbf{2 0 \%}$ & $67.5 \%$ & $66.1 \%$ & $64.6 \%$ & $63.2 \%$ & $61.7 \%$ & $60.2 \%$ & $58.6 \%$ & $57.1 \%$ & $55.5 \%$ \\
Unit) & & & & & & & & & & \\
\hline
\end{tabular}

Tabla 87.

Resultado del análisis de escenarios

\begin{tabular}{crrrr}
\hline $\begin{array}{c}\text { Indicadores } \\
\text { financieros }\end{array}$ & $\begin{array}{r}\text { Valores } \\
\text { actuales: }\end{array}$ & Pesimista & Esperado & Optimista \\
\hline VPN & $2,710,885$ & $1,723,777$ & $2,710,885$ & $3,695,813$ \\
TIR & $47 \%$ & $34 \%$ & $47 \%$ & $58 \%$ \\
\hline
\end{tabular}

El factor Precio es relevante, por ello lograr cualquier incremento en los precios será beneficioso para el negocio. En el escenario optimista, el incremento de la variable precio en un $10 \%$ y reducción de los costos en un $10 \%$ implica un incremento del $36.3 \%$ en el Valor Presente Neto del proyecto. 


\section{Capítulo X: Conclusiones}

- El plan de negocios se desarrolló con la finalidad de evaluar la factibilidad de implementar el servicio de salón de belleza móvil en empresas del sector financiero. El sector elegido ha mostrado en los últimos años gran interés por elevar sus indicadores de clima laboral interno a través de la generación de políticas de beneficios que favorecen e incrementan la productividad de sus colaboradores y a su vez, consolidan en la sociedad la buena imagen de la empresa lo que repercute positivamente en la retención y atracción del talento humano.

- El entorno en el cual se ha desarrollado el presente plan de negocios muestra un escenario favorable y creciente del mercado de la belleza. Asimismo, el impulso de las pequeñas empresas y las mejoras en la regulación y supervisión por parte del Estado Peruano incrementan dicha perspectiva.

- El análisis de la información, de forma cuantitativa y cualitativa, demuestra que el sector financiero está compuesto en un 50\% por mujeres trabajadoras donde más del 80\% de ese porcentaje estaría dispuesto a atenderse en el Salón de belleza móvil ubicado dentro de las instalaciones de su centro de trabajo.

- Para el consumidor final la principal ventaja de un salón de belleza móvil ubicado en las instalaciones de su centro laboral es el ahorro de tiempo, debido a que no deberá destinar tiempo adicional para trasladarse al salón. Además, según los resultados obtenidos en el focus group, las colaboradoras del sector financiero buscan un servicio ágil y de calidad lo cual demuestra que la propuesta está acorde a sus necesidades.

- La inversión principal está en el activo del proyecto que en el hipotético caso que el proyecto fracasara, puede venderse y recuperar gran parte de la inversión. Esto indica que el nivel de riesgo de la empresa es medio. Esto también queda demostrado con la tasa de descuento o costo de capital calculado. 
- Los cálculos se realizaron con prudencia y perfil conservador, por ello se consideró que la tasa de uso de la capacidad de atención será incremental, estando al 65\% en el primer año y terminando con un $85 \%$ de uso de capacidad al finalizar el quinto año. Esto determina que se tiene un potencial mayor y que si se logra conectar con las clientes se podría incluso superar las expectativas planteadas en el proyecto y devolver a los inversionistas su inversión en un plazo menor.

- El Payback por la inversión inicial entre Activos y Capital de trabajo se recuperará en un período menor a tres años, lo cual demuestra la capacidad del negocio para ser auto sostenible. Se estima que los inversionistas recuperarán su inversión al finalizar el tercer año.

- El Valor actual Neto es un cálculo que indica cuanto es el valor de la idea de negocio. Este valor recoge algunos supuestos basados en las variables económicas más relevantes para el negocio. A priori este negocio podría venderse a un valor de S/2'220,405. Este valor paga una prima porque considera que se tiene los contactos necesarios para lograr la asociación con los bancos target. 


\section{Capítulo XI: Recomendaciones}

- Aprovechar el interés del sector financiero privado por elevar los indicadores de clima laboral relacionados al bienestar y beneficios que brindan a sus trabajadores lo cual impacta en los niveles de productividad.

- Explotar la actual regulación en materia de creación de empresas, la cual favorece a la pequeña y micro empresa. La reducción de barreras y trámites burocráticos facilita la inversión en este tipo de negocios.

- Brindar el servicio enfocado en el creciente número de mujeres que laboran en empresas del sector financiero privado, las cuales ostentan cada vez más, puestos dentro de las empresas que les permiten una completa independencia financiera.

- Llevar a cabo la implementación del presente plan de negocios debido a que los estudios realizados y la nula competencia directa demuestran la factibilidad de la puesta en marcha y la rentabilidad que generaría.

- Brindar una atención de calidad que destaque por su agilidad para no impactar con las limitaciones de tiempo de los consumidores finales, dado que el servicio se brindará dentro de su centro de labores y en horario de trabajo.

- Mantener los indicadores presupuestados en capítulos anteriores con la finalidad de obtener la rentabilidad esperada recuperando la inversión inicial en el período previamente establecido (2 años 11 meses, aproximadamente).

- Revisar periódicamente las estrategias de marketing para cuantificar el posicionamiento de la empresa en el mercado y llevar a cabo, de ser el caso, acciones correctivas o acciones de fidelización.

- Analizar las posibilidades de expansión del negocio a otras industrias o sectores puesto a que al tratarse de un Salón de belleza móvil el servicio puede resultar atractivo para 
otras empresas que también presenten una cultura organizacional orientada a la búsqueda del bienestar del personal.

- Evaluar la factibilidad de adquirir una tercera unidad móvil a partir del término del quinto año de ejecución del negocio.

- Mantener evaluación periódica de los indicadores financieros y de gestión con la finalidad de tomar las medidas correctivas a fin de asegurar la rentabilidad del negocio. 


\section{Referencias}

(Facebook), O. (s.f.). OPI Perú. Obtenido de https://www.facebook.com/pg/opiperuoficial/about/?ref=page_internal

Arellano. (2019). Aportes a los cambios sociales. Obtenido de El rombo social: https://www.arellano.pe/aportes-los-cambios-sociales/

Banco Mundial. (s.f.). Perú Panorama general. Obtenido de https://www.bancomundial.org/es/country/peru/overview

BCRP. (Junio de 2016). Reporte de inflación. Obtenido de http://www.bcrp.gob.pe/docs/Publicaciones/ReporteInflacion/2016/junio/reporte-de-inflacion-junio-2016.pdf

BCRP. (Enero de 2019). Notas de Estudio del BCRP - Actividad Económica: Junio. Obtenido de http://www.bcrp.gob.pe/docs/Publicaciones/NotasEstudios/2019/nota-de-estudios-23-2019.pdf

Carl McDaniel, Jr. y Roger Gates. (2016). Investigación de Mercados. México: CENGAGE Learning. Obtenido de https://www.ebooks724.com:443/?il=2757\&pg=348

Correo, D. (25 de Febrero de 2015). Rubro de belleza mueve 50 mil locales en Perú. Obtenido de https://diariocorreo.pe/economia/belleza-mueve-50mil-locales-en-peru-567624/

Correo, D. (22 de Marzo de 2015). Una peluquería genera ganancias desde S/. $9 \mathrm{mil}$. Obtenido de https://diariocorreo.pe/economia/una-peluqueriagenera-ganancias-desde-s-9-mil-573947/

David, F. R. (2013). Administración Estratégica (Decimocuarta ed.). México: Pearson.

Diario El Peruano. (10 de Febrero de 2019). Sube proyección de crecimiento de PBI para 2019. Obtenido de https://elperuano.pe/noticia-subeproyeccion-crecimiento-pbi-para-2019-75587.aspx

Diario Gestión. (30 de Octubre de 2013). Plaza BCP: Donde entretenerse y trabajar es parte de una estrategia para retener el talento. Obtenido de https://gestion.pe/economia/empresas/plaza-bcp-entretenerse-parteestrategia-retener-talento-51598 
Diario La República. (27 de febrero de 2019). Mujeres lideran fuerza laboral bancaria en el Perú. Obtenido de https://larepublica.pe/economia/1421636-mujeres-lideran-fuerza-laboralbancaria-peru/

El Comercio, D. (6 de Enero de 2015). Ejecutivos ven crecimiento económico menor al $5 \%$ para el 2015. Obtenido de https://elcomercio.pe/economia/peru/ejecutivos-ven-crecimientoeconomico-menor-5-2015-182926

El Peruano, D. (5 de Febrero de 2007). Normas Legales. Obtenido de http://www.leyes.congreso.gob.pe/Documentos/Leyes/28976.pdf

Gestión, D. (13 de Febrero de 2012). El 43\% de los 15 mil centros de belleza en Lima es informal. Obtenido de https://gestion.pe/economia/empresas/4315-mil-centros-belleza-lima-informal-31513

Gestión, D. (16 de Noviembre de 2012). Los dueños de Belcorp y Yanbal serían los más ricos del Perú. Obtenido de https://gestion.pe/tendencias/duenosbelcorp-yanbal-serian-ricos-peru-24618

Gestión, D. (28 de Noviembre de 2012). Montalvo Spa factura alrededor de S/ 30 millones. Obtenido de https://archivo.gestion.pe/empresas/montalvosalon-spa-factura-alrededor-s-30-millones-al-ano-25-locales-peru2052911?href=mas_leidas

INEI. (Enero de 2010). Clasificación Industrial Internacional Uniforme. Obtenido de https://www.inei.gob.pe/media/MenuRecursivo/publicaciones_digitales/E st/Lib0883/Libro.pdf

INEI. (2016). INEI. Obtenido de https://www.inei.gob.pe/media/MenuRecursivo/boletines/informetecnico-n06_mercado-laboral-mar-abr-may2016_1.pdf

INEI. (Agosto de 2018). Boletín Demografía Empresarial en el Perú II Trimestre 2018. Obtenido de https://www.inei.gob.pe/media/MenuRecursivo/boletines/03-informetecnico-n-03-demografia-empresarial-ii-trim2018_ago2018.pdf 
INEI. (Agosto de 2018). Informe Técnico 3 - Demografia Empresarial - II Trimestre 2018. Obtenido de https://www.inei.gob.pe/media/MenuRecursivo/boletines/03-informetecnico-n-03-demografia-empresarial-ii-trim2018_ago2018.pdf

INEI. (Febrero de 2019). Informe Técnico: Comportamiento de los indicadores de mercado laboral a nivel nacional. Obtenido de https://www.inei.gob.pe/media/MenuRecursivo/boletines/informetecnico-de-empleo-trimestral-nacional.PDF

INEI. (Febrero de 2019). Informe-tecnico-de-empleo-lima-metropolitanafebrero2019. . Obtenido de https://www.inei.gob.pe/media/MenuRecursivo/boletines/informetecnico-de-empleo-lima-metropolitana-febrero2019.pdf

INEI. (Enero de 2019). Lima Metropolitana: Población en edad de trabajar según condición de actividad. Obtenido de https://www.inei.gob.pe/media/MenuRecursivo/boletines/boletinestadistico-n01-enero-2019.pdf

Kotler, P., \& Armstrong, G. (2012). Marketing. México: Peason.

Kotler, P., \& Armstrong, G. (s.f.). Fijación de precios por valor agregado. En Marketing (pág. 293). Pearson.

Malhotra, Naresh K. (2020). Ivestigación de Mercados (6ta edición ed.). México: Editorial Pearson. Obtenido de https://www.ebooks724.com:443/?il=10289\&pg=358

Mincetur. (Julio de 2013). Plan Nacional de Seguridad Ciudadana. Obtenido de http://www.pcm.gob.pe/seguridadciudadana/wpcontent/uploads/2013/08/Seccion-PLAN-Plan-2013-2018.pdf

Montalvo Spa, S. d. (s.f.). Historia - Montalvo Spa. Obtenido de http://www.montalvospa.com/montalvo_historia.php?seccion=mujeres

Montalvo Spa, S. d. (s.f.). Montalvo Spa. Información sobre Montalvo Spa. Obtenido de https://www.facebook.com/MontalvoSalonSpa/info/?tab=page_info Moyano Castillejo, L. E. (2015). Plan de Negocios. Lima: Macro EIRL. 
Municipalidad de San Isidro. (s.f.). Salud Humana. Obtenido de http://msi.gob.pe/portal/salud-humana/carne-sanitario/

N, C. (29 de Marzo de 2015). Marco Aldany: un salón en Perú puede llegar a facturar 200 mil dólares mensuales. Obtenido de https://canaln.pe/actualidad/marco-aldany-salon-peru-puede-llegarfacturar-200-mil-dolares-mensuales-n175420

Network, F. (27 de Junio de 2017). Marco Aldany y Montalvo siguen apostando por Perú. Obtenido de https://pe.fashionnetwork.com/news/MarcoAldany-y-Montalvo-siguen-apostando-porPeru,841324.html\#.XHCf5Oj0nDd

Network, F. (4 de Enero de 2018). Crece el mercado de la belleza y perfumería en Perú en 2017. Obtenido de https://pe.fashionnetwork.com/news/Crece-el-mercado-de-la-belleza-yperfumeria-en-Peru-en-2017,909401.html\#.XSJtS-j0nDd

Perú21, D. (25 de Abril de 2010). Saúl Pinto: "Llevamos el spa a la casa de nuestras clientas". Obtenido de http://archivo.peru21.pe/noticia/467372/saul-pinto-llevamos-spa-casanuestras-clientas

SBS. (Diciembre de 2018). Información de las Empresas Financieras- Número de Personal. Obtenido de http://intranet2.sbs.gob.pe/estadistica/financiera/2018/Diciembre/B-2305di2018.XLS

SIICEX. (s.f.). Sistema Integrado de Información de Comercio Exterior. Obtenido de http://www.siicex.gob.pe/siicex/portal5ES.asp?_page_=234.00000

Translatio y Cultura. (2015). En Translatio y Cultura. Madrid. 


\section{Anexos}

\section{Anexo A. Focus Group}

\section{Instrumento:}

Guía de indagación: Mujeres que trabajan en el sector financiero (labores administrativas) con los siguientes tópicos y/o temas a tratar.

- $\quad$ Frecuencia de visita al salón para servicio de manicura, cepillado y planchado del cabello.

- Precios.

- $\quad$ Marcas de productos.

- $\quad$ Tipos de servicios.

- $\quad$ Tiempos de espera promedio.

- $\quad$ Calidad esperada.

- Interés en la propuesta (ahorro de tiempo).

\section{Ficha técnica:}

1. Instrumento: Guía de Indagación Focus Group Mujeres que trabajan en el sector financiero (labores administrativas).

2. Fechas: $11 / 05 / 19,18 / 05 / 19$ y $25 / 05 / 19$.

3. Lugar: Domicilio de integrante del proyecto de tesis María Julia Chávez Rodríguez.

4. Duración: 1 hora y 30 minutos por sesión.

5. Dirigido a: Preferencias en servicios de belleza de corta duración.

6. Número de participantes: 8 por evento.

7. Significación: Ayuda a recoger percepciones sobre los servicios de belleza de corta duración que se pueden brindar en espacios pequeños.

8. Materiales: Guía de indagación, hojas adicionales, grabadora y tarjetas.

9. Conductor: Integrante del proyecto de tesis María Julia Chávez Rodríguez. 


\begin{tabular}{|c|c|c|c|}
\hline Objetivo & Indicador & & Cuestionario \\
\hline \multirow{4}{*}{$\begin{array}{l}\text { Desarrollar un } \\
\text { plan de negocio } \\
\text { para generar } \\
\text { rentabilidad que } \\
\text { asegure la } \\
\text { sostenibilidad y } \\
\text { crecimiento de la } \\
\text { empresa. }\end{array}$} & $\begin{array}{l}\text { Validación del uso del } \\
\text { servicio }\end{array}$ & 1 & ¿Asiste Ud. a salones de belleza? \\
\hline & Frecuencia & 2 & $\begin{array}{l}\text { ¿Con qué frecuencia acude Ud. a } \\
\text { salones de belleza? }\end{array}$ \\
\hline & Precios & 3 & $\begin{array}{l}\text { ¿Cuánto es el costo promedio por } \\
\text { servicio de manicura solicitado? }\end{array}$ \\
\hline & & 4 & $\begin{array}{l}\text { ¿Cuánto es el costo promedio por } \\
\text { servicio de cepillado o planchado } \\
\text { solicitado? }\end{array}$ \\
\hline \multirow{9}{*}{$\begin{array}{l}\text { Brindar un buen } \\
\text { servicio a los } \\
\text { clientes mediante } \\
\text { la adecuación de } \\
\text { una móvil. }\end{array}$} & Marcas de productos & 5 & $\begin{array}{l}\text { ¿Qué marca de productos usa } \\
\text { habitualmente? (cuidado de uñas). }\end{array}$ \\
\hline & Tipo de servicio & 6 & $\begin{array}{l}\text { ¿Qué tipo de servicio de manicura } \\
\text { solicita con más frecuencia? }\end{array}$ \\
\hline & & 7 & $\begin{array}{l}\text { ¿Qué tipo de servicio solicita con más } \\
\text { frecuencia? }\end{array}$ \\
\hline & Tiempos de espera & 8 & $\begin{array}{l}\text { ¿Cuánto tiempo invierte Ud. en el salón } \\
\text { de belleza? }\end{array}$ \\
\hline & Calidad esperada & 9 & ¿Qué valora más en la atención? \\
\hline & $\begin{array}{l}\text { Aceptación del modelo } \\
\text { propuesto }\end{array}$ & $\begin{array}{l}1 \\
0\end{array}$ & $\begin{array}{l}\text { Si tuviera un salón que brinde los } \\
\text { servicios de manicura, planchado y } \\
\text { cepillado de cabello dentro de su centro } \\
\text { de labores, ¿se atendería? }\end{array}$ \\
\hline & & $\begin{array}{l}1 \\
1\end{array}$ & $\begin{array}{l}\text { ¿Por qué no se atendería en un salón de } \\
\text { belleza dentro de las instalaciones de su } \\
\text { centro de labores? }\end{array}$ \\
\hline & & $\begin{array}{l}1 \\
2\end{array}$ & $\begin{array}{l}\text { ¿Cuánto más estaría dispuesta a pagar } \\
\text { por atenderse en un salón de belleza } \\
\text { dentro de las instalaciones de su centro } \\
\text { de labores? }\end{array}$ \\
\hline & & $\begin{array}{l}1 \\
3\end{array}$ & $\begin{array}{l}\text { ¿En cuál horario le gustaría ser } \\
\text { atendida? }\end{array}$ \\
\hline
\end{tabular}

En cuanto al Focus Group las preguntas que se realizaron a las participantes estuvieron alineadas con los objetivos del presente proyecto: 


\section{Anexo B. Preguntas de entrevistas a gerentes del área de RRHH de entidades financieras}

Se utilizó la siguiente guía de preguntas las cuales responden a los objetivos planteados:

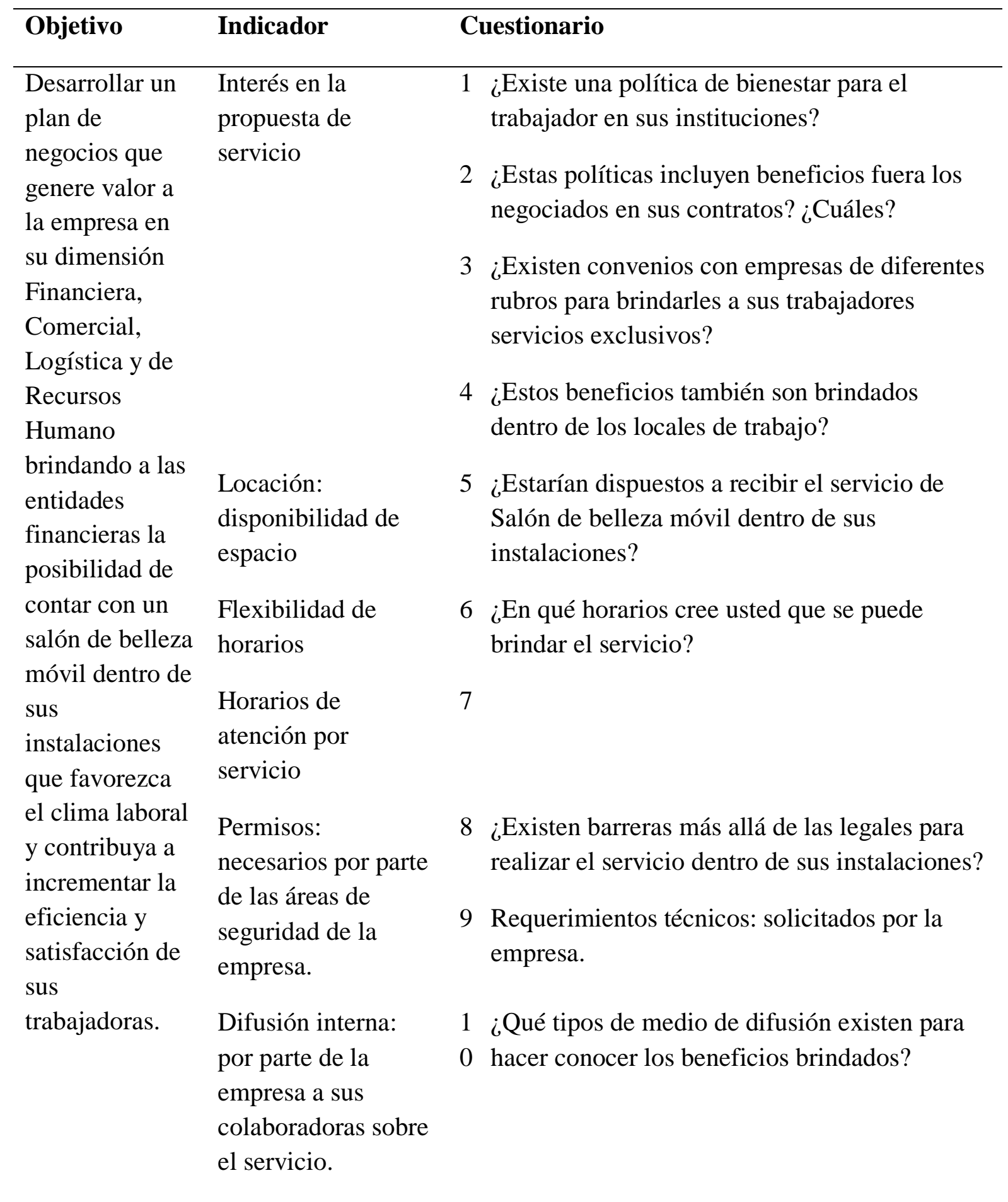


El detalle de las respuestas a cada pregunta se detalla en el siguiente cuadro:

\section{Nro Pregunta}

¿Existe una política de bienestar

1 para el trabajador en sus instituciones?

¿Estas políticas incluyen beneficios

2 fuera los negociados en sus contratos? ¿Cuáles?

¿Existen convenios con empresas

3 de diferentes rubros para brindarles

a sus trabajadores servicios exclusivos?

¿Estos beneficios también son

4 brindados dentro de los locales de trabajo?

¿Estarían dispuestos a recibir el

5 servicio de Spa Móvil dentro de sus instalaciones?

Respuesta

Respuesta. Si existe, esto se traduce con convenios entre las entidades

bancarias y algunas empresas que brindan descuentos en sus productos y

servicios ofrecidos solo con la presentación de alguna identificación que

acredite que el trabajador labora en el banco. Además, cada cierto tiempo se

permite el ingreso de empresas que ofrece la venta de productos en los mismos

edificios corporativos a precios especiales.

Respuesta. Si, como se mencionó anteriormente se tienen campañas de ofertas para los colaboradores.

Respuesta. Efectivamente, las ofertas y campañas son de cualquier rubro; venta Usado en la Introducción, Antecedentes, de perfumes, joyería, entradas al cine y teatro, accesorios de vestir femeninos y Oportunidades y amenazas, Matriz EFE, masculinos, licores, etc.

Respuesta. Sí, siempre y cuando la logística no sea muy elaborada debido a que ocupan un espacio de libre circulación para el personal del banco.

Respuesta. Sí, siempre y cuando se coordinen oportunamente las necesidades de espacio, en el caso de la propuesta de negocio se muestra una ventaja ya que no se utilizarían espacios de libre circulación dentro del propio edificio.

¿En qué horarios cree usted que se Respuesta. El tema del horario les es indiferente ya que conocen que las

puede brindar el servicio? ¿Existen barreras más allá de las

7 legales para realizar el servicio dentro de sus instalaciones? ¿Qué tipos de medio de difusión

8 existen para hacer conocer los beneficios brindados?

\section{Referencia de uso}

Usado en la Introducción, Antecedentes, Oportunidades y amenazas, Matriz EFE Focus Group y Encuestas

Usado en la Introducción, Antecedentes, Oportunidades y amenazas, Matriz EFE Focus Group y Encuestas

Focus Group y Encuestas

Usado en la Introducción, Antecedentes, Oportunidades y amenazas, Matriz EFE, Focus Group y Encuestas

Usado en la Introducción, Antecedentes, Oportunidades y amenazas, Matriz EFE Focus Group y Encuestas

Usado en Focus Group y Encuestas

Respuesta. Ninguna.

N/A

Respuesta. Boletines internos (virtuales) murales y volantes (entregados por el Usado en estrategias de promoción y propio personal de la empresa interesada en brindar sus servicios). 


\section{Anexo C. Preguntas de entrevistas a expertos del rubro de salones de belleza}

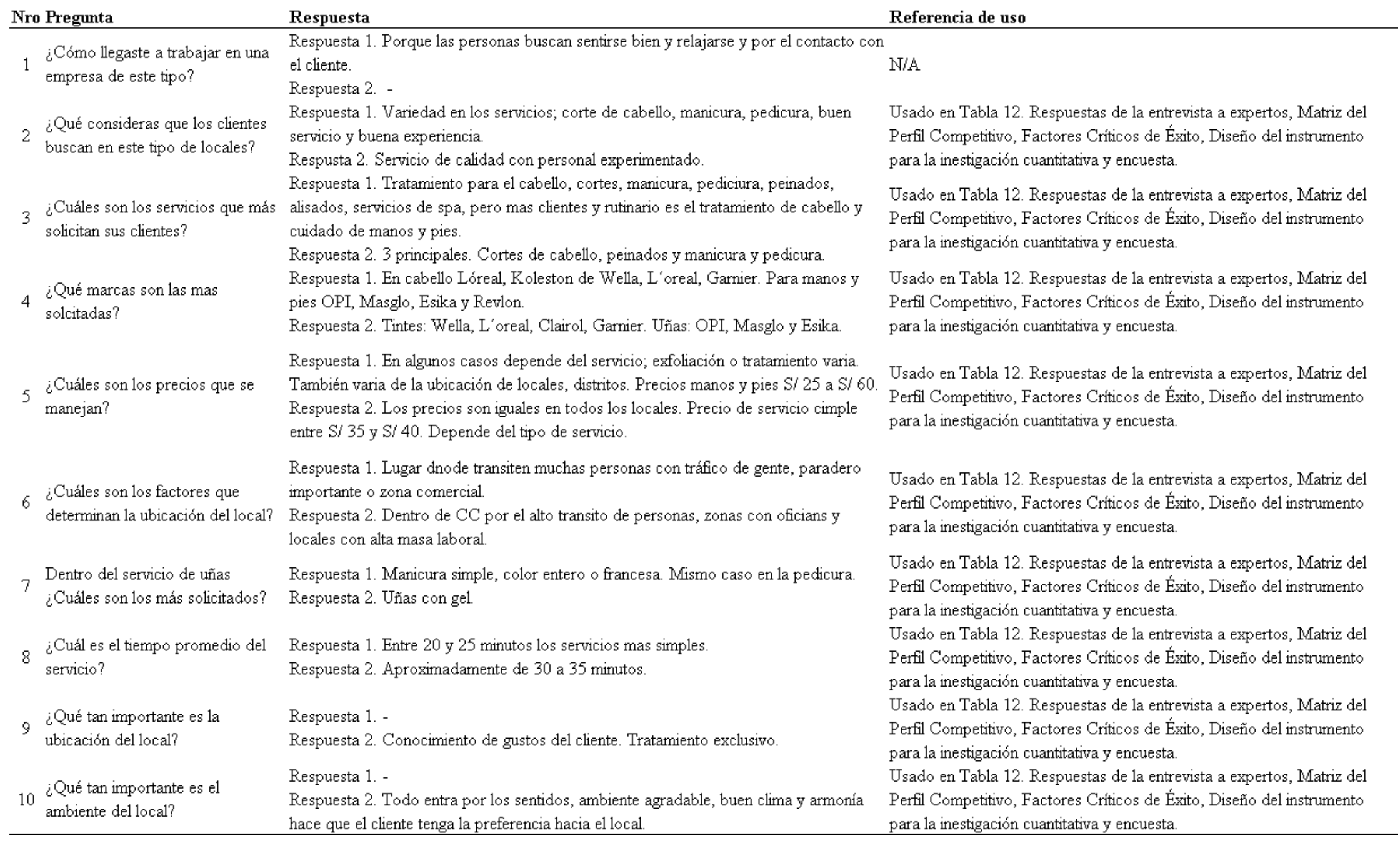


Anexo D. Guía de preguntas a los expertos en el sector asociada a objetivos

\section{$\begin{array}{lll}\text { Objetivo } & \text { Indicador } & \text { Cuestionario }\end{array}$}

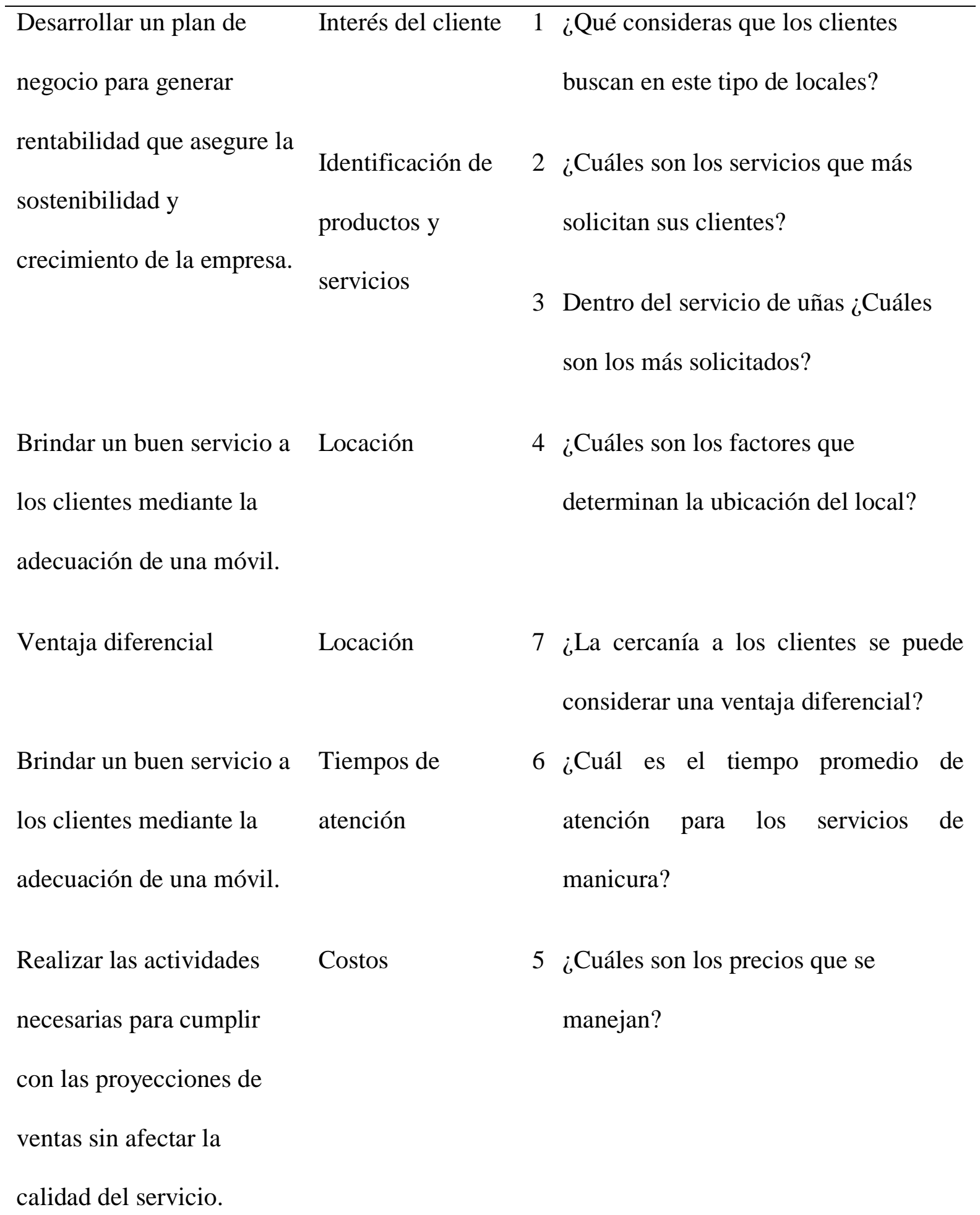




\section{Anexo E. Flujo de preguntas de la encuesta}

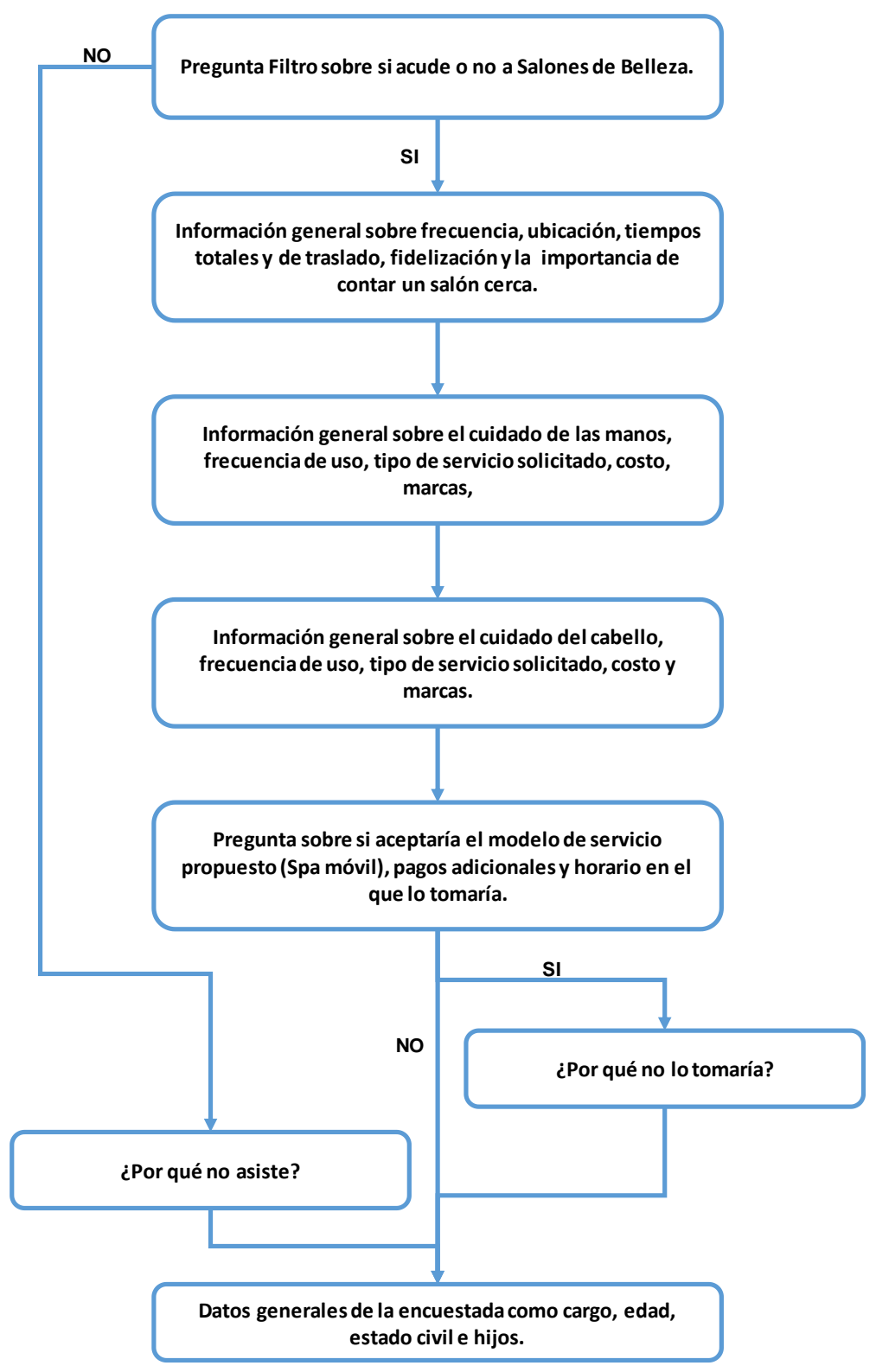




\section{Anexo F. Encuesta}

\section{Instrumento:}

Cuestionario con 22 preguntas agrupadas en 6 partes: validación del uso del servicio de manicura, cepillado y planchado de cabello en un centro especializado; sobre la frecuencia, cercanía de locales, tiempos de atención e importancia del servicio; tipos de servicio y costos de manicura; tipos de servicio y costos de cepillado y planchado de cabello; nivel de aceptación del modelo propuesto y por último el sexto grupo es información general de las encuestadas.

Cuestionario:

\begin{tabular}{|c|c|c|c|}
\hline Objetivo & Indicador & & Cuestionario \\
\hline \multirow{9}{*}{$\begin{array}{l}\text { Desarrollar un } \\
\text { plan de negocio } \\
\text { para generar } \\
\text { rentabilidad que } \\
\text { asegure la } \\
\text { sostenibilidad y } \\
\text { crecimiento de } \\
\text { la empresa. }\end{array}$} & $\begin{array}{l}\text { Validación del uso del } \\
\text { servicio }\end{array}$ & 1.1 & $\begin{array}{l}\text { ¿Asiste Ud. a salones de belleza? } \\
\text { ¿Por qué no asiste? }\end{array}$ \\
\hline & Fidelización & 2 & $\begin{array}{l}\text { ¿Acude Ud. siempre al mismo salón } \\
\text { de belleza? }\end{array}$ \\
\hline & & 3 & $\begin{array}{l}\text { ¿Por qué acude a estos salones de } \\
\text { belleza en particular? }\end{array}$ \\
\hline & & 4 & $\begin{array}{l}\text { Los salones de belleza a los que asiste } \\
\text { generalmente: }\end{array}$ \\
\hline & Tiempos de traslado & 5 & $\begin{array}{l}\text { ¿Cuánto tiempo emplea Ud. para } \\
\text { trasladarse al salón de belleza? }\end{array}$ \\
\hline & Importancia de cercanía & 6 & $\begin{array}{l}\text { ¿Qué tan importante es tener un salón } \\
\text { de belleza cerca de Ud.? }\end{array}$ \\
\hline & Frecuencia & 7 & $\begin{array}{l}\text { ¿Con qué frecuencia acude Ud. a } \\
\text { salones de belleza? }\end{array}$ \\
\hline & $\begin{array}{l}\text { Cercanía y servicios en } \\
\text { salones de belleza }\end{array}$ & 8 & $\begin{array}{l}\text { ¿Cuánto tiempo invierte Ud. en el } \\
\text { salón de belleza? }\end{array}$ \\
\hline & & 9 & $\begin{array}{l}\text { En términos de frecuencia con que los } \\
\text { solicita, ordene estos servicios }\end{array}$ \\
\hline
\end{tabular}




\begin{tabular}{|c|c|c|c|}
\hline Objetivo & Indicador & & Cuestionario \\
\hline & Servicios de Manicura & 10 & $\begin{array}{l}\text { ¿Con qué frecuencia solicita el } \\
\text { servicio de manicura? }\end{array}$ \\
\hline & & 11 & $\begin{array}{l}\text { ¿Qué tipo de servicio de manicura } \\
\text { solicita con mayor frecuencia? }\end{array}$ \\
\hline & & 12 & $\begin{array}{l}\text { ¿Cuánto es el precio que usted paga } \\
\text { en promedio por servicio de } \\
\text { manicura? }\end{array}$ \\
\hline & & 13 & $\begin{array}{l}\text { ¿Qué marca de productos para } \\
\text { manicura solicita habitualmente? }\end{array}$ \\
\hline & $\begin{array}{l}\text { Servicios de Planchado y } \\
\text { Cepillado }\end{array}$ & 14 & $\begin{array}{l}\text { ¿Con qué frecuencia solicita los } \\
\text { servicios de planchado y/o cepillado } \\
\text { de cabello? }\end{array}$ \\
\hline & & 15 & $\begin{array}{l}\text { ¿Cuánto es el costo promedio por } \\
\text { servicio de cepillado o planchado? }\end{array}$ \\
\hline \multirow[t]{4}{*}{$\begin{array}{l}\text { Brindar un } \\
\text { buen servicio a } \\
\text { los clientes } \\
\text { mediante la } \\
\text { adecuación de } \\
\text { una móvil. }\end{array}$} & $\begin{array}{l}\text { Aceptación del modelo } \\
\text { propuesto }\end{array}$ & 16 & $\begin{array}{l}\text { Si tuviera un salón que brinde los } \\
\text { servicios de manicura, planchado y } \\
\text { cepillado de cabello en las } \\
\text { instalaciones de su centro de labores } \\
\text { ¿se atendería? }\end{array}$ \\
\hline & & 16.1 & $\begin{array}{l}\text { ¿Por qué no se atendería en un salón } \\
\text { de belleza dentro de las instalaciones } \\
\text { de su centro de labores? }\end{array}$ \\
\hline & & 17 & $\begin{array}{l}\text { ¿Cuánto más estaría dispuesta a pagar } \\
\text { por atenderse en un salón dentro de su } \\
\text { centro laboral? }\end{array}$ \\
\hline & & 18 & $\begin{array}{l}\text { ¿En qué horario le gustaría y podría } \\
\text { atenderse? }\end{array}$ \\
\hline
\end{tabular}




\begin{tabular}{llll}
\hline \multicolumn{1}{c}{ Objetivo } & \multicolumn{1}{c}{ Indicador } & & Cuestionario \\
\hline $\begin{array}{l}\text { Realizar las } \\
\text { actividades }\end{array}$ & Información general & 19 & ¿Qué cargo tiene? \\
$\begin{array}{l}\text { necesarias para } \\
\text { cumplir con las } \\
\text { proyecciones de } \\
\text { ventas sin }\end{array}$ & 20 & ¿Qué edad tiene? \\
$\begin{array}{l}\text { afectar la } \\
\text { calidad del }\end{array}$ & 21 & ¿Cuál es su estado civil? \\
servicio. & 22 & ¿Tiene hijos?, ¿Cuántos? \\
\end{tabular}

A continuación, la encuesta tal como se muestra en la pantalla de una computadora.

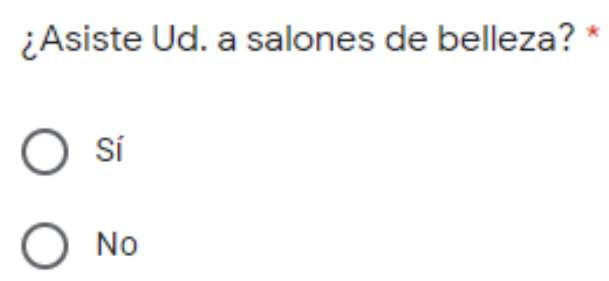

En el caso de responder "No", preguntará ¿Por qué no?, caso contrario avanzará a la pregunta 2 .
¿Por qué no asiste? *
Alto costo de los servicios
Yo misma me atiendo
Falta de tiempo para ir al salón
Mucha inseguridad en la ciudad
No tengo un salón cercano
Otro: 
A continuación, la segunda sección sobre el grado de fidelización de las encuestadas.

¿Acude Ud. siempre al mismo salón de belleza? *

○ sí

$\bigcirc$ No

En el caso que la respuesta sea "No", saltará a la sección de preguntas sobre los servicios solicitados en los salones de belleza, caso contrario continuará con las otras preguntas sobre fidelización.

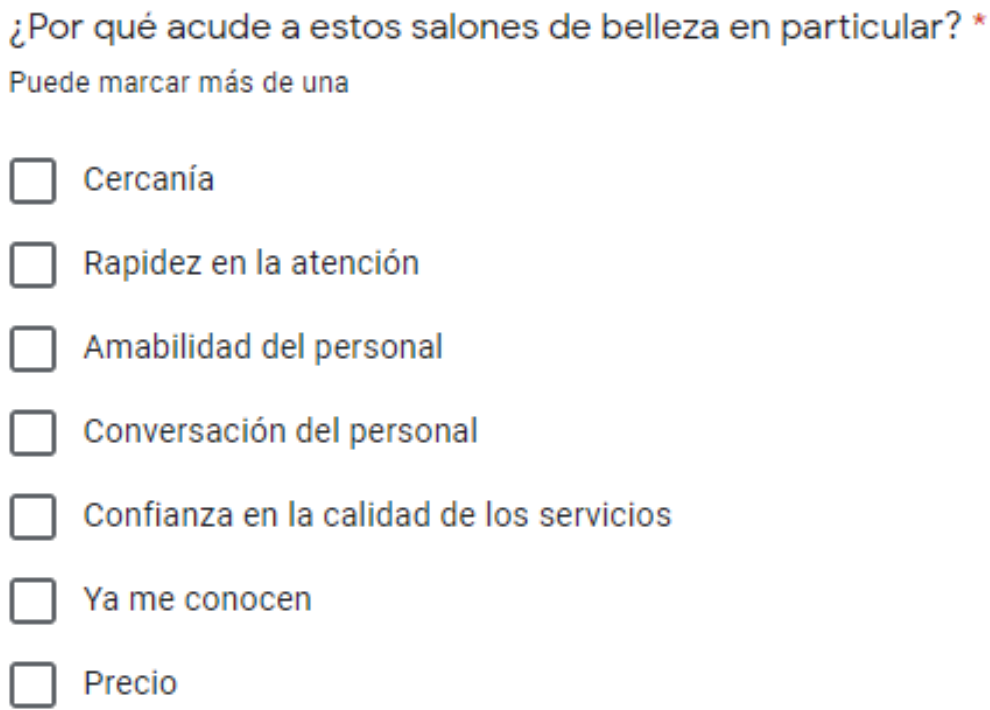

En esta sección, se hará preguntas sobre los servicios solicitados en los salones de belleza.

Los salones de belleza a los que asiste generalmente: *

¿Están cerca de su casa?

$\bigcirc$ ¿Están cerca de su trabajo?

No está cerca a casa ni al trabajo 
¿Cuánto tiempo emplea Ud. para trasladarse al salón de belleza? *

Hasta 10 minutos

De 10 a 20 minutos

De 20 a 30 minutos

De 30 a una hora

Más de una hora

¿Qué tan importante es tener un salón de belleza cerca de Ud.? *
1 - Nada importante
2- Poco importante
3 - Me es indiferente
4- Importante
5 - Muy importante

¿Con qué frecuencia acude Ud. a salones de belleza? *

Semanalmente o con más frecuencia

Quincenalmente

Cada tres semanas

Mensualmente

Menos de una vez al mes

¿Cuánto tiempo invierte Ud. en el salón de belleza? *

Hasta 30 minutos

Hasta 1 hora

Hasta 2 horas

Más de 2 horas 
En términos de frecuencia con que los solicita, ordene estos servicios *

Numere del 1 al 4 , siendo 1 el de uso más frecuente y 4 el de uso menos frecuente, por favor no repita la numeración.

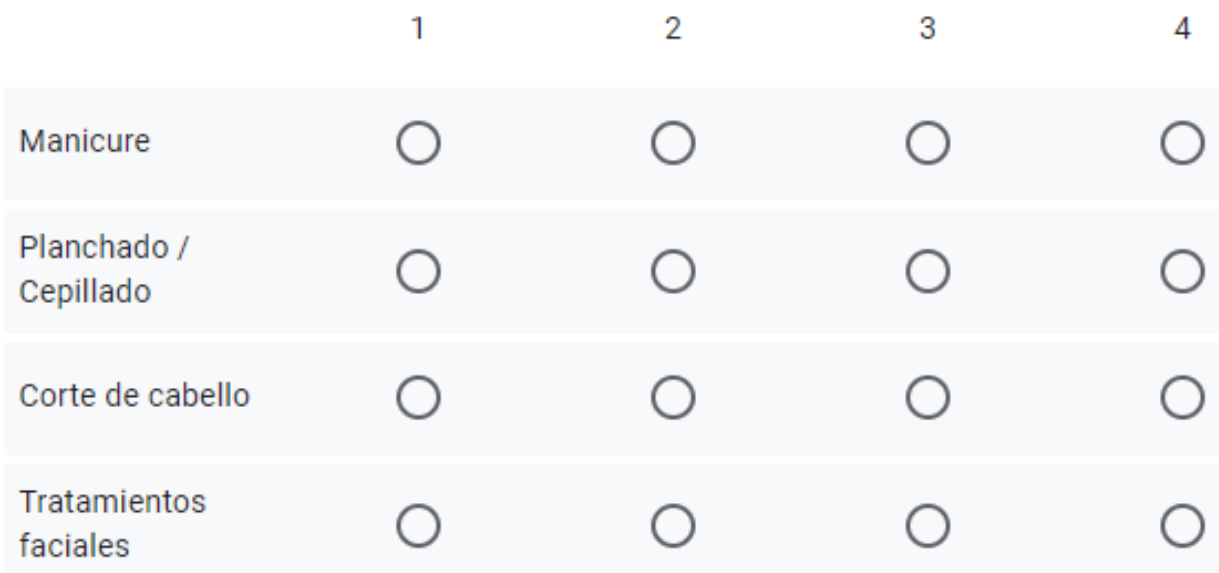

En la tercera sección de la encuesta se realizarán preguntas sobre los servicios de manicura solicitados en los salones de belleza donde acuden las encuestadas.

¿Con qué frecuencia solicita el servicio de manicura? *

Semanalmente o con más frecuencia

Quincenalmente

Cada tres semanas

Mensualmente

Menos de una vez al mes

Nunca

¿Qué tipo de servicio de manicura solicita con mayor frecuencia? *

Un solo color

Francesa

Gel

Acrílicas

Con diseño 
¿Cuánto es el precio que usted paga en promedio por servicio de manicura? *

Responda en función al servicio que más solicita (pregunta anterior)

Menos de $\mathrm{S} / 20$

Entre $S / 20$ y $s / 30$

Entre $\mathrm{S} / 30$ y $\mathrm{S} / 45$

Más de $\mathrm{S} / 45$

¿Qué marca de productos para manicura solicita habitualmente? *

Esika

Masglo

OPI

Revlon

Unique

En la cuarta sección de la encuesta se realizarán preguntas sobre los servicios de asociados con el cabello solicitados en los salones de belleza donde acuden las encuestadas.

¿Con qué frecuencia solicita los servicios de planchado y/o cepillado de cabello?

*

- 1 vez a la semana

Cada 2 semanas

Cada 3 semanas

Cada 4 semanas

Solo en caso de eventos especiales

$\bigcirc$ Nunca 
¿Cuánto es el costo promedio por servicio de cepillado o planchado? *

Menos de $\mathrm{S} / 20$

Entre $\mathrm{S} / 20$ y $\mathrm{S} / 30$

Entre $S / 30$ y $S / 40$

Más de $\mathrm{S} / 40$

En la quinta sección de la encuesta se realizan preguntas para conocer la opinión de las encuestas sobre el modelo de negocio propuesto en el presente trabajo.

Si tuviera un salón que brinde los servicios de manicura, planchado y cepillado de cabello en las instalaciones de su centro de labores ¿se atenderia? *

Nuestra propuesta es llevar los salones de belleza a los centros de labores para que puedan atenderlas dentro de nuestras móviles estacionadas dentro de las instalaciones de su empresa, ofrecemos servicios ágiles y de calidad.

1 - Definitivamente No

2 - Probablemente No

3 - Indeciso

4 - Probablemente sí

5 - Definitivamente sí

Solo en caso la respuesta sea una de las 3 primeas opciones se preguntará la razón / motivo y luego se derivará a las encuestadas a la sexta y última sección de la encuesta sobre información general. 
¿Por qué no se atenderia en un salón de belleza dentro de las instalaciones de su centro de labores? *

Ambiente no me parece el adecuado

Prefiero no realizar actividades personales en el trabajo

Tengo un salón de confianza donde siempre me atiendo

Otro:

¿Cuánto más estaria dispuesta a pagar por atenderse en un salón dentro de su centro laboral? *

Ni un sol más

Entre $\mathrm{S} / 1$ y $\mathrm{S} / 4$ soles más

Entre $\mathrm{S} / 5$ y $\mathrm{S} / 10$ soles más

Más de $S / 10$ soles

¿En qué horario le gustaria y podria atenderse? *

Antes del ingreso al trabajo

Después de la hora de salida

Durante el refrigerio

En cualquier momento del día

Finalmente, la sexta y última sección de preguntas busca recabar información adicional acerca de las encuestadas.

¿Qué cargo tiene? *

Manager-Gerente

Jefe-Supervisor

Colaborador 
¿Qué edad tiene? *

Entre 20 y 30 años

Entre 30 y 40 años

Entre 40 y 50 años

50 a más años

¿Cuál es su estado civil? *

Soltera

Casada

Convive con su pareja

Divorciada/Separada

$\bigcirc$ Viuda

¿Tiene hijos? ¿Cuántos? *

No tengo hijos

Si, 1 hijo(a)

Si, 2 hijos(as)

Si, 3 o más hijos(as) 